Rochester Institute of Technology

RIT Scholar Works

Theses

$10-1-2007$

\title{
Willingness to pay for a clear night sky: use of the contingent valuation method
}

Stephanie N. Simpson

Follow this and additional works at: https://scholarworks.rit.edu/theses

\section{Recommended Citation}

Simpson, Stephanie N., "Willingness to pay for a clear night sky: use of the contingent valuation method" (2007). Thesis. Rochester Institute of Technology. Accessed from 
Willingness to Pay for A Clear Night Sky:

Use of the Contingent Valuation Method

Masters in Science, Technology, and Public Policy Thesis Submitted in Fulfillment of the Graduation Requirements for the

College of Liberal Arts/Public Policy Program at ROCHESTER INSTITUTE OF TECHNOLOGY

\author{
Rochester, New York
}

October 2007

Submitted by:

Stephanie N. Simpson

(Signature)

(Date)

Accepted by:

James J. Winebrake, Ph.D.

Faculty Advisor and Program Chair

(Signature)

(Date)

Department of STS/Public Policy, Rochester Institute of Technology

Bridget Gleeson-Hanna, Ph.D.

(Signature)

(Date)

Thesis Committee Member

Department of Economics, Rochester Institute of Technology

M. Ann Howard, J.D.

(Signature)

(Date)

Thesis Committee Member

Department of STS/Public Policy, Rochester Institute of Technology

Franz Foltz, Ph.D.

(Signature)

(Date)

Graduate Coordinator

Department of STS/Public Policy, Rochester Institute of Technology 
List of Figures ...........................................................................................................................

List of Tables.......................................................................................................................5

Acknowledgements................................................................................................6

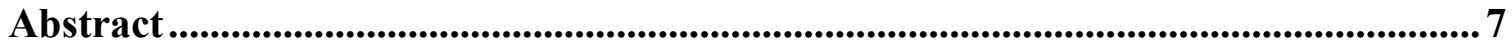

1. Introduction ...................................................................................................................... 8

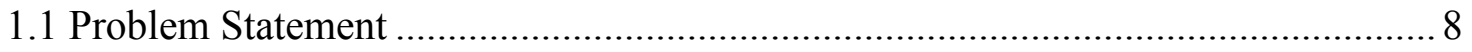

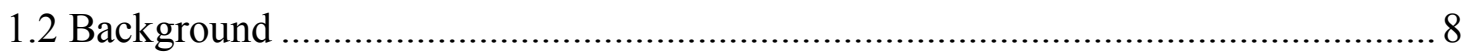

1.2.1 Light Pollution....................................................................................... 8

1.2.2 Ecological and Human Health Effects of Light Pollution................................... 11

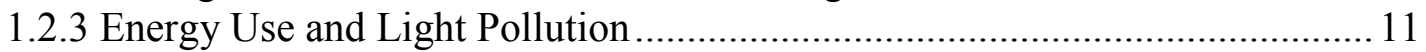

1.2.4 Effects on Scientific Research................................................................... 12

1.2.5 Light Pollution Regulation and Statistics........................................................ 14

1.2.6 Aesthetic Consequences of Light Pollution ................................................... 17

1.2.6 Justification for Government Intervention ..................................................... 18

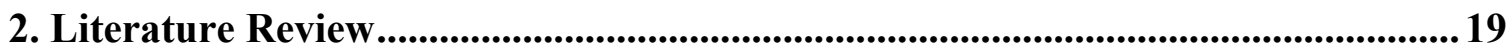

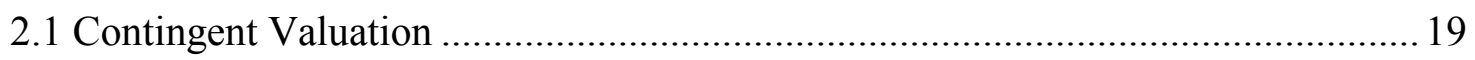

2.1.1 Contingent Valuation Overview................................................................ 19

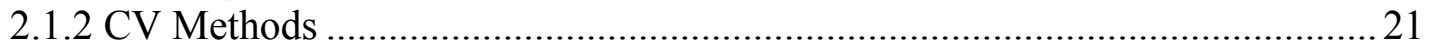

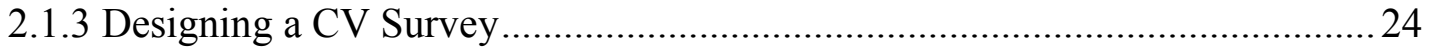

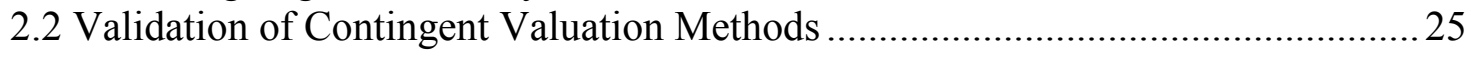

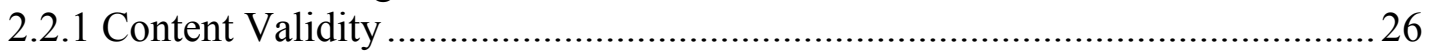

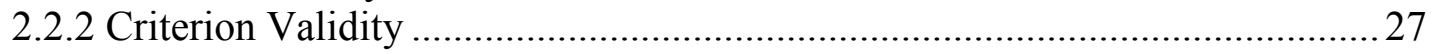

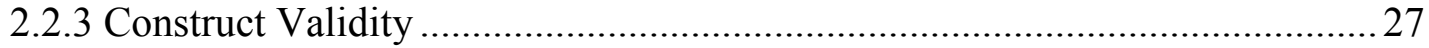

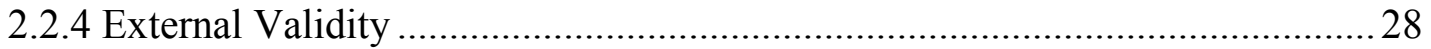

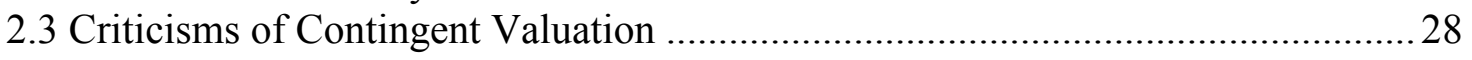

3. Methodology ………................................................................................................................36

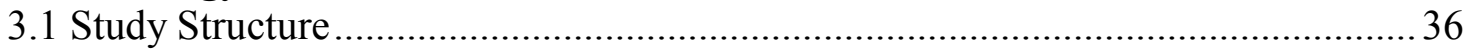

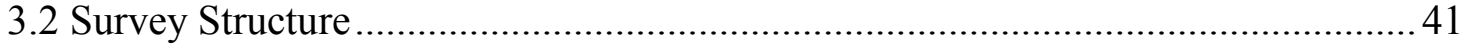

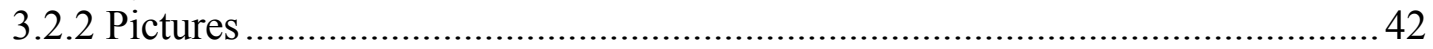

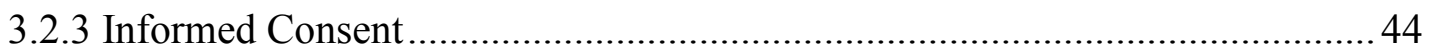

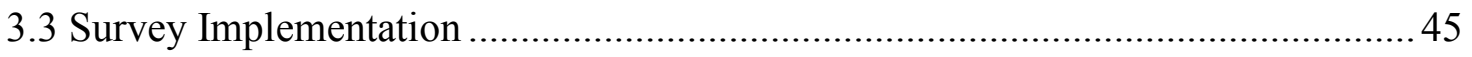

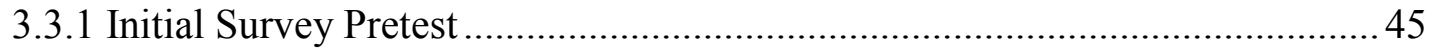

3.3.2 Administration of Final Survey ..................................................................... 46

4. Analysis .........................................................................................................................4

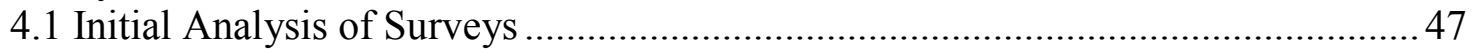

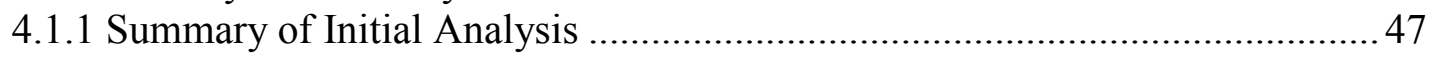

4.1.2 Development of Final Survey Population ........................................................ 49

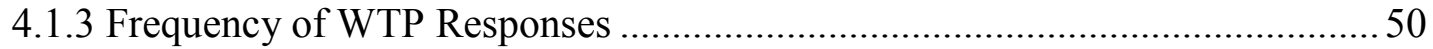

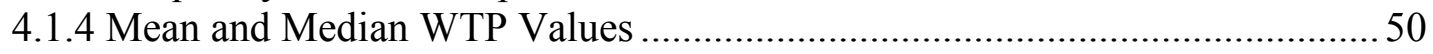

4.1.5 Variable Histograms and Correlation Tables …………………………..........5

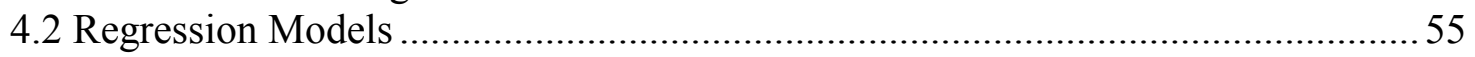

4.2.1 Ordinary Least Squares Regression Model .....................................................55

4.2.2 Interval Censoring Regression Model ...........................................................5 57

4.2.3 Tobit Regression Model ……………………….....................................5

5. Results .............................................................................................................................60 


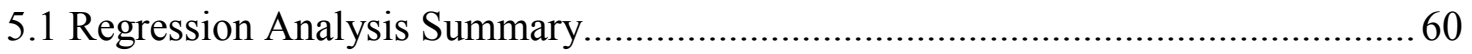

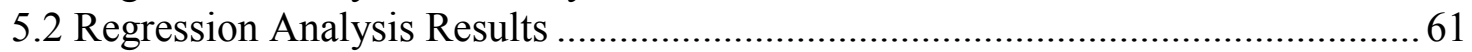

6. Discussion and Policy Implications................................................................... 70

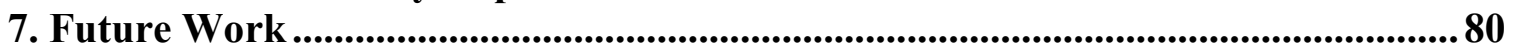

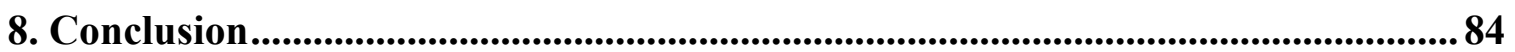

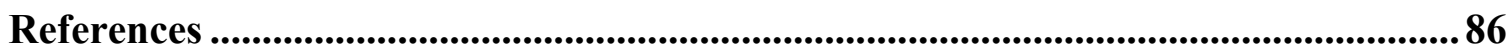

Appendix A. Light Pollution Survey ............................................................................... 91

Appendix B. Informed Consent Statement ................................................................. 102

Appendix C. Correlation Table and Histograms ...................................................... 103

Appendix D. Regression Equation Results .......................................................................... 119 


\section{List of Figures}

Figure 1. Diagram of potential lighting scheme of a typical street lamp...................... 10

Figure 2. Closed-ended question survey mailing (Deck, 1997) ................................... 38

Figure 3. Closed-ended question survey mailing continued (Deck, 1997)..................... 39

Figure 4. Open-ended question survey interview (Deck, 1997). ................................... 40

Figure 5. Example of WTP question from light pollution survey................................. 42

Figure 6. Example of PowerPoint slide used in survey presentation............................. 44

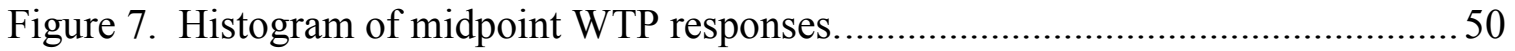

Figure 8. Visual representation of some payment card interval possibilities..................51

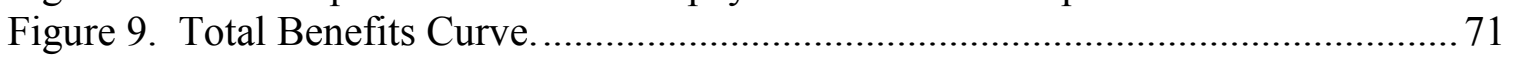

Figure 10. WTP 1 Responses vs. Size of Hometown...................................................... 103

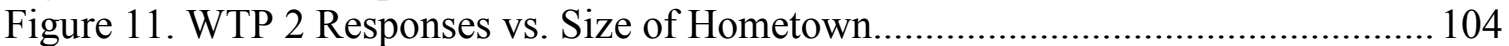

Figure 12. WTP 3 Responses vs. Size of Hometown.................................................. 104

Figure 13. WTP 1 Responses vs. Income................................................................... 105

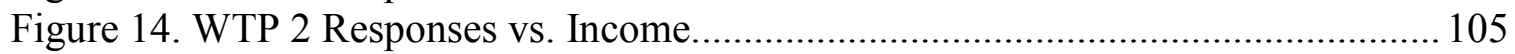

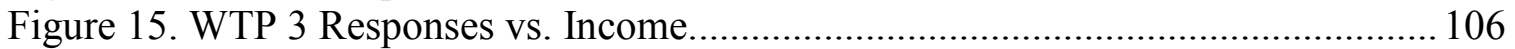

Figure 16. WTP 1 Responses vs. Year in College. ......................................................... 106

Figure 17. WTP 2 Responses vs. Year in College. ...................................................... 107

Figure 18. WTP 3 Responses vs. Year in College. ....................................................... 107

Figure 19. WTP 1 Responses vs. Major (by College)................................................. 108

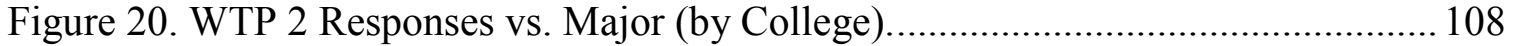

Figure 21. WTP 3 Responses vs. Major (by College)................................................ 109

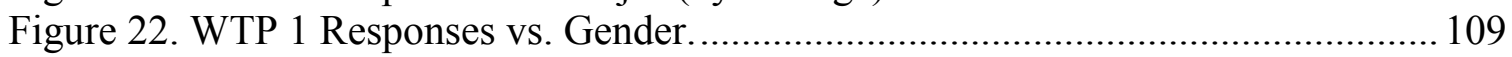

Figure 23. WTP 2 Responses vs. Gender................................................................... 110

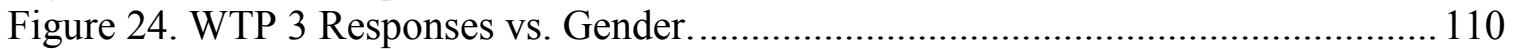

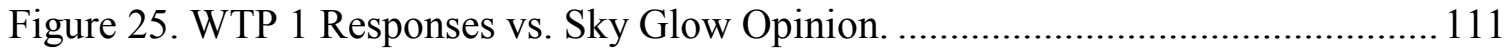

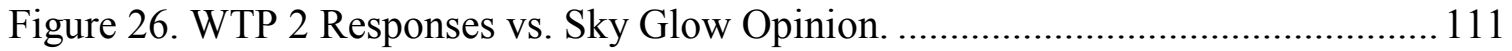

Figure 27. WTP 3 Responses vs. Sky Glow Opinion. ................................................... 112

Figure 28. WTP 1 Responses vs. Heard of Sky Glow ............................................... 112

Figure 29. WTP 2 Responses vs. Heard of Sky Glow. .................................................. 113

Figure 30. WTP 3 Responses vs. Heard of Sky Glow. ................................................ 113

Figure 31. WTP Responses vs. Experience of Sky Glow.......................................... 114

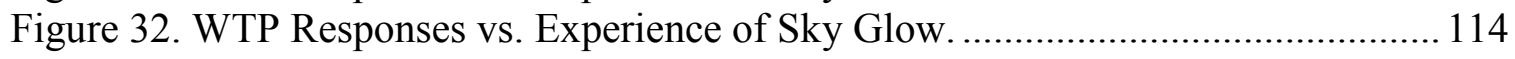

Figure 33. WTP Responses vs. Experience of Sky Glow........................................... 115

Figure 34. WTP 1 Responses vs. Campus Residence.................................................. 115

Figure 35. WTP 2 Responses vs. Campus Residence.................................................... 116

Figure 36. WTP 3 Responses vs. Campus Residence................................................... 116

Figure 37. WTP 1 Responses vs. Time Spent Outside................................................ 117

Figure 38. WTP 2 Responses vs. Time Spent Outside............................................... 117

Figure 39. WTP 3 Responses vs. Time Spent Outside................................................. 118 


\section{List of Tables}

Table 1. Specifics of Adobe Photoshop alterations made to StarSplatter images........... 43

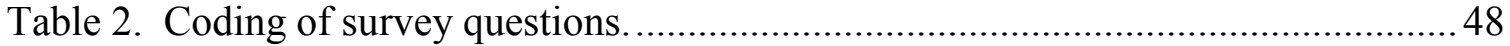

Table 3. Frequency of responses and non-responses for individual ..............................49

Table 4. Descriptive statistics for WTP 1, WTP 2, and WTP 3 .................................54

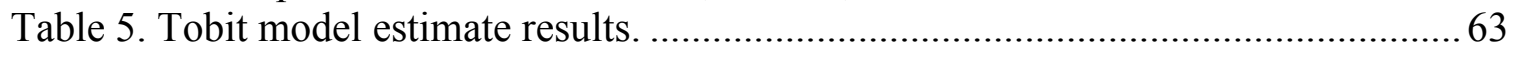

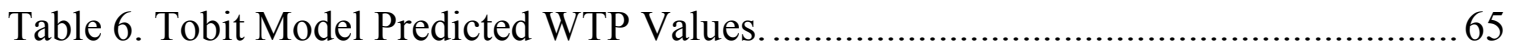

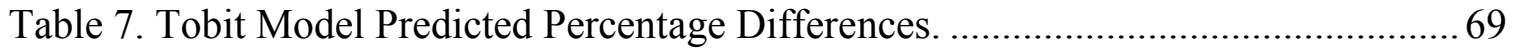

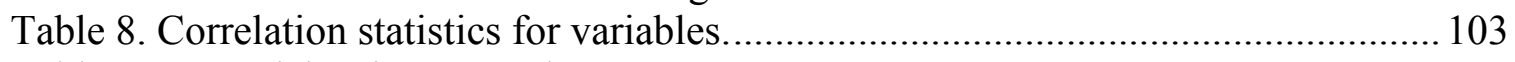

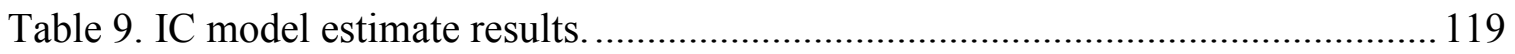

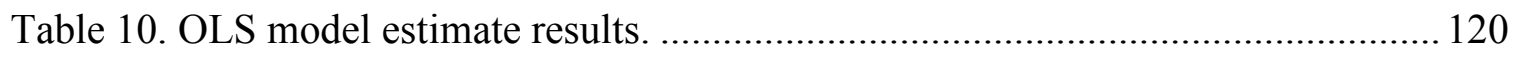

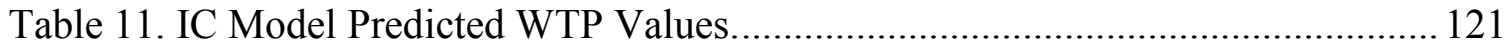

Table 12. OLS Model Predicted WTP Values............................................................ 122

Table 13. IC Model Predicted Percentage Differences. ................................................. 123

Table 14. OLS Model Predicted Percentage Differences. ............................................ 124 


\section{Acknowledgements}

\section{Thesis Committee:}

Dr. Jamie Winebrake

Dr. Brid Gleeson-Hanna

Professor Ann Howard

\section{Thesis Support:}

Light Pollution Images

Dr. Jake Noel-Storr, RIT

Dr. Frank Summers, Space Telescope Science Institute

Survey Classes

Professor Cappon, Sci. Tech. Values class, Winter 2007

Professor Larizza, Sci. Tech. Values class, Winter 2007

Professor Shearman. Intro. To Environmental Studies class, Winter 2007

Dr. Brid Gleeson-Hanna and Applied Econometrics class, Winter 2007

\section{Graduate Coordinator:}

Dr. Franz Foltz 


\begin{abstract}
A clear night sky is a public good, and as a public good government intervention to regulate it is justifiable. Light pollution decreases the ability to view a clear, unobstructed night sky and can have biological, human health, energy related, and scientific consequences. In order for governments to intervene more effectively, an economic analysis of light pollution with regards to costs and benefits needs to be performed. This thesis demonstrates the use of the contingent valuation method to place an economic value on light pollution. Students in the RIT community were surveyed regarding their willingness to pay for a clear night sky. The mode WTP was \$0; consequently the regression analysis focuses on use of the Tobit model. The most significant factors affecting WTP were whether or not the student thought sky glow is a problem on RIT's campus, how many years the student had been at RIT, the amount of the student's personal income, and the amount of time the student spent outside on RIT's campus at night. The results of this research are then applied to policy making at the local, state, and federal level. This research concludes that the contingent valuation method is applicable to the study of light pollution and development of light pollution related policies by local, state and federal policymakers, and the appropriateness of the contingent valuation method is enhanced both when respondents are informed about light pollution and its consequences, as well as with improvements in survey methodology and analysis.
\end{abstract}




\section{Introduction}

\subsection{Problem Statement}

A clear night sky is a public good, and as a public good government intervention to regulate it is justifiable. Light pollution decreases the ability to view the unobstructed night sky, and can have ecological, human health, energy related, and scientific consequences. Many local governments have put in place or are proposing to enact ordinances regulating lighting practices in their jurisdictions. In order for governments to intervene more effectively, an economic analysis of light pollution with regards to costs and benefits needs to be performed. This thesis will demonstrate the use of the contingent valuation method based on the idea of "willingness to pay" to place an economic value on light pollution. More specifically, this thesis will address the research question of how much RIT (Rochester Institute of Technology) students would be willing to pay to reduce the amount of light pollution on RIT's campus. The results of this thesis will then be used to propose ways in which the contingent valuation method can be effective in government policy decision making processes regarding light pollution at the local, state, and federal level.

\subsection{Background}

\subsubsection{Light Pollution}

The Lighting Research Center at Rensselaer Polytechnic Institute defines light pollution as "an unwanted consequence of outdoor lighting [that] includes such effects as sky glow, light trespass, and glare." To help facilitate understanding, a few terms that are commonly used in discussions of light pollution are defined below: 
- Glare - the sensation produced by luminances within the visual field that are sufficiently greater than the luminance to which the eyes are adapted, which causes annoyance, discomfort, and or loss in visual performance and ability. (Luminance is defined as the intensity of light per unit area of its source [“Luminance", 1997].)

- Light trespass - an undesirable condition in which spill light is cast where it is not wanted.

- Sky Glow - a brightening of the sky caused by outdoor lighting and natural atmospheric and celestial factors.

- Spill Light - light that falls outside the area intended to be lighted ("What is light", 2004).

Figure 1 depicts how these forms of light pollution are created from the light of a typical streetlamp. 


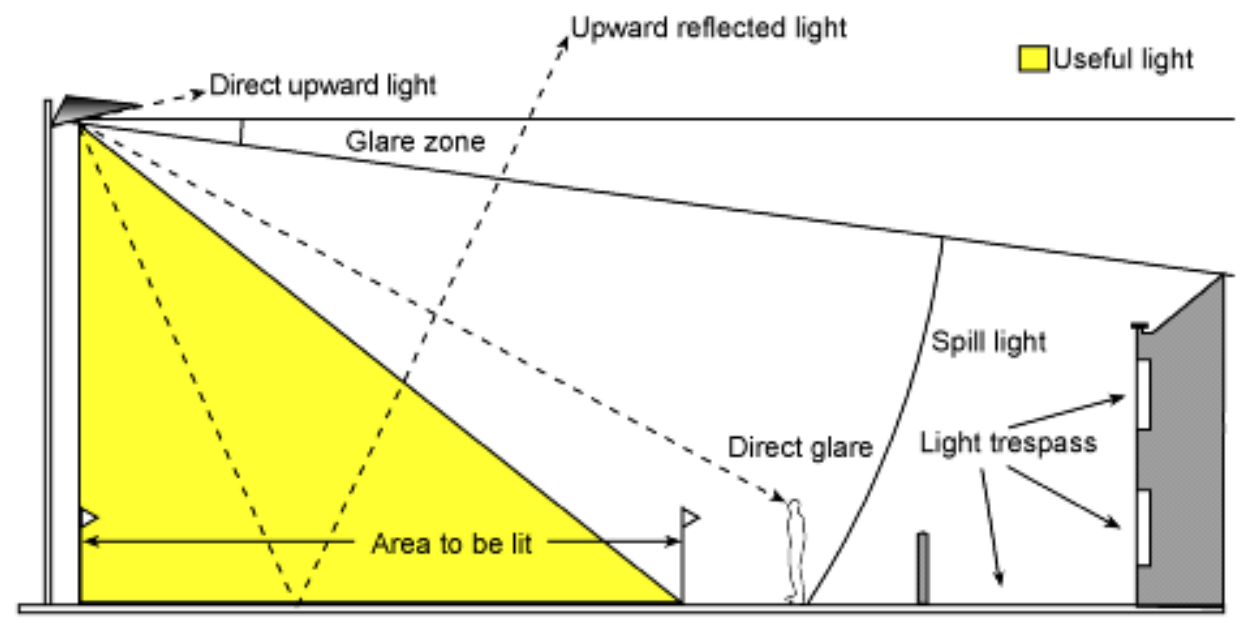

Light pollution is often caused by the way light is emitted from lighting equipment. Choosing proper equipment and carefully mounting and aiming it can make a significant difference.

Figure 1. Diagram of potential lighting scheme of a typical street lamp.

Source:

http://www.lrc.rpi.edu/programs/nlpip/lightinganswers/lightpollution/lightPollution.asp. Last accessed November 5, 2007.

As the diagram demonstrates, light trespass, spill light, and sky glow all send light where it is not wanted or needed and are forms of light pollution.

Artificial outdoor lighting is used for many purposes such as: to allow stores to function in various aspects after dark, to beautify cities, to create safe and secure residential areas, to illuminate historic monuments and sites, to create safe driving conditions on roads and highways, and to make nighttime outdoor sporting events possible (Narisada and Schreuder, 2004). Sky glow, light trespass, and glare are all potential consequences of these or any types of artificial outdoor lighting, and have various effects on animals and humans. Although many of the studies and legislation that will be mentioned in the next sections focus on light pollution that comes from all sources of artificial nighttime lighting, this study will focus specifically on sky glow and its dimming of the night sky. 


\subsubsection{Ecological and Human Health Effects of Light Pollution}

Most studies associated with light pollution concern the effects of artificial nighttime lighting on various species of animals; light pollution disrupts these creatures' natural biological processes, affecting their interactions with the environment. Sea turtles nesting habitats are compromised when bright nighttime lighting deters the turtles from laying their eggs on the affected beaches. Baby sea turtle hatchlings are drawn to areas lit by artificial nighttime lighting and consequently never find the ocean (Salmon, 2003). Interestingly, beach mice forage for less food when they are exposed to nighttime lights, specifically low-sodium lights that have been shown to be appropriate for sea turtle habitats (Bird, et al., 2004). Singing patterns of American robins (characterized by sunlight triggering song) are also disturbed by artificial nighttime lighting (Miller, 2006). Additionally, researchers have recently suggested that artificial nighttime lighting has adverse effects on humans because nighttime light disturbs normal sleeping patterns and circadian rhythms (Harder, 2006; Chen and Franklin, 1996; Rimmer et al., 2000).

\subsubsection{Energy Use and Light Pollution}

The effects of artificial nighttime lighting on humans are not just biological, but economic as well. Hunter and Crawford (1991) estimated the amount of energy and dollars spent in the U.S on artificial nighttime lighting directed into the night sky. From their calculations, Hunter and Crawford found that the United States spends approximately $\$ 644$ million on lighting that is projected only upward. Additionally, 
researchers recognize that light directed into an area in which it is not wanted or intended is a wasted use of energy. Today, the International Dark-Sky Association estimates that $\$ 10.4$ billion is spent on light that is "ill-conceived, inefficient, and ineffective"; $70 \%$ of the energy for this lighting is estimated to come from non-renewable resources, such as coal, petroleum, or gas (“The costs of", 2006).

To calculate the amount of money wasted on light that causes sky glow, researchers must measure many characteristics of the light fixture and its surroundings, including: the amount of dust and gas in the atmosphere, weather conditions, the amount of and direction of light emanating from the fixture, and the reflectivity of any ground surface the light is directed toward. (To what extent reflected light contributes to sky glow is still being discussed by scientists and researchers.) ("What is sky", 2004; Narisada and Schreuder, 2004).

\subsubsection{Effects on Scientific Research}

In addition to biological and economic effects, light pollution affects scientific research. Astronomers in the United States and around the world are particularly concerned with the effects of sky glow and upward-directed artificial nighttime lighting on their ability to study astronomy. As Narisada and Schreuder (2004) state, all astronomical observation is a measure of contrast. When the amount of contrast between the luminance of the object being observed and the luminance of the background is diminished due to sky glow, the final observation of the object is changed. 
The measurement of contrast between the observed object and the background under "sky glow-free" conditions is represented by

$$
C=\frac{L_{O}-L_{B}}{L_{B}}
$$

where $L_{O}=$ luminance of observed object and $L_{B}=$ luminance of the background. The measurement of contrast between the observed object and the background under sky glow conditions is represented by

$$
\begin{gathered}
C^{\prime}=\frac{\left(L_{O}+L_{B}\right)-\left(L_{B}+L_{V}\right)}{\left(L_{B}+L_{V}\right)} \\
C^{\prime}=\frac{\left(L_{O}-L_{B}\right)}{\left(L_{B}+L_{V}\right)}
\end{gathered}
$$

where $L_{V}$ represents the luminance of the light veil created by the sky glow and all other variables remain the same. Comparing the two equations, $C^{\prime}<C$, demonstrating that the observed contrast $\mathrm{C}$ is diminished due to sky glow (Narisada and Schreuder, 2004).

Astronomers determine the amount of sky glow present in a night sky in a couple of different ways. First, astronomers quantify sky glow by measuring the sky brightness in a dark or "blank" area of the sky. The Lighting Research Center at Rensselaer Polytechnic Institute estimates that a suburban night sky can be 5 to 10 times brighter at the zenith point than a natural night sky, and at city center the night sky can be 25 to 50 times brighter than a natural night sky ("What is sky", 2004).

Astronomers also utilize Walker's Law to measure sky glow, which characterizes sky brightness as a function of the distance of the observing point from the city creating the 
brightness, the population of the city, and an additional factor which takes into account other variables such as reflexivity of the ground and the multiplier needed to express the term using correct units (Narisada and Schreuder, 2004). Walker's law can be expressed in equation form as:

$$
I=C P d^{-2.5}
$$

where $I=$ sky brightness in direction of source under $45^{\circ}$ elevation, $d=$ distance, $P=$ population of city, and $C=$ multiplier based on units, "luminous flux per inhabitant, and others such as reflectivity of the ground" (Narisada and Schreuder, 2004). Since the calculation requires the population of the city in question as well as the luminous flux per inhabitant, Walker's law is not easily used in non-populated light polluted areas.

\subsubsection{Light Pollution Regulation and Statistics}

Cinzano and his colleagues published "The First World Atlas of the Artificial Night Sky Brightness" in 2001. Using the United States Air Force Defense Meteorological Satellite Program (DMSP) Operational Linescan System, Cinzano et al. measured artificial night sky brightness and associated it with various population centers throughout the world. From the DMSP satellite data and their measurements of natural sky brightness, Cinzano et al. determined that 99 percent of the United States and European Union populations live in areas where the night sky brightness is above the light pollution status threshold, which has been established as $10 \%$ of the natural night sky brightness above $45^{\circ}$ of elevation; the natural night sky brightness of an area at a given time is affected by the amount of solar activity, the geographic location, the area of the sky observed, and the amount of time since sunset (Cinzano, Falchi, and Elvidge, 2001). Cinzano et al. (2001) 
also determined that $40 \%$ of the United States population no longer views the night sky with night vision due to sky brightness.

Sky brightness has also been measured in specific areas of the United States; most of the measurements regard astronomical observation sites. At Mount Wilson Observatory near Los Angeles, Garstang observed that the increase in sky brightness that has occurred between 1910 and 1990 was mainly due to population growth in that area, as opposed to smog (defined as "air pollution") increase (Garstang, 2000). Meanwhile, Mount Hamilton (UC Santa Cruz, California) has shown a light pollution increase of .065 magnitudes per year since 1948. Additionally, the light pollution at Kitt Peak (Tucson, Arizona) in 1987 was .07 magnitudes above the natural background, Mount Hopkins (Amado, Arizona) showed a light pollution magnitude .49 above the natural level in 1996, and Flagstaff (Arizona) skies were .45 magnitudes above the natural background brightness in 1996 (Narisada and Schreuder, 2004). ${ }^{1}$ These light pollution increases at astronomical sites, coupled with the DMSP satellite data, suggest that increases in light pollution are occurring all across the United States.

The increase in light pollution in the U.S. has led not only academic researchers to study the issue, but national organizations as well. The National Park Service considers the night sky as an integral part of the ecosystems they protect, and has developed a Night Sky Team to assess the current state of the night sky at national parks across the U.S. Understanding the status of the night sky over national parks is critical for this organization because many national parks consider the quality of their night sky to be a

\footnotetext{
${ }^{1}$ See Luginbuhl, 2001, for details on how these measurements were made.
} 
"vital sign", "a physical or biological element of a park that represents the overall condition or is a particularly valuable attribute" ("Natural lightscapes", 2006).

Cities and state governments in the United States have also begun to address the growing issue of light pollution in more recent years. Flagstaff, Arizona, was declared the first International Dark-Sky Community by the International Dark-Sky Association (IDA) in 2001, however no other communities have been given that designation since then. The economic impact of astronomy and related industries has always been a motivating force in the push to reduce light pollution in Arizona; in 1958 Flagstaff first addressed the issue of light pollution at the request of astronomers at Lowell and U.S. Naval Observatories by banning advertising searchlights used by retailers such as car dealerships (Hoversten, 1999). The recurring economic benefits to the state of Arizona, along with the ease of implementation (and associated energy cost savings) have prompted not only cities such as Flagstaff and Tucson, but the entire state of Arizona to enact light pollution mitigating legislation (Greeley, 1985; Arizona, 2007). In 2002, astronomy-related research and technology projects brought almost $\$ 1$ billion to the state (Thomsen, 2002).

In addition to Arizona and its cities, the IDA lists many cities and states that currently have lighting regulations, such as cities in Idaho, Michigan, and New York; Alvarez et al. write that as of 2003, 6 states in the United States had state lighting ordinances. Many states, such as Michigan, are also creating dark-sky parks in their state parks and other natural areas to protect and preserve areas where the night sky is particularly lightpollution free (Resources, 2006; Alvarez del Castillo et al., 2003; Bauer, 2007). 


\subsubsection{Aesthetic Consequences of Light Pollution}

Both the National Parks Service and Narisada and Schreuder (2004) address an additional consequence of light pollution that has not been explicitly mentioned in the studies above. The night sky has a certain aesthetic quality, not only to those who study the night sky, but to "everyday" people who have the opportunity to look up and see the stars. The National Parks Service remarks that many patrons come to the national parks expecting to see an abundance of stars in the nighttime sky (Kirkwood, 2006). However, citizens of New York City were amazed at the number of stars that were visible after the blackout there in 2003 (Reiss, 2003), and many people were confused by the starry sky which resulted after the Los Angeles earthquake of 1994 knocked out power to the area. Some residents wondered if the earthquake had caused the stars to appear (Feder, 2005).

The comments made after both the Northeast power outage and the Los Angeles earthquake suggest that increased light pollution is resulting in a lost connection between humans and the night sky, and this loss is an additional consequence of light pollution. The night sky and its patterns have been the inspiration for many works of religion, philosophy, art, and culture; throughout history the night sky has provided a resource for navigation and understanding of the passing of time and season, as well as works of art, scientific research, and other human endeavors (Narisada and Schreuder, 2004; "Natural lightscape", 2006). Without the ability to view the clear night sky, the opportunity for human beings to continue make intellectual, emotional, and spiritual connections viewing 
the night sky as they have throughout human history are eliminated, and future opportunities for inspiration and advancement in these areas are lost.

\subsubsection{Justification for Government Intervention}

The rapid increase in light-polluted night skies over the past decades and the consequent increase in the adverse affects of light pollution mentioned previously suggests that some type of intervention is necessary to decrease light pollution and mitigate its negative consequences. In the United States, government intervention into a situation is justified by evidence of market failure, including the presence of (environmental) externalities.

A free (perfectly competitive) market requires four things: numerous buyers and sellers, perfect exit and entry into the market, perfect flow of information, and lack of externalities (Gupta, 2001). Market failure occurs when any of these factors are not present. In the case of a clear night sky, there are many negative externalities present; as described previously, the amount of light pollution in a night sky affects scientific research, biological systems and human beings near to and far from the polluted night sky area. Without some sort of regulation of light pollution, there is no consequence for those who cause light pollution, but there are consequences to those whom it affects. Thus the social cost of light pollution is greater than the market cost. Government intervention into the market could cause these costs to be borne by those who are causing the light pollution, balancing out the social costs with the market costs. Much like regulations regarding air quality, government intervention to protect and regulate the 
clear night sky would alleviate the issues caused by market failure and externalities and further the social good.

\section{Literature Review \\ 2.1 Contingent Valuation}

\subsubsection{Contingent Valuation Overview}

The benefits of creating and/or preserving a dark night sky range from the easily quantifiable, such as energy savings, to the very abstract, such as philosophical inspiration or beauty. Appropriate government intervention and creation of policies regarding light pollution requires knowledge of both the policy issue at hand as well as the potential effectiveness of any policies that would be implemented. One typical method of determining the appropriateness of a policy decision is to use cost-benefit analysis. Cost-benefit analysis uses a monetary comparison of the costs of a good or service with the benefits of the good or service to determine whether or not implementation or continuation of the good or service is an appropriate policy decision. Environmental goods and services, however, have values which do not exist in a typical "buy and sell" market, and are consequently more difficult to monetize than typical market goods.

Though difficult, the valuation of non-market environmental goods is not impossible, and can be done using contingent valuation $(\mathrm{CV})$, which is a form of stated preference method (Freeman, 2003). The CV method creates a market for a non-market good or service (also called a "program") through the development of a scenario. The scenario 
includes a description of the hypothetical program, a description of the hypothetical market in which it exists, and any other information deemed necessary to make an informed decision. For example, a program to reduce the amount of rainforest degradation by $15 \%$ over the next 5 years would be described by including the way in which the program would be funded, any expenses incurred by participants being surveyed, and other details such as where the program would take place and the benefits of and alternatives to the program. Based on the program and market described in the scenario, study participants are asked to state their "willingness to pay" (WTP) for implementation of the program by answering either open-ended questions or closedended questions (such as bidding or creating a hypothetical referendum). A typical CV study also collects demographic information to further characterize the monetary costs and/or benefits that participants place on the program. Policy decisions based on these costs and benefits can be made just as decisions would be made in a typical cost-benefit analysis (Mitchell and Carson, 1989; Portney, 1994).

The CV method was first proposed by Ciriacy-Wantrup in 1947 as a way to value natural resources and later suggested by Schelling in 1968. By the 1970s, the CV method was being used more often in tests to determine the method's validity, studying subjects such as air pollution, hunting, reduced health risks in various situations, and water quality. By the 1980s, organizations such as the United States Environmental Protection Agency (EPA) were beginning to accept the $\mathrm{CV}$ method as a valid assessment tool (Hanemann, 1994; Mitchell and Carson, 1989). Today more than 2000 studies have used the CV method in some way (Carson, Flores, and Meade, 2001). 


\subsubsection{Methods}

Though CV studies tackle many different subjects, such as the environment (Alberini, et al., 1997), consumer marketing (Bjørner et al., 2004), and government services such as health care (Golan and Shechter, 1993), there are a few common ways of performing a CV analysis. The following information is from Mitchell and Carson (1989) and Boyle and Bishop (1988) who address four of these methods: bidding, payment card, dichotomous choice, and referendum.

Bidding (Iterative Bidding): In this method, participants are asked if they are willing to pay $\mathrm{Z}$ dollar amount for the program that has been described in the hypothetical market scenario described above. If the participant answers "yes", then the dollar amount is raised until a "no" is received. Then the dollar amount is decreased in smaller increments until a "yes" is received again. Advantages of this method include that the participants are able to examine the answer they have given and modify it if they choose. However, the starting point at which the bidding is begun may influence the participant's answer as well. Some researchers have attempted to get around this bias by allowing the participant to name the starting bid.

Payment Card: Participants are asked to give one WTP response based on the hypothetical market scenario they are given by using a payment card to select the value that most represents their WTP for the program. The payment card is not necessarily an actual card, but is a series of values for the respondent to choose from that start with zero 
and increase. Depending on how the payment card is being used, participants may also see various dollar amounts highlighted on the payment card, called anchors, that represent appropriate choices for individuals who have a particular characteristic (such as a certain household income). The payment card method is useful because it eliminates the problem of suggesting a particular value as the "starting point" that is found when using the bidding method. However, using anchors on the payment card may also affect respondents' selection of WTP values.

Dichotomous Choice: In this method, sometimes called "take-it-or-leave-it", after participants have read the hypothetical market scenario, they are then given a randomly assigned WTP value and asked if they would be willing to pay that value. Participants are not given any other choices, and provide a yes or no response. Each WTP value in the set is offered to the same number of people and consequently this method can take a longer amount of time to complete than other methods. Additionally, only qualitative analysis can be performed, as participants do not respond with a WTP value. Occasionally the dichotomous choice survey may include an opportunity for a second response, where participants are given a pre-selected random higher or lower value depending on whether they respond yes or no to the first question.

Referendum: The referendum method is similar to the dichotomous choice method (described above), where participants are asked if they are willing to pay a specific amount. In the referendum method, participants are given the hypothetical market scenario and asked whether or not they would vote yes or no for the proposal were it to 
be considered on an actual ballot. Additionally, some referendum studies compare hypothetical referendum decisions and actual referendum decisions. For example, Robert Johnston performed a study regarding installation of a public water system, finding that the participants' hypothetical voting preferences and actual voting preferences were almost identical (Johnston, 2006). An advantage of the referendum model is that it is familiar to many participants in both format and context (voting in a referendum is a frequent way to determine the value of a specific program or provision to a group of individuals). A hypothetical referendum CV survey may also be preferable over an actual referendum in some instances, as the CV survey may be more able to obtain responses from all demographics in the population (Mitchell and Carson, 1989).

In comparing three of these methods (iterative bidding, payment card, and dichotomous choice), Boyle and Bishop (1988) find that none of the three stands out as a "better" method, and they recognize problems with each method. In their study, iterative bidding contained a starting point bias problem, the payment cards had an anchor bias, and both the payment cards and the dichotomous choice methods had an interviewer effect. However, the results of their WTP questions showed that the dichotomous choice WTP value was the only statistically significantly different value when compared to the other two. Though each type of study may have specific issues related to methodology, these issues can be recognized and overcome by designing and executing a well constructed CV survey. 


\subsubsection{Designing a CV Survey}

Once a particular method of $\mathrm{CV}$ is chosen for a particular study, the $\mathrm{CV}$ survey can be developed. One of the many challenges of any of the $\mathrm{CV}$ methods is survey design. A $\mathrm{CV}$ survey has to be able to clearly convey the program and scenario and elicit the intended responses from survey participants without providing additional unnecessary information that would bias the participants' responses. The survey itself cannot be too long or short; the CV survey should not lose participants' attention but should also have enough content to gather the required information to perform a thorough analysis.

The wording and order of survey content is also a survey design concern. The specific questions that are asked, the vocabulary used to ask those questions, and the sequence of the questions can all have an effect on the survey respondents' WTP. Questions to determine how much participants know about the amenity or program in question, as well as information to clarify any misconceptions about the program can help to clarify the issue that the CV study is addressing and ensure that the survey participants are answering the "right" WTP question. Consequently, the placement of questions and information before or after the actual WTP questions can have an effect on the participants' WTP responses.

The survey audience also has to be appropriate for the survey topic. The researcher should determine who would bear the costs and benefits of the program; these participants are the ideal survey respondents. However, this population may not necessarily be the most accessible population for the $\mathrm{CV}$ researcher. Based on time, 
money, accessibility, and the actual program itself the researcher(s) must decide on the ideal population to survey.

To eliminate some of these issues with survey design, Mitchell and Carson (1995) recommends using focus groups and pre-tests. Once the survey researcher(s) determine what exactly their program (good or service) is and why they are valuing it, focus groups can address the program and identify any preconceived ideas that the survey population might have regarding the topic. A focus group can also help to identify strong points and weaknesses in the survey scenario. Similarly, pre-tests provide two additional ways to better understand the $\mathrm{CV}$ survey: pre-tests with the survey administrators ensure that they are familiar with the subject matter and content; additionally, a formal pre-test with sample respondents allows the researchers to analyze the results and determine if any additional rewording, reordering, clarifications, or omissions are necessary in the survey content (Mitchell and Carson, 1995).

\subsection{Validation of Contingent Valuation Methods}

When performing a formal pre-test, another issue to be concerned with regarding the CV survey is validity. Validity is an especially important part of CV studies, particularly in those instances where a public good is being evaluated. According to Mitchell and Carson (1989), the three types of validity that CV studies are concerned with are content validity, criterion validity, and construct validity. 


\subsubsection{Content Validity}

A survey has content validity when the survey questions, scenario, and other information are well-worded and address the correct topic. The presence of content validity is necessary because the wording of a $\mathrm{CV}$ scenario and subsequent questions can alter the way a participant responds to the WTP questions (Mitchell and Carson, 1989). The content of the scenario must fully disclose all the necessary details that the participant needs to make a decision without leading the participant toward one type of answer or another. Mitchell and Carson (1995) write that after reading a scenario, respondents should "clearly understand the characteristics of the good and the context in which it is being offered" as well as find both the method of providing the good and the method of payment for the good to be plausible. If the method of provision of or payment for the good and its relationship to the participants is not taken into account, the survey may exhibit "vehicle bias", a term used to describe the effect stating a specific payment vehicle may have on survey participants' responses (Freeman, 2003). In order to prevent this, the scenario should be only as detailed as necessary while still conveying the information that makes the scenario clear and realistic to respondents.

Similarly, the WTP questions offered to the participants must not over or underestimate the importance of the participant's decision - the participant should feel compelled to make a decision without feeling pushed to make a specific decision (for example, to choose a higher WTP than he or she believes that his or her household could actually afford) (Mitchell and Carson, 1995). After reading the scenario and the questions, the respondents should clearly understand their preferences regarding the scenario and 
program. If they cannot make a decision easily, then their final decision may be biased by any "implied values cues" found in the scenario or the questions (Freeman, 2003).

\subsubsection{Criterion Validity}

Another form of validity that CV studies are concerned with is criterion validity whether or not the method the CV study is using gives results that are comparable to some other set of data. Tests of criterion validity that compare self-reported survey results with official reports have supported the results of $\mathrm{CV}$ studies in most cases, but if a particular event is sensitive, a lack of willingness to self-report may occur (Mitchell and Carson, 1989). Additionally, Venkatachalam (2004) suggests comparing the WTP values of the good to a 'market price' of the good being valued as a way of determining content validity.

\subsubsection{Construct Validity}

A CV survey exhibits construct validity based on how well the measures used in the CV study coincide with other theories, or how the CV study compares with different measurements of the same type of statistic. These issues of compatibility with other theories and measurements have been important parts of economic arguments for and against the CV method (Mitchell and Carson, 1989). Recent literature on the CV method and its use discusses the validity of the "scope test" (Heberlein et al., 2005), which theorizes that WTP amounts should reflect the amount of a good or service being addressed in the survey. If a participant is asked how much they would be willing to pay in property taxes to clean up one of the lakes in his or her town, that value should be 
lower than the amount the participant would be willing to pay in property taxes to clean up all of the lakes in their town, provided that they are willing to pay any amount at all toward the project. Heberlein et al. finds that the scope sensitivity test may not be effective as a measure of validity.

\subsubsection{External Validity}

External validity is the final type of validity that should be looked for in a CV survey. For a survey to have external validity, the survey must be able to accurately generalize about a population. That is, if a CV survey is externally valid, the results from the sample population used in the CV survey should reflect the results that would be obtained if the entire population were surveyed. The sample population needs to be appropriate both in sample size as well as in proportions of demographic and socioeconomic representation contained in the sample. One way to test for external validity is to compare the results of the hypothetical market CV studies against actual market results for the same situation or scenario (Hanemann, 1994; for an example see Vossler and Kerkvliet [2003]).

\subsection{Criticisms of Contingent Valuation}

Despite these efforts to ensure validity in a CV study, criticisms of the method are still present. The fact that respondents are participating in the hypothetical market of the CV study, rather than an actual market, is a major criticism of $\mathrm{CV}$ studies. Is the individual stating the same amount they would be willing to pay in an actual market? Or if the market were to suddenly exist in reality, would the individual be willing to pay a higher 
or lower amount for the same program, instead of the amount they had stated in the WTP survey? This is a common external validity problem with CV studies, which can be addressed by using the referendum format for the study. Using the referendum format creates the opportunity to compare $\mathrm{CV}$ results with actual voting choices and behaviors and determine if participants are willing to pay the same or different amounts in each situation. The 1993 National Oceanic and Atmospheric Association (NOAA) panel on contingent valuation (described in more detail later in this section) also suggests that $\mathrm{CV}$ studies be performed in the hypothetical market of a referendum, in part because it is a more familiar situation for the respondent to provide a yes or no answer (Arrow, et al., 1993; Portney, 1994).

Another criticism of CV studies regards the individuals who are making use of the program described in the CV survey. Even if an individual has a WTP value for a particular program, that individual may never make personal use of or benefit from the program in question. Consequently, the study of non-marketable goods and services includes the idea of "existence value" or "nonuse value". These terms are many times used interchangeably, but can mean different things (Lazo et al., 1997). Existence value is the value that a particular resource has to an individual based on his or her knowledge that the resource exists, even if he or she does not intend to ever personally use the resource or benefit from it (Portney, 1994). Nonuse value is similar, but represents the value that a particular resource has to an individual in order to keep it at its current state (to prevent degradation of the resource) whether or not they intend to use it (Freeman, 2003). For example, individuals surveyed regarding the rainforest degradation reduction 
program mentioned previously might still state a value that reflects their true WTP for such a reduction even if they never plan to travel to or interact with the rainforest in their lifetime. "Existence value" will be used to generally refer to both defined valuation preferences for the remainder of this work.

Existence value is thought by some economists to be the CV method's rejection of economic theory (Hanemann, 1994). These economists argue that if existence value is included, the CV method does not represent the true economic preferences of the respondents as it claims to, but instead represents other preferences based on something other than economics, such as feelings. For example, Diamond and Hausman (1994) write that preferences and feelings such as "....receiving a 'warm glow' from expressing support for good causes", "describing what [individuals] think is good for the country", and "expressing a reaction to actions that have been taken rather than evaluating the state of a resource" may be expressed by such a large proportion of the survey population that the CV survey is not accurately estimating the overall economic preference of that population. Additionally, Stevens et al. (1991) remark that if decisions in WTP studies (particularly concerning wildlife) are being made based on moral values, the CV method may not be the best method to use in these cases.

Cooper et al. (2004) also writes regarding the idea of participants" use of "non-economic" decision making processes when making their decisions regarding WTP. This argument against the $\mathrm{CV}$ method has come about in part due to the absence in many studies of the scope sensitivity that was mentioned previously. Cooper et al. state that if participants 
are placing a WTP value on an item because of a desire to "do the right thing" rather than because they agree with the scenario presented to them, the CV study is not accurately collecting the data it seeks.

Critics also remark that feelings of altruism can affect a person's WTP, if the respondent is expressing paternalistic altruism. Paternalistic altruism is based on the respondent caring about the amount of a good that another person experiences or consumes, while nonpaternalistic altruism is based on the respondent caring about the level of happiness or utility of another. While paternalistic altruism affects the Pareto optimum allocation of resources, (that is, the allocation of resources for which no person can be made better off without making at least one person worse off [cite CBA book]), nonpaternalistic altruism does not have an effect. Consequently, if responses based on nonpaternalistic altruism are counted in the value of the resource, then some values of the resource are being ““double counted' across generations” (Lazo et al., 1997; Freeman, 2003). Therefore, if the respondent is expressing paternalistic altruism, his or her cost-benefit function is changed as a result of the value that he or she places on the resource (Freeman, 2003), implying that these individuals should be included in the cost-benefit analysis/CV study.

However, while strict economics focuses on the cost-benefit function and market price related to the program being valued, policymakers find that it is valuable to focus on the WTP of an individual whether or not their cost-benefit function is changed. Individuals make decisions to support or oppose policy decisions because of such feelings as concern for others and patriotism. For example, an individual might choose to support pro-life 
abortion policies based on a moral conviction or religious beliefs. As Hanemann (1994) notes, researchers performing other types of economic studies take into account preferences that are not monetary or economic when surveying populations. Hanemann's example is a survey regarding people's purchase of fish over a given time period. This survey did not exclude Catholics, even though Catholics eat fish in part as a religious obligation (Hanemann, 1994).

Thus, whether an individual being surveyed is exhibiting paternalistic or nonpaternalistic altruism is irrelevant. The important issue to the policymaker is that the individual is willing to pay the amount they stated to support that particular policy, regardless of their reasons for doing so. A person who is a medical doctor working the night shift may feel very strongly that the clear night sky is important, and have a large WTP value to implement a program protecting a clear night sky, even if he or she does not ever look at or use the night sky. This individual is willing to support and contribute to a policy that will affect others (such as astronomers) rather than themselves, and potentially increase the happiness of others. Therefore this individual's WTP value should be counted because he or she is someone who is willing to pay for the implementation of the suggested program.

Hanemann (1994) lists several other objections to CV surveys and the CV method that he argues contain both unfounded criticisms against CV surveys as well as demonstrate actual flaws with CV surveys. First, Hanemann writes that surveys "are vulnerable to response effects", referring to the survey design options such wording of questions, 
vocabulary used in the survey, and the order of questions that can have an effect on the responses that respondents give. However with careful pre-testing and analysis of the CV survey, many response effects can be mitigated. Nonetheless, Hanemann points out that response effects will never be completely eliminated.

A second objection to CV surveys Hanemann discusses is that "the survey process creates the values [that respondents give]". The validity of the responses that are given in CV surveys can be evaluated in several ways, including comparing the results of multiple surveys to one another, and comparing survey results to actual results.

As has been previously mentioned, one way to compare a CV survey to actual results is to use the referendum format and compare the survey results to the results of an actual referendum. Although some critics remark that "ordinary people are ill-trained to value the environment", Hanemann states that when using the referendum CV format, no knowledge should be required in order to participate. If there is a concern that respondents are not answering the "correct" question when responding to the survey, extensive pre-testing as well as interviews of survey respondents after they have filled out the survey can reveal any errant interpretations that may be occurring. These pre-testing efforts and comparisons to actual results also dismiss the other objections that Hanemann discusses, including that "survey responses can’t be verified” (Hanemann, 1994).

Finally, the most noted criticism of CV studies came about when CV was still a relatively new policy analysis tool. The Exxon-Valdez oil spill of 1989 prompted debate over both 
the use of the CV method as a measurement of values of resources as well as the inclusion of these nonuse values in damage estimates in environmental situations, when it was discovered that nonuse values obtained from a CV study were to be used as part of the litigation regarding damages caused by the spill ${ }^{2}$. As a result, regulations and recommendations regarding both inclusion of nonuse use values and use of the $\mathrm{CV}$ method in general were developed by the National Oceanic and Atmospheric Administration and the Department of the Interior (Arrow, et al., 1993). These recommendations included:

- Administration of CV surveys by personal interview

- Pre-testing to identify interviewer effects

- Pre-testing of CV questionnaire

- Use of conservative design

- Use of willingness to pay format

- Use of referendum format

- Accurate description of the program or policy

- Pre-testing of photographs

- Acknowledgement of undamaged substitute commodities

- Asking yes/no follow up questions

- Allow "no answer" option in referendum format

- Include questions used for interpreting responses (cross tabulation)

\footnotetext{
${ }^{2}$ The CV study performed in response to the oil spill is Carson, R. T., et al. (1992). A Contingent Valuation Study of Lost Passive Use Values Resulting from the Exxon Valdez Oil Spill; Report to the Attorney General of the State of Alaska, La Jolla, CA: Natural Resource Damage Assessment, Inc.
} 
- Reporting of statistics of survey, such as sample size, etc.

- Alternative expenditure possibilities

- Deflection of transaction values (attempt to deflect responses away from inaccurate indicators such as "warm glow" feelings)

- Ensure respondents can distinguish steady state or interim losses

As the NOAA suggests, not all recommendations will apply to every CV survey, but authors of the survey should attempt to meet as many of the recommendations as possible (Arrow, et al., 1993).

Eventually, a symposium of three articles that summed up the controversy prompted by the oil spill was published by Portney (1994), Hanemann (1994) and Diamond and Hausman (1994) (all of which have been previously cited in this thesis), discussing the use of the CV method in general (Freeman, 2003). While Portney commented on the importance of the CV method as a policy analysis tool both in environmental and other situations and how to use the CV method well, Hanemann replied to many objections of economists, including Diamond and Hausman, regarding the use of the CV method and the inclusion of existence value in economic studies. Finally, Diamond and Hausman contributed their stance on why the CV method does not accurately measure people's true preferences, and additionally suggest that changes to survey design, methodology, etc. will not make $\mathrm{CV}$ method results more accurate. 
The criticisms and corresponding rebuttals presented above demonstrate that although the CV method as a policy analysis tool has potential drawbacks, these drawbacks do not prevent contingent valuation from being a useful policy analysis tool. Careful development, pre-testing, and implementation of the $\mathrm{CV}$ survey will ensure that the $\mathrm{CV}$ study is valid and addresses the appropriate program and research questions. Additionally, the NOAA's recommendations above coincide well with the preceding recommendations of Hanemann and of Mitchell and Carson regarding survey design and implementation. Taking into account as many of these recommendations as possible while being aware of the criticisms of the contingent valuation method will ensure that the CV study is used in the most valid and appropriate way possible.

\section{Methodology}

\subsection{Study Structure}

This research draws upon many of the recommendations of the NOAA panel and others to create a CV study that determines the WTP for a clear night sky. More specifically, this study focuses on the WTP of Rochester Institute of Technology (RIT) students for a clear night sky on RIT's campus. A study based on a measure of air pollution is used as a model for measuring WTP using the payment card CV method. This study is detailed in "Economic Analyses at EPA" and describes a benefits study related to visibility at the Grand Canyon (Deck, 1997). The EPA suggested that a reduction of sulfur emissions at a nearby generating station (Navajo Generating Station) would increase visibility at the Grand Canyon. Participants in the survey mailing were asked to compare photographs of four different visibility levels at the Grand Canyon, and to answer various questions 
regarding WTP for programs resulting in different degrees of visibility at the Grand Canyon (Figure 2, Figure 3) (Deck, 1997). The results of the survey allowed the EPA to monetize the benefits of implementing each pollution reduction program in the Grand Canyon area, and make a decision regarding which program would be most suitable to the situation. A second study of the same issue used a similar approach with open-ended interview questions to monetize the same benefits (Figure 4) (Deck, 1997). 
WHAT IS THE VALUE OF PROTECTING VISIBILITY

AT NATIONAL PARKS IN THE SOUTHWEST?

New air pollution controls being considered for the protection of visibility at national parks in the southwest could mean higher prices and higher taxes throughout the country. The next questions concern how much obtaining improvements and preventing worsening in visibility at national parks in the southwest would be worth to your household.

These questions concern only visibility at national parks in the Southwest and assume there will be no change in visibility at national parks in other regions. Other households are being asked about visibility, human health and vegetation protection in urban areas and at national parks in other regions. For these questions, assume you could be sure that any change would occur next year and continue forever, and all households now and in the future would also pay the most it is worth to them to protect visibility.

Q-12 With additional air pollution controls, average visibility conditions in and around all national parks in the Southwest could improve. What is the most your household would be willing to pay every year in increased prices and taxes to have average visibility improve from Grand Canyon photograph $C$ to Photograph B at all national parks in the Southwest? (Circle best answer)

$\begin{array}{llrlrll}\$ 0.00 & \$ 2 & \$ 8 & \$ 25 & \$ 60 & \$ 150 & \$ 400 \\ \$ 0.50 & \$ 3 & \$ 10 & \$ 30 & \$ 75 & \$ 200 & \$ 500 \\ \$ 1.00 & \$ 4 & \$ 15 & \$ 40 & \$ 100 & \$ 250 & \$ 750 \\ \$ 1.50 & \$ 5 & \$ 20 & \$ 40 & \$ 125 & \$ 300 & \text { MORE THAN } \$ 750\end{array}$

Q-13 What is the most your household would be willing to pay every vear in increased prices and taxes to have average visibility improve from Grand Canyon Photograph C to Photograph $\underline{A}$ at all national parks in the Southwest? (Circle best answer)

$\begin{array}{llrrrrr}\$ 0.00 & \$ 2 & \$ 8 & \$ 25 & \$ 60 & \$ 150 & \$ 400 \\ \$ 0.50 & \$ 3 & \$ 10 & \$ 30 & \$ 75 & \$ 200 & \$ 500 \\ \$ 1.00 & \$ 4 & \$ 15 & \$ 40 & \$ 100 & \$ 250 & \$ 750 \\ \$ 1.50 & \$ 5 & \$ 20 & \$ 40 & \$ 125 & \$ 300 & \text { MORE THAN } \$ 750\end{array}$

Q-14 It is also possible that some additional air pollution controls may be needed just to keep visibility at national parks in the southwest from getting worse. What is the most your

Figure 2. Closed-ended question survey mailing (Deck, 1997). 
household would be willing to pay every year in increased prices and taxes to prevent average visibility at all national parks in the Southwest from becoming like photograph D for Grand Canyon rather than like Photograph C. (Circle best answer)

$\begin{array}{llrrrrr}\$ 0.00 & \$ 2 & \$ 8 & \$ 25 & \$ 60 & \$ 150 & \$ 400 \\ \$ 0.50 & \$ 3 & \$ 10 & \$ 30 & \$ 75 & \$ 200 & \$ 500 \\ \$ 1.00 & \$ 4 & \$ 15 & \$ 40 & \$ 100 & \$ 250 & \$ 750 \\ \$ 1.50 & \$ 5 & \$ 20 & \$ 40 & \$ 125 & \$ 300 & \text { MORE THAN } \$ 750\end{array}$

Q-15 Please provide any information that helps explain your answers to Questions 12, 13, and 14 above. You may also use the back page of the questionnaire.

Q-16 We understand it may be difficult to determine the most you are willing to pay for changes in visibility at national parks. Would you say your answers to Questions 12, 13, and 14 are: (Circle number of best answer)

$\begin{array}{ll}1 & \text { VERY ACCURATE? } \\ 2 & \text { WITHIN THE BALLPARK? } \\ 3 & \text { SOMEWHAT INACCURATE? } \\ 4 & \text { PROBABLY VERY INACCURATE? }\end{array}$

Figure 3. Closed-ended question survey mailing continued (Deck, 1997). 


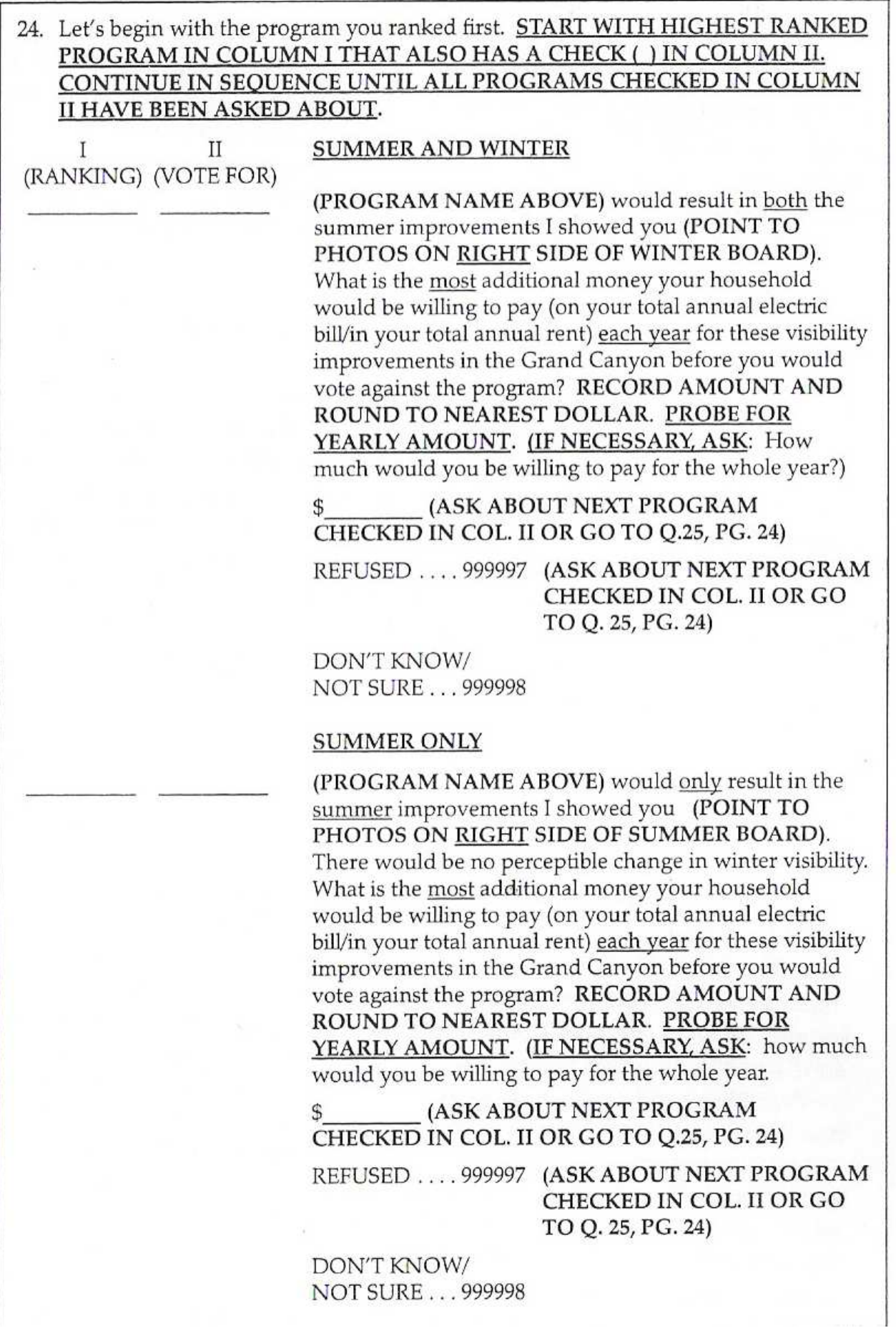

Figure 4. Open-ended question survey interview (Deck, 1997). 


\subsection{Survey Structure}

The approach in this research is based on the closed-ended WTP survey mailing used by the EPA, and uses a payment-card format to determine the WTP of RIT students for a decrease in light pollution on RIT's campus.

The first section of the survey gathers background information about the students' understanding of light pollution. Questions lead the students to a simple understanding of what light pollution is, and then lead them to think about how much time they spend outside at night on RIT's campus. Students are also asked to state whether or not they feel that light pollution is a problem on RIT's campus.

The second section of the survey asks the students to choose their WTP for three different changes in light pollution. The students read a scenario which describes how changes to the amount of light pollution might be implemented. Students are also informed that payments they would make to allow these changes will come from their personal income. The three changes in light pollution levels are represented by four pictures that depict a starting level of light pollution, and the three resulting changes in the light pollution level that could occur. There are two sets of pictures, each using a different constellation, and the pictures are displayed in a running slideshow during the time the students are taking the survey. The students' WTP is determined using a payment card method similar to that of the EPA study. Figure 5 is an example of a WTP question from the survey. 
Q.1. With additional light pollution controls aimed at reducing sky glow, average visibility conditions of the night sky on RIT's campus could improve. What is the most you would be willing to pay in out of pocket expenses per quarter for a change in visibility from Picture A to Picture B? (In the table below, circle the value that best represents your willingness to pay for the change described above.)

$\begin{array}{llllllc}\$ 0.00 & \$ 2 & \$ 8 & \$ 25 & \$ 60 & \$ 150 & \$ 400 \\ \$ 0.50 & \$ 3 & \$ 10 & \$ 30 & \$ 75 & \$ 200 & \$ 500 \\ \$ 1.00 & \$ 4 & \$ 15 & \$ 40 & \$ 100 & \$ 250 & \$ 750 \\ \$ 1.50 & \$ 5 & \$ 20 & \$ 50 & \$ 125 & \$ 300 & \text { More than } \$ 750\end{array}$

Figure 5. Example of WTP question from light pollution survey.

Finally, in the third section of the survey, demographic information is collected including gender, year in school, size of hometown, and estimate of personal income.

The survey used for this study can be found in Appendix A.

\subsubsection{Pictures}

The second characteristic of the EPA survey that this research mimics is the use of picture comparisons to supplement the payment card WTP questions. Ideally, actual images of RIT's night sky at various levels of light pollution would be used for the survey. However, due to the complex and time-intensive process of obtaining and processing these images, taking actual photographs was not feasible. No images were available from other sources that recreated the variations in light pollution that the $\mathrm{CV}$ survey asked respondents to consider; consequently, the best method of obtaining these images was to create artificial representations of the various levels of light pollution 
described. The main challenge in creating these images was that the pictures needed to accurately represent the appearance of sky glow in the sky over RIT's campus.

With the assistance of the Department of Imaging Science at RIT, four light pollution images were created - two sets of four images were used for the survey, each set using a different constellation. The images were adaptations of images of constellations created by Frank Summers of the Space Telescope Science Institute using a program called StarSplatter (Summers, 2006). Representations of the constellations Orion and Centaurus were taken from Dr. Summers' website and modified in Adobe Photoshop to create the effect of different amounts of sky glow on the night sky. The images were overlaid with gradient and grayscale as described in Table 1.

\begin{tabular}{|c|c|c|c|}
\hline Picture & $\begin{array}{c}\text { Light Pollution } \\
\text { Level Change }\end{array}$ & $\begin{array}{c}\text { Gradient } \\
\text { (color: ff8912) }\end{array}$ & $\begin{array}{c}\text { Grayscale } \\
\text { (color: c0baba) }\end{array}$ \\
\hline Picture A & None & $50 \%$ & $50 \%$ \\
\hline Picture B & Improvement & $40 \%$ & $40 \%$ \\
\hline Picture C & Improvement & $30 \%$ & $30 \%$ \\
\hline Picture D & Worsening & $60 \%$ & $60 \%$ \\
\hline
\end{tabular}

Table 1. Specifics of Adobe Photoshop alterations made to StarSplatter images.

Each set of four images (Orion and Centaurus) was grouped together on a PowerPoint slide which was displayed at the front of the room during survey implementation (Figure 6). 


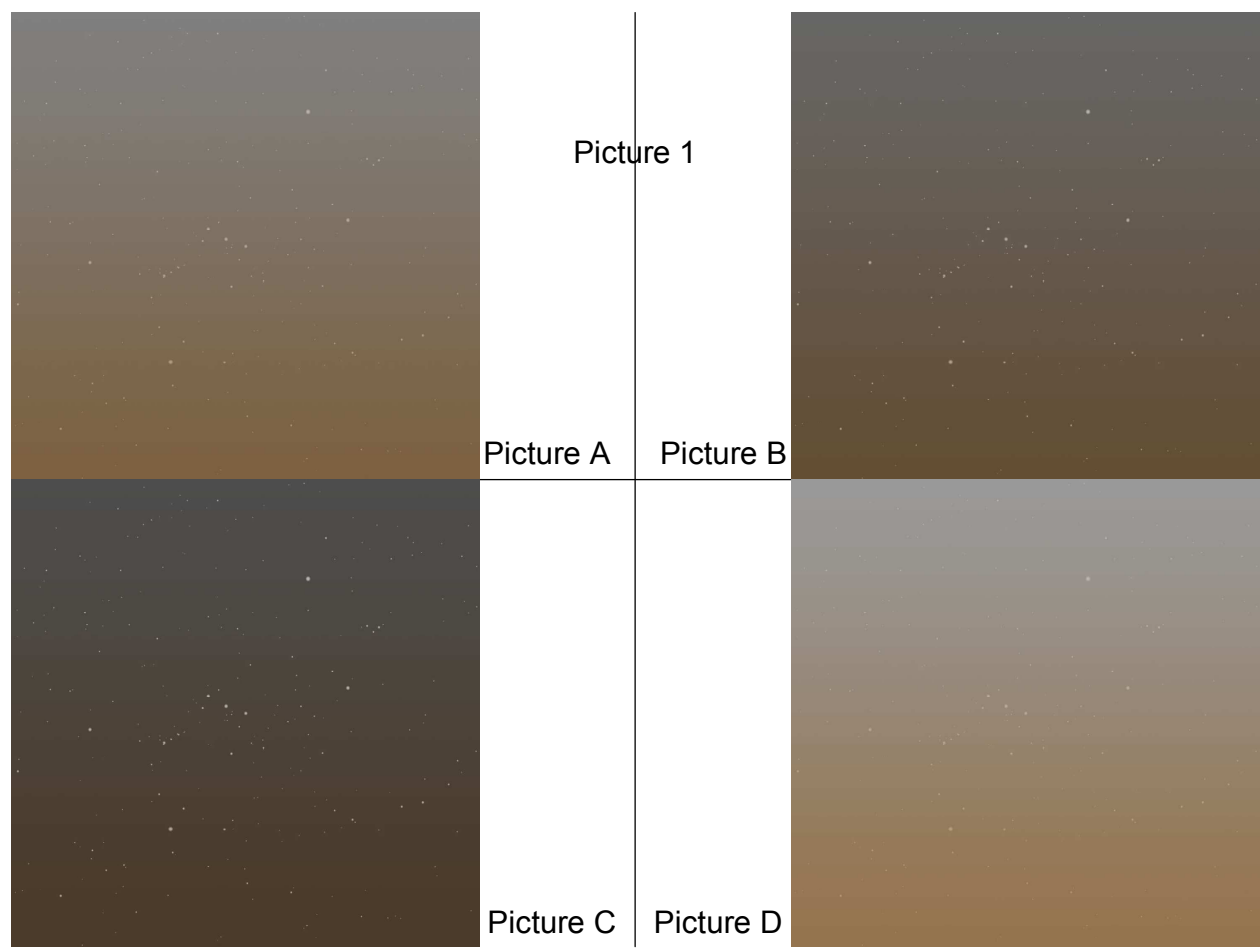

Figure 6. Example of PowerPoint slide used in survey presentation.

\subsubsection{Informed Consent}

Before administering the survey, approval of the project was obtained from the Institutional Review Board for the protection of human subjects. An introduction script was written to inform students of their rights regarding participation in the survey, and an informed consent paragraph was added to the instruction page of the survey. The introduction script can be found in Appendix B. 


\subsection{Survey Implementation}

\subsubsection{Initial Survey Pretest}

A survey pretest was performed during RIT's fall quarter of 2006 with the 0521-402 Policy Analysis I course. Students were asked to participate in the survey, as well as asked to write any feedback they had regarding the survey on the final page, but participation was voluntary. The purpose of the pretest was to determine if any errors were made in the writing of the survey, if any questions or statements were confusing, and if the survey was leading or misleading in any way. In addition to any issues that were not anticipated, the pre-test was performed to assess several survey design issues, including:

- The clarity of the scenario describing the light pollution reduction program

- Whether survey respondents understood the WTP questions and the comparisons they were asked to make using the light pollution pictures

- Whether survey respondents found the light pollution images to be believable and/or realistic

- Whether the order and wording of the questions elicited the desired responses for each question

The survey pretest showed that the description of the comparisons to be made using the light pollution images was unclear. The description was rewritten to better describe which pairs of light pollution images were associated with each WTP question. The survey was also found to take approximately 15 to 20 minutes to complete. 
A simple statistical analysis of the pretest showed that most frequent response for any of the three light pollution scenarios was $\$ 0$. This result was anticipated and not surprising. The survey pretest also showed that students were willing to pay approximately the same amount for the small light pollution improvement (WTP 1) as they were willing to pay for the prevention of the worsening of the light pollution by the same amount (WTP 3). Both of these results were consistent with the preferences of the actual survey population which will be discussed in more detail in a later chapter.

\subsubsection{Administration of Final Survey}

The survey population chosen for this analysis was the RIT student community. The RIT student community was very accessible due to ease of contact with professors teaching classes and the availability of students during their regular class time. Students in three RIT undergraduate courses were given a self-administered survey modeled after the survey given to participants in the National Parks study described above. These courses, which occurred during the 2006 winter quarter at RIT, were 0508-211 Science and Technology Values, 0511-457 Applied Econometrics, and 0508-212 Introduction to Environmental Studies. In all, four groups of students received the survey (two Science and Technology Values classes, one Environmental Studies class, and one Applied Econometrics class). The variety of courses (introductory vs. advanced, various subjects) helped to ensure that a variety of students were surveyed. 
Surveys were administered at the beginning of each class session (as was chosen by the professors). Students were read the introduction script informing them of the purpose of the research as well as of their rights regarding survey participation. Surveys were handed out to those students that were willing to participate. Students were given as much time as needed to complete the survey, but were informed that the survey would take approximately 15 to 20 minutes. The light pollution images contained in the PowerPoint slideshow were on display at the front of the room for the duration of the survey.

\section{Analysis}

\subsection{Initial Analysis of Surveys}

\subsubsection{Summary of Initial Analysis}

After implementation of the methodology described above, the variables included in the survey were coded and input into Microsoft Excel and SAS. Table 2 describes how each question was coded for analysis. The survey results were initially analyzed to recognize and discard any outliers and non-responses from the results as well as to determine the final frequency of responses for each variable. Next, means, medians and other descriptive statistics were produced using Microsoft Excel. The WTP data was translated from dollar values into cent values to allow for easier interpretation of calculations later on, and "interval midpoint values" for each WTP response were also calculated. The descriptive statistics produced by the WTP responses imply that the WTP has a nonnormal distribution. The non-normal distribution was accounted for by taking the natural $\log$ of the actual and midpoint WTP responses. Finally correlation tables regarding each 
of the variables were produced to determine if WTP was potentially correlated with any of the variables based on the survey results. Details of each of these steps are provided in the next sections.

\begin{tabular}{|l|l|}
\hline Question & Code \\
\hline $\begin{array}{l}\text { Have you ever heard the term 'light } \\
\text { pollution" used before? }\end{array}$ & HEARDOF \\
\hline Have you ever experienced sky glow? & EXPERIENCESG \\
\hline $\begin{array}{l}\text { In your personal opinion, is sky glow a } \\
\text { problem on Rochester Institute of } \\
\text { Technology's (RIT's) campus at night? }\end{array}$ & SGRIT \\
\hline $\begin{array}{l}\text { Do you reside on - campus or off - } \\
\text { campus? }\end{array}$ & RESIDE \\
\hline $\begin{array}{l}\text { On average during your academic year, } \\
\text { how many hours per week would you say } \\
\text { that you spend on campus? }\end{array}$ & TIMEON \\
\hline $\begin{array}{l}\text { On average during your academic year, } \\
\text { how many hours per week would you say } \\
\text { that you spend outside on campus at night } \\
\text { (after sunset and before sunrise)? }\end{array}$ & TIMEOUT \\
\hline $\begin{array}{l}\text { What is the most you would be willing to } \\
\text { pay in out of pocket expenses per quarter } \\
\text { for a change in visibility from Picture A to } \\
\text { Picture B? }\end{array}$ & WTP1 \\
\hline $\begin{array}{l}\text { What is the most you would be willing to } \\
\text { pay in out of pocket expenses per quarter } \\
\text { for a change in visibility from Picture A to } \\
\text { Picture C? }\end{array}$ & WTP2 \\
\hline $\begin{array}{l}\text { What is the most you would be willing to } \\
\text { pay in out of pocket expenses to prevent } \\
\text { average visibility on RIT's campus from } \\
\text { becoming like Picture D rather than } \\
\text { remaining at the level of Picture A? }\end{array}$ & WTP3 \\
\hline Gender & \\
\hline Major (responses grouped by college) & MAJORBC \\
\hline Year in College & YRCOLLEGE \\
\hline Hometown & HMTWN \\
\hline Personal Income per quarter & INCOME \\
\hline Accuracy of Income Estimate & \\
\hline
\end{tabular}

Table 2. Coding of survey questions. 


\subsubsection{Development of Final Survey Population}

In total, 164 surveys were handed out and returned. However, one survey was discarded due to a student volunteering that he or she had previously participated in the pretest of the survey that occurred in fall quarter. The final survey return was 163 surveys.

Not every survey was returned entirely complete, and questions that were unanswered or for which the answer was unclear were discarded. WTP outliers were chosen by selecting responses that were at least two standard deviations from the mean as identified in a SAS plot of the WTP data points. Three surveys were removed for outlying WTP responses, and one survey was removed due to an outlying TIMEOUT response. The total number of responses from the remaining surveys for each question is described in Table 3.

\begin{tabular}{|l|c|c|}
\hline Category & Responses & Non-responses \\
\hline HEARDOF & 159 & 0 \\
\hline EXPERIENCESG & 159 & 0 \\
\hline SGRIT & 157 & 2 \\
\hline RESIDE & 158 & 1 \\
\hline TIMEON & 153 & 6 \\
\hline TIMEOUT & 154 & 5 \\
\hline WTP 1,2,3 & 159 & 0 \\
\hline GENDER & 158 & 1 \\
\hline MAJORBC & 158 & 1 \\
\hline YRCOLLEGE & 157 & 2 \\
\hline HMTWN & 156 & 3 \\
\hline INCOME & 142 & 17 \\
\hline ACCURAT & 148 & 11 \\
\hline
\end{tabular}

Table 3. Frequency of responses and non-responses for individual survey questions. 


\subsubsection{Frequency of WTP Responses}

Overall, $35 \%$ of the 160 respondents mentioned in Table 3 chose $\$ 0$ as their WTP value for WTP $1.22 \%$ of respondents chose $\$ 0$ as their WTP value for WTP 2 , and $33 \%$ chose $\$ 0$ as their WTP for WTP 3. The second most frequent WTP response for all three WTP questions was $\$ 10$. The frequency of responses for WTP 1, WTP 2, and WTP 3 is found in Figure 7.

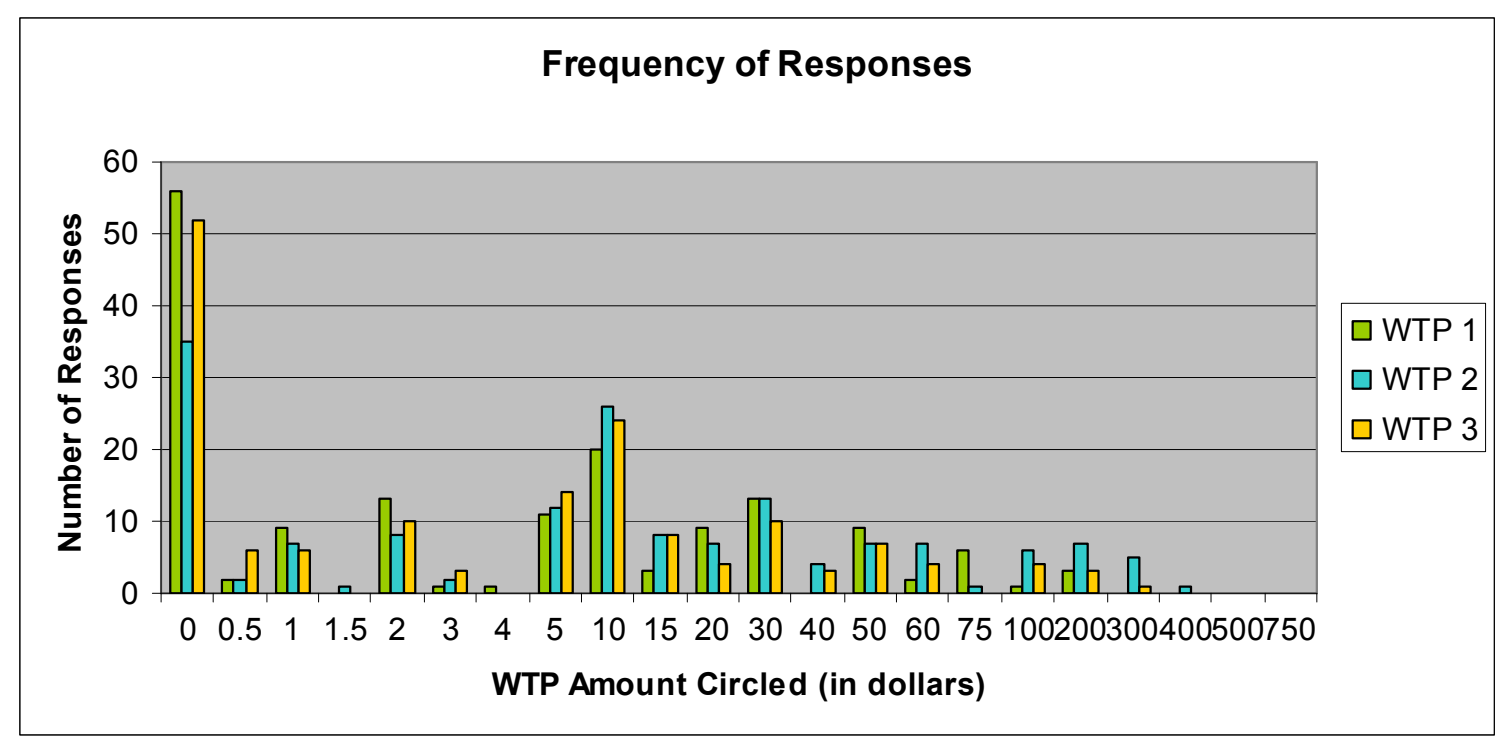

Figure 7. Histogram of midpoint WTP responses.

\subsubsection{Mean and Median WTP Values}

The means for all of the WTPs are higher than the most frequently chosen value of $\$ 0$.

On average, students were willing to pay $\$ 14.99$ for the improvement described in WTP $1, \$ 33.97$ for the greater improvement described in WTP 2 , and $\$ 17.23$ to prevent the worsening described in WTP 3, based on their circled WTP values. However, Hackl and Pruckner (1999) find that the WTP value that a respondent circles on a payment card is 
not his or her actual WTP value. Instead, the respondent's WTP is an unknown value in the interval between the number they circled on the payment card and the next highest value (Hackl and Pruckner, 1999). Depending on the wording of the WTP question, the respondent's interval could also be (for example) between the number they circled and the next lowest value, or within another interval (Figure 8). A data point that lies within an interval of two numbers is called interval censored.

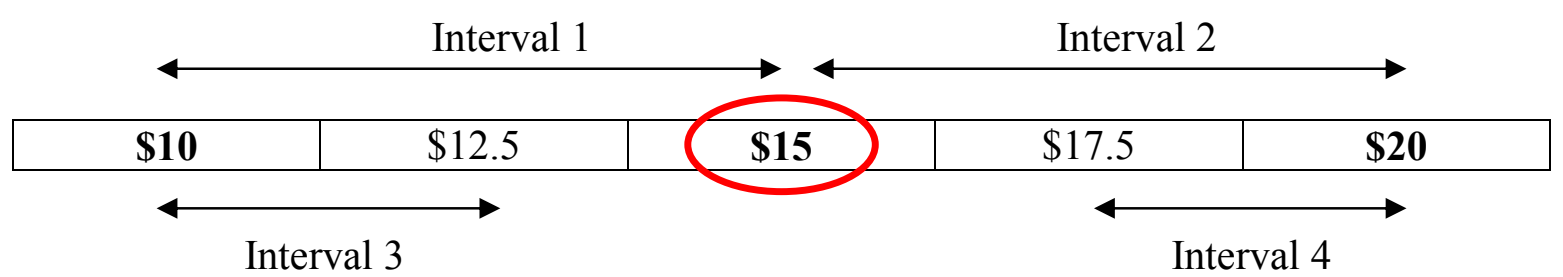

Figure 8. Visual representation of some payment card interval possibilities. Boldface values represent values seen on the payment card.

Based on the wording of the WTP questions in this survey (see Appendix A), it is reasonable to assume that Hackl and Pruckner's findings are appropriate. That is, if $C_{L}$ represents the actual number circled on the payment card by the survey respondent, the respondent's actual WTP lies somewhere between $C_{L}$ and $C_{H}$, where $C_{H}$ represents the next highest value above $C_{L}$ on the payment card. If the actual WTP values of students who circled a specific $C_{L}$ on the payment card are assumed to be evenly distributed within the interval $\left(C_{L}, C_{H}\right)$, then the expected WTP values of those students is the midpoint value

$$
y=\frac{1}{2}\left(C_{L}+C_{H}\right)
$$


where $y=$ actual WTP. (From this point forward, this value will be called the "interval midpoint value"). The interval midpoint value is used when calculating mean WTP values as well as when performing more sophisticated analysis techniques, which will be detailed further in a later section.

In addition to the interval censoring exhibited by the WTP survey data, the high proportion of $\$ 0$ responses (represented by the midpoint value of $\$ 0.25$ ) suggests that the WTP data is not normally distributed. Tests for skewness and kurtosis shown in Table 4 also suggest non-normality. In order to account for the non-normal distribution of the WTP data, the data can be transformed by taking the natural log of the interval midpoint WTP values. The actual WTP is then a modification of equation 1 and is described in equation 2 below.

$$
y=\ln \left(\frac{1}{2}\left(C_{L}+C_{H}\right)\right)
$$

The resulting descriptive statistics for the WTP questions suggest that the data becomes more normally distributed after the natural log is taken (Table 4). There are two important items to note when looking at the natural log means: 1) the data was transformed from dollar values into cents values before the natural log was taken to eliminate negative numbers, and 2) the resulting calculations are the means of the natural $\log$ of the WTP value, rather than mean of the WTP value itself. The zero WTP 
responses, which would be undefined when the natural log is taken, were accounted for by using the interval midpoint WTP values, as was previously described. 


\begin{tabular}{|c|c|c|c|c|c|c|}
\hline & $\begin{array}{c}\text { Mid WTP 1 } \\
\text { (dollars) }\end{array}$ & $\begin{array}{c}\text { Mid WTP 2 } \\
\text { (dollars) }\end{array}$ & $\begin{array}{c}\text { Mid WTP 3 } \\
\text { (dollars) }\end{array}$ & $\begin{array}{c}\text { In (Mid } \\
\text { WTP 1) } \\
\text { (cents) }\end{array}$ & $\begin{array}{c}\text { In (Mid } \\
\text { WTP 2) } \\
\text { (cents) }\end{array}$ & $\begin{array}{c}\text { In (Mid } \\
\text { WTP 3) } \\
\text { (cents) }\end{array}$ \\
\hline Mean & 17.23 & 38.62 & 19.73 & 5.73 & 6.58 & 5.81 \\
\hline $\begin{array}{c}\text { Standard } \\
\text { Error }\end{array}$ & 2.42 & 5.77 & 3.42 & 0.17 & 0.18 & 0.17 \\
\hline Median & 2.50 & 12.50 & 6.50 & 5.52 & 7.13 & 6.48 \\
\hline Mode & 0.25 & 0.25 & 0.25 & 3.22 & 3.22 & 3.22 \\
\hline $\begin{array}{c}\text { Standard } \\
\text { Deviation }\end{array}$ & 30.49 & 72.70 & 43.16 & 2.16 & 2.21 & 2.15 \\
\hline $\begin{array}{c}\text { Sample } \\
\text { Variance }\end{array}$ & 929.53 & 5285.95 & 1863.14 & 4.65 & 4.90 & 4.61 \\
\hline Kurtosis & 9.99 & 11.24 & 27.21 & -1.46 & -1.03 & -1.33 \\
\hline Skewness & 2.92 & 3.18 & 4.65 & 0.07 & -0.28 & 0.06 \\
\hline Range & 174.75 & 449.75 & 349.75 & 6.55 & 7.50 & 7.24 \\
\hline Minimum & 0.25 & 0.25 & 0.25 & 3.22 & 3.22 & 3.22 \\
\hline Maximum & 175.00 & 450.00 & 350.00 & 9.77 & 10.71 & 10.46 \\
\hline Sum & 2739.25 & 6140.25 & 3137.00 & 910.73 & 1045.99 & 923.44 \\
\hline Count & 159.00 & 159.00 & 159.00 & 159.00 & 159.00 & 159.00 \\
\hline $\begin{array}{c}\text { Confidence } \\
\text { Level } \\
\text { (95.0\%) }\end{array}$ & 4.78 & 11.39 & 6.76 & 0.34 & 0.35 & 0.34 \\
\hline Tab4. & & & & & \\
\hline
\end{tabular}

Table 4. Descriptive statistics for WTP 1, WTP 2, and WTP 3. 


\subsubsection{Variable Histograms and Correlation Tables}

The last initial analysis of the data that was performed after averages and other descriptive statistics were produced was to create histograms and correlation tables for each of the variables listed in Table 2. The complete set of histograms and correlation tables can be found in Appendix C. There are no strong correlations between WTP and any of the variables used in the survey; the highest correlation value is 0.23 . Although no correlations stand out, responses to the survey questions can still be used to help predict WTP by developing regression equations to represent the data.

\subsection{Regression Models}

\subsubsection{Ordinary Least Squares Regression Model}

A multiple regression equation is used as a tool to predict the value of a dependent variable based on the values that a set of independent variables take on; that is, to express the causal relationships between an independent variable and a set of dependent variables. However, it is important to note that although the regression equation appears to express the causal relationships between the variables, the regression equation cannot prove causality. The most the regression equation can do is to demonstrate the degree of co-occurrence of the variables and suggest causality (Gupta, 2001).

To form the regression equation for a set of variables, the variables have to be operationalized. Quantitative variables are by definition operationalized; qualitative variables are operationalized by using "intercept dummy" variables - for example, yes 
values are given a value of 1 and no values are given a value of 0 (Gupta, 2001). An ordinary least squares (OLS) regression equation is written as

$$
y=\alpha_{0}+\alpha_{1} s g+\alpha_{2} \text { timeout }+\alpha_{3} x_{3}+\alpha_{4} x_{4} \ldots \ldots+\alpha_{i} x_{i}+u
$$

where $y=\mathrm{WTP} ; s g=1$ if the respondent thinks sky glow is a problem, 0 if the respondent does not think sky glow is a problem, and -1 if the respondent is unsure whether or not sky glow is a problem; timeout $=$ the amount of time the respondent spends outside at night on campus; and $x_{3}, x_{4}, \ldots, x_{i}$ are the independent variables used in the regression analysis, and $u=$ the error term (Gupta, 2001). This regression model assumes that the average (“expected") value of $u$, given specific values of $s g$, timeout, etc., is zero. Therefore the average ("expected") value of $y$, given specific values of $s g$, timeout, etc., is:

$$
E\left(y \mid s g, \text { timeout }, x_{3}, x_{4}, \ldots, x_{i}\right)=\alpha_{0}+\alpha_{1} s g+\alpha_{2} \text { timeout }+\alpha_{3} x_{3}+\alpha_{4} x_{4} \ldots . .+\alpha_{i} x_{i}
$$

That is, once we have estimated the parameters $\alpha_{0}, \alpha_{1}, \alpha_{2}, \ldots, \alpha_{i}$, we can produce average WTP values for specific values of the independent variables.

The OLS model requires use of a specific WTP value for each survey respondent. We can use the midpoint value described by equation (2) to represent the WTP, just as the midpoint was used in the previous discussion of calculating means. 
The WTP for each respondent can be predicted using the OLS regression model. The OLS model estimates the values for each of the coefficients based on the respondent's specific values of $s g$, timeout, etc. More specifically, the OLS model finds values for the coefficients of each variable (the $\alpha$ s) such that on average across the entire sample, the average prediction error $u$ is zero.

\subsubsection{Interval Censoring Regression Model}

As previously stated, the respondent's actual WTP value lies somewhere in the interval $\left(C_{L}, C_{H}\right)$, and this interval changes depending on which value was circled on the payment card. In other words, the WTP results obtained in the survey are interval censored. The interval censored (IC) model takes into account that the respondent's WTP data lies in this interval, that is, the model allows for a more realistic interpretation of the data, compared to the OLS regression model. (Wooldridge, 2006).

In the case of the IC model, the relevant regression equation for the respondent's actual WTP is still equation (3). The IC model uses the WTP survey data $\left(C_{L}\right)$ to make predictions of estimates of the coefficients from equation (3), just as the OLS model does, and these estimates can be used to predict the respondent's actual WTP. Technically, the IC model finds estimates of the coefficients such that the number of respondents whose predicted WTP falls within the WTP interval associated with their circled WTP value is maximized. The average value of y (WTP) is still represented by equation (4), which 
assumes that the prediction error $u$ is zero. Therefore, the estimates of the coefficients from the IC model can be interpreted in the same way as they are in the OLS model (Wooldridge, 2006).

\subsubsection{Tobit Regression Model}

While the IC model takes into account data that is interval censored, the Tobit model accounts for data variables with (usually) non-negative values and data observations that tend to pile up at zero. The advantage of the Tobit model for this research is that the Tobit model not only accounts for the fact that that a high number of respondents chose $\$ 0$ as their WTP value, but also takes into account that the data is interval censored. However, the Tobit model also relies on the assumption that the error term, discussed previously, is normally distributed - if the error term is not normally distributed or homoscedastic, the maximum likelihood estimate is affected (Lexin, 2007).

For the Tobit model, a circled value of $\$ 0$ was interpreted to mean that the actual WTP of the respondent was $\$ 0$, while the rest of the respondents' actual WTP values lie in the interval $\left(C_{L}, C_{H}\right)$. The Tobit model prevents predicted (WTP) values from taking on negative values. Therefore, for the Tobit model, equation (3) (in addition to the assumption that the average $u$ is still zero) applies, but is relevant only in the case where $y$ takes on non-zero values.

The objective of the Tobit model is, as with the OLS and IC models, to produce a set of coefficient estimates that allow us to compute a predicted WTP value based on the 
respondent's characteristics. The coefficient estimates are chosen to maximize the likelihood that the resulting predicted WTP values equal the actual WTP values (which are frequently zero). More specifically, the Tobit model first estimates the log-likelihood function for each WTP observation $i$ by combining two equations: the density of each WTP response $y_{i}$, and the probability that $y_{i}=0$, given a particular $x_{i}$. The coefficient $\beta$ is then estimated by maximizing the log-likelihood values for each WTP response (Wooldridge, 2006). However, the interpretation of the resulting coefficient estimates and determination of the predicted WTP value is different for this model. The linear relationship that the coefficient estimates describe in the OLS and IC models is not necessarily the actual relationship between independent variables and the WTP value. In the case of the Tobit model, the relationship between the variables and WTP is nonlinear, shown by equation (5) (which corresponds to equation (4) above and is a derivation of the density and probability equations previously discussed):

$$
E\left(y \mid s g, s g d k, x_{3}, x_{4} \ldots . . x_{k}\right)=\Phi\left(\frac{X \beta}{\sigma}\right) X \beta+\sigma \phi\left(\frac{X \beta}{\sigma}\right)
$$

where $X \beta=$ the expression given on the right-hand-side of equation (4) (with $X \beta$ representing the set of values $\left.X_{i} \beta_{i}\right), \Phi=$ the cumulative normal distribution function, (which is a function of $\left(\frac{X \beta}{\sigma}\right), \phi=$ the standard normal probability density function (which is a function of $\left(\frac{X \beta}{\sigma}\right)$ ), and $\sigma=$ the standard deviation of $\mathrm{u}$, which has to be estimated together with the set of $\alpha$ parameters (Wooldridge, 2006). 


\section{Results}

\subsection{Regression Analysis Summary}

The OLS model, the IC model, and the Tobit model are appropriate methods for the data set, each addressing a specific set of characteristics of the data. One method may represent the data better than another, or all three methods may yield similar WTP estimates. In order to find the regression equations that most accurately represent the WTP data obtained in the survey, a five step process was implemented: choose the most interesting independent variables, run the IC models and the Tobit model, remove any insignificant variables from the equations, and run the OLS model using the final set of chosen variables.

Although many questions were asked in the WTP survey, not all of the responses are interesting to look at as far as how they relate to an individual's WTP. Other questions were included to help the respondent think about important information that might help them answer the next question. Based on all of the variables available (listed previously in Table 2), the following variables were chosen for the initial regression analysis: EXPERIENCESG, SGRIT, TIMEOUT, GENDER, MAJORBC, YRCOLLEGE, INCOME, RESIDE, and HMTWN.

Not every variable used in the initial regression analysis was equally statistically significant. Additionally, including and excluding different variables produced differently statistically significant overall results. Therefore, the "best" combination of variables had to be determined, that is, the combination of variables that produced the 
most interesting and most statistically significant results. Numerous iterations of the Tobit model were coded into and run in SAS, each model using a different subset of the initial set of nine variables. The statistical outputs for each of these runs were then analyzed and compared to one another to determine which variables should be eliminated and which variables should be included. Each time a variable was eliminated, new iterations of the Tobit model were coded and run with the new sets of variables, and new variables were eliminated based on the statistical significance of the output. This process led to the selection of a four variable model, which included the variables SGRIT, TIMEOUT, YRCOLLEGE, and INCOME.

Once the final set of variables was determined, the next step was to run the IC regression model with the same four-variable set that was chosen for the Tobit model. Again, multiple iterations of the IC model were run, each representing a different interval possibility, and the IC model represented by the interval $\left(C_{L}, C_{H}\right)$ was chosen to represent this WTP data set, along with the Tobit model. For comparison, the OLS model was run using the final set of variables chosen for the IC and Tobit models.

\subsection{Regression Analysis Results}

The final analysis and discussion will focus on the Tobit model, which is assumed to be most appropriate for this data set based on the previous discussion. Tables 5, 6, and 7, describe the results from the Tobit model, and data tables for the IC and OLS models can be found in Appendix D. 
Table 5 describes the estimates for each variable, based on students' WTP. Recalling the previously discussed equations, the estimates represent the alpha coefficients for each variable in the regression equation. For the OLS and IC models, the estimates are plugged into regression equation (4), and predicted WTP is calculated. For the Tobit model, these estimates are plugged into the $X \beta$ portion of equation (5), and equation (5) is used to calculate WTP. 


\begin{tabular}{|c|c|c|c|c|}
\hline Tobit Model & & WTP 1 & WTP 2 & WTP 3 \\
\hline Description & Variable & $\begin{array}{c}\text { Estimate } \\
\text { (Standard Error) }\end{array}$ & $\begin{array}{c}\text { Estimate } \\
\text { (Standard Error) }\end{array}$ & $\begin{array}{c}\text { Estimate } \\
\text { (Standard Error) }\end{array}$ \\
\hline Intercept & INTERCEPT & $\begin{array}{l}6.2156^{*} \\
(0.4604)\end{array}$ & $\begin{array}{l}7.2706^{*} \\
(0.4713)\end{array}$ & $\begin{array}{c}6.8325^{*} \\
(0.4708)\end{array}$ \\
\hline $\begin{array}{c}\text { "Don't know if } \\
\text { sky glow is a } \\
\text { problem at } \\
\text { RIT" }\end{array}$ & SGRIT (-1) & $\begin{array}{c}-0.8758^{*} \\
(0.3270)\end{array}$ & $\begin{array}{c}-0.8163 * \\
(0.3465)\end{array}$ & $\begin{array}{c}-0.6888^{*} \\
(0.3261)\end{array}$ \\
\hline $\begin{array}{c}\text { "Sky glow is } \\
\text { not a problem at } \\
\text { RIT" }\end{array}$ & SGRIT (0) & $\begin{array}{l}-0.5571 \\
(0.4008)\end{array}$ & $\begin{array}{c}-0.9253^{*} \\
(0.4110)\end{array}$ & $\begin{array}{r}-0.4851 \\
(0.4178)\end{array}$ \\
\hline "First year" & $\begin{array}{l}\text { YRCOLLEGE } \\
\text { (1) }\end{array}$ & $\begin{array}{l}1.1853 * \\
(0.4133)\end{array}$ & $\begin{array}{l}0.7271 * \\
(0.4284)\end{array}$ & $\begin{array}{l}0.7559 \\
(0.4464)\end{array}$ \\
\hline "Second year" & $\begin{array}{l}\text { YRCOLLEGE } \\
\text { (2) }\end{array}$ & $\begin{array}{l}1.2679 * \\
(0.4496)\end{array}$ & $\begin{array}{l}1.0454 * \\
(0.4736)\end{array}$ & $\begin{array}{l}0.6810 \\
(0.4713)\end{array}$ \\
\hline "Third year" & $\begin{array}{l}\text { YRCOLLEGE } \\
\text { (3) }\end{array}$ & $\begin{array}{l}0.9879 \\
(0.6714)\end{array}$ & $\begin{array}{l}0.5320 \\
(0.6935)\end{array}$ & $\begin{array}{l}0.5468 \\
(0.7474)\end{array}$ \\
\hline "Fourth year" & $\begin{array}{l}\text { YRCOLLEGE } \\
\text { (4) }\end{array}$ & $\begin{array}{l}0.3245 \\
(0.4745)\end{array}$ & $\begin{array}{l}-0.0549 \\
(0.4618)\end{array}$ & $\begin{array}{l}0.1989 \\
(0.4729)\end{array}$ \\
\hline $\begin{array}{l}\text { "Time spent } \\
\text { outside on } \\
\text { campus at } \\
\text { night" }\end{array}$ & TIMEOUT & $\begin{array}{l}0.0030 \\
(0.0051)\end{array}$ & $\begin{array}{l}0.0003 \\
(0.0057)\end{array}$ & $\begin{array}{l}-0.0020 \\
(0.0051)\end{array}$ \\
\hline $\begin{array}{l}\text { "Personal } \\
\text { income" }\end{array}$ & INCOME & $\begin{array}{c}0.0003 * \\
(0.0001)\end{array}$ & $\begin{array}{l}0.0001 \\
(0.0001)\end{array}$ & $\begin{array}{l}0.0000 \\
(0.0001)\end{array}$ \\
\hline
\end{tabular}

Table 5. Tobit model estimate results. ${ }^{3}$

\footnotetext{
${ }^{3}$ Starred values are significant at the $5 \%$ level. SGRIT(-1) and SGRIT(0) are dummy variables, where SGRIT (1) ("sky glow is a problem at RIT") is the comparison group. YRCOLLEGE(1), YRCOLLEGE(2), YRCOLLEGE(3), YRCOLLEGE(4) are dummy variables, where YRCOLLEGE (5) ("Fifth year") is the comparison group. TIMEOUT is measured in hours per week and INCOME is measured in dollars. Sample size is 86 observations for WTP 1, 105 observations for WTP 2, and 86 observations for WTP 3.
} 
The results of the WTP calculation using the Tobit estimates from Table 5, that is, plugging the estimates into the $X \beta$ portion of equation (5), are found in Table 6 . These values represent the predicted WTP of an individual, based on their characteristics and can be used to compare individuals' WTP across characteristics. These values are given in cents, not in dollars. For example, a student who thinks that sky glow is not a problem at RIT, who is in their fifth year, spends 15.01 hours outside on campus at night per week (average), and who has an income of $\$ 1375.07$ (average) is predicted to have a WTP of 308.71 cents (\$3.09) for a slight improvement in clarity of the night sky (WTP 1), 440.39 cents (\$4.40) for a greater improvement in the clarity of the night sky (WTP 2), and 418.39 cents (\$4.18) to prevent worsening of the clarity of the night sky (WTP 3). A person who DOES think that sky glow is a problem on campus but has all the same characteristics, however, is willing to pay 245.50 cents $(\$ 2.46)$ more for a slight improvement, 717.46 cents $(\$ 7.17)$ more for a greater improvement, and 275.51 cents (\$2.76) more to prevent worsening of the night sky. 


\begin{tabular}{|c|c|c|c|c|}
\hline Tobit Model & & WTP 1 & WTP 2 & WTP 3 \\
\hline Description & Variable & \multicolumn{3}{|c|}{ Predicted Value (cents) } \\
\hline $\begin{array}{c}\text { "Don't know if sky } \\
\text { glow is a problem } \\
\text { at RIT" }\end{array}$ & SGRIT (-1) & 221.23 & 493.58 & 338.19 \\
\hline $\begin{array}{l}\text { "Sky glow is not a } \\
\text { problem at RIT" }\end{array}$ & SGRIT (0) & 308.71 & 440.39 & 418.39 \\
\hline $\begin{array}{l}\text { "Sky glow is a } \\
\text { problem at RIT" }\end{array}$ & SGRIT (1) & 552.21 & 1157.85 & 693.90 \\
\hline "First year" & $\begin{array}{l}\text { YRCOLLEGE } \\
\text { (1) }\end{array}$ & 1892.47 & 2468.24 & 1522.44 \\
\hline "Second year" & $\begin{array}{l}\text { YRCOLLEGE } \\
\text { (2) }\end{array}$ & 2061.42 & 3435.44 & 1408.58 \\
\hline "Third year" & $\begin{array}{l}\text { YRCOLLEGE } \\
\text { (3) }\end{array}$ & 1542.38 & 2015.03 & 1225.42 \\
\hline "Fourth year" & $\begin{array}{l}\text { YRCOLLEGE } \\
\text { (4) }\end{array}$ & 774.22 & 1093.37 & 853.54 \\
\hline "Fifth year" & $\begin{array}{l}\text { YRCOLLEGE } \\
\text { (5) }\end{array}$ & 552.21 & 1157.85 & 693.90 \\
\hline $\begin{array}{l}\text { "Average time } \\
\text { spent outside on } \\
\text { campus at night" }\end{array}$ & $\begin{array}{l}\text { TIMEOUT } \\
\text { (AVERAGE) }\end{array}$ & 552.21 & 1157.85 & 693.90 \\
\hline $\begin{array}{l}\text { "No time spent } \\
\text { outside on campus } \\
\text { at night" }\end{array}$ & TIMEOUT (0) & 526.57 & 1152.81 & 715.89 \\
\hline $\begin{array}{l}\text { "Average personal } \\
\text { income" }\end{array}$ & $\begin{array}{c}\text { INCOME } \\
\text { (AVERAGE) }\end{array}$ & 552.21 & 1157.85 & 693.90 \\
\hline $\begin{array}{l}\text { "No personal } \\
\text { income" }\end{array}$ & INCOME (0) & 384.01 & 1024.23 & 671.20 \\
\hline
\end{tabular}

Table 6. Tobit Model Predicted WTP Values. ${ }^{4}$

\footnotetext{
${ }^{4}$ Unless otherwise stated, predicted values are for those who think sky glow is a problem, are in their 5th year, spend the average amount of time outside on campus at night (15.01 hrs), and who have average personal income (\$1375.07). In most cases, the predicted WTP1 and WTP3 are not statistically different from one another. However, in most cases, the predicted WTP2 is statistically bigger than the predicted WTP1 and the predicted WTP2 is also statistically bigger than the predicted WTP3.
} 
Finally, Table 7 shows the predicted percentage differences between similar characteristics of WTP. These are related to the differences that are obtained by comparing the predicted values in Table 6. Just as with Table 6, Table 7 compares the alternative values of a variable to the baseline value of the same variable, that is, all other values of the variable are compared to those who think sky glow is a problem, who are in their $5^{\text {th }}$ year, who spend an average amount of time outside on campus at night, and who have an average income. Using the same example as was used in describing Table 6, the predicted percentage difference between a person who does not think sky glow is a problem at RIT and a person who does think sky glow is a problem at RIT (but has all other characteristics similar), is $-44 \%$ for WTP 1 ; those who think sky glow is not a problem at RIT are willing to pay $44 \%$ less for the improvement described in WTP 1 than those who do think that sky glow is a problem at RIT.

The greatest predicted percentage difference is found between those in their second year in college and those in their fifth year in college for WTP 1 and WTP 2 (273\% and 197\%, respectively), while the greatest difference for WTP 3 was found between the first year in college and the fifth year in college (119\%). The results of the Tobit model demonstrate that there is not a statistically significant difference between the WTP values for those in the first year in college and those in the second year in college. Therefore, these two years can statistically be treated as one group.

The smallest predicted percentage difference overall was found to be between a person who spends an average amount of time outside on campus at night and a person who 
spends 0 time outside on campus at night with regard to the second WTP question. Additionally, the timeout variable exhibited the lowest predicted percentage difference for all three WTP questions.

Finally, although Table 7 does describe the predicted percentage differences for each group, not every comparison is statistically significant. There are predicted percentage difference values for years in college 3 and 4 , but these groups were not found to be statistically significant in the Tobit regression model. Consequently, the predicted percentage values for those groups are not accurate representations of what the percentage differences between the WTP of each of those groups would be. Table 7 also does not describe percentage differences for "non-average" timeout or income values.

Similarly to the Tobit model, the IC and OLS models also produce predicted percentage differences, predicted WTP values, and estimates of the coefficients for the regression equation. As previously stated, the Tobit model was chosen because of its characteristics (the Tobit model accounts for both the interval censoring of the data as well as the "piling up" of zero values) but the Tobit model may or may not be the appropriate model for this type of survey and data set. Comparing the results for the IC models and OLS models to the Tobit model shows that in general overall the results are similar, but also that there are some differences between them. For example, the signs of both the estimates and the predicted percentage differences are not necessarily the same from one model to the next. Additionally, the predicted WTP values are also different between the Tobit models, with neither the IC nor the OLS models producing consistently higher or lower WTP values as compared to the Tobit model. The differences and similarities between the three sets of 
regression models suggest that further research would be needed in order to determine the appropriateness of one model over another. More specifically, further calculation of an adjustment factor would be needed to compare the Tobit and OLS models in more detail (Wooldridge, 2006). (See Appendix D for the IC and OLS model results.) 


\begin{tabular}{|c|c|c|c|c|c|}
\hline Tobit Model & & & WTP 1 & WTP 2 & WTP 3 \\
\hline Value of Variable & $\begin{array}{c}\text { Compared To } \\
\text { (Baseline Value) }\end{array}$ & Difference & \multicolumn{3}{|c|}{$\begin{array}{l}\text { Predicted Percentage Difference in } \\
\text { WTP }\end{array}$} \\
\hline $\begin{array}{l}\text { "Don't know if sky glow is } \\
\text { a problem at RIT" }\end{array}$ & \multirow{2}{*}{$\begin{array}{l}\text { "Sky glow is a } \\
\text { problem at RIT" }\end{array}$} & SGRIT (-1) - SGRIT (1) & -0.60 & -0.57 & -0.51 \\
\hline $\begin{array}{c}\text { "Sky glow is not a problem } \\
\text { at RIT" }\end{array}$ & & SGRIT (0) - SGRIT (1) & -0.44 & -0.62 & -0.40 \\
\hline "First year" & \multirow{4}{*}{ "Fifth year" } & YRCOLLEGE (1) - YRCOLLEGE (5) & 2.43 & 1.13 & 1.19 \\
\hline "Second year" & & YRCOLLEGE (2) - YRCOLLEGE (5) & 2.73 & 1.97 & 1.03 \\
\hline "Third year" & & YRCOLLEGE (3) - YRCOLLEGE (5) & 1.79 & 0.74 & 0.77 \\
\hline "Fourth year" & & YRCOLLEGE (4) - YRCOLLEGE (5) & 0.40 & -0.06 & 0.23 \\
\hline $\begin{array}{l}\text { "No time spent outside on } \\
\text { campus at night" }\end{array}$ & $\begin{array}{l}\text { "Average time } \\
\text { spent outside on } \\
\text { campus at night" }\end{array}$ & TIMEOUT (0) - TIMEOUT (average) & -0.05 & 0.00 & 0.03 \\
\hline "No personal income" & $\begin{array}{c}\text { "Average } \\
\text { Personal Income" }\end{array}$ & INCOME (0) - INCOME (average) & -0.44 & -0.13 & -0.03 \\
\hline
\end{tabular}

Table 7. Tobit Model Predicted Percentage Differences.

\footnotetext{
${ }^{5}$ The results of the Tobit regression analysis show that there is no statistically significant difference between those in year 1 of college and those in year 2 of college. There is also no statistically significant difference between those who do not know whether there is a problem with light pollution on RIT's campus and those who do not think there is a problem with light pollution on RIT's campus. Therefore these two sets of variables may be treated as one distinct group. The values for year 3 of college and year 4 of college are not statistically significant.
} 


\section{Discussion and Policy Implications}

The results of this CV survey and regression analysis are at most representative of the RIT student population, and describe the students' willingness to pay for a clear night sky on RIT's campus. However the purpose of this thesis is not to use the results of this thesis to make policy recommendations for RIT, but rather to utilize the RIT population as a case study for testing the validity of the CV method in the case of light pollution. From the results of this WTP survey, policy recommendations regarding both the use of the $\mathrm{CV}$ method in the case of light pollution reduction programs, as well as what information about the survey population can be obtained using the CV method will be made.

As was mentioned in the beginning of the previous section, the most frequent WTP response of students was $\$ 0$. However, students are still, on average, willing to pay to improve (and prevent the worsening) of the clarity of RIT's night sky. A total benefits curve plotting the mean WTP values, shows that WTP based on incremental improvements (or prevention of worsening) can be represented by a second-degree polynomial function. Although the second-degree polynomial curve appears to be a strong fit, this is in part due to the fact that there are only three points in the data set. In Figure 9, mean WTP is plotted as a function of percent decrease in light pollution; each change in the amount of light pollution was a $10 \%$ change from the previous point. 


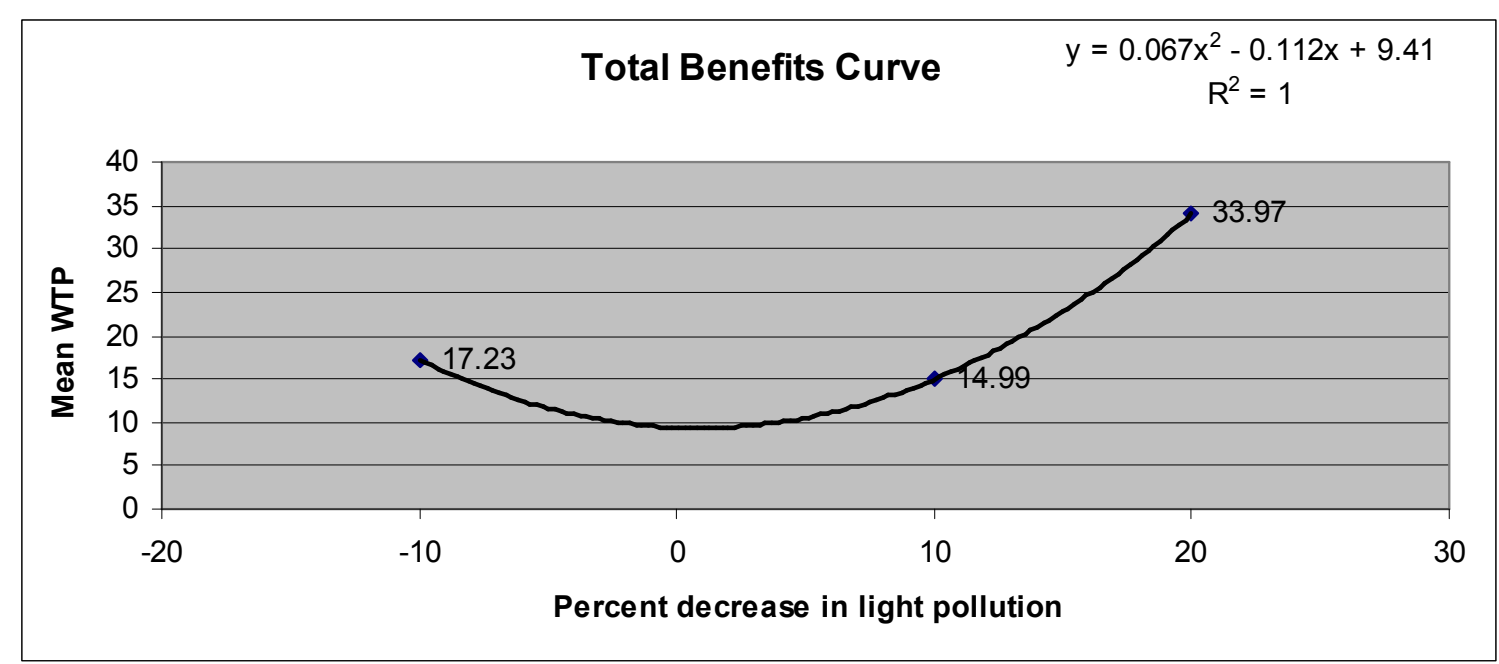

Figure 9. Total Benefits Curve.

Whether or not the second-degree polynomial curve is a strong fit for this data (which could be determined by collecting additional data), the plot of the three WTP data points demonstrates that the student population is overall willing to pay essentially the same amount for a $10 \%$ increase in the clarity of the night sky (WTP $1, \$ 14.99$ ) as they are to prevent a night sky from becoming increasingly light polluted by $10 \%$ (WTP 3, \$17.23).

In addition to the similarities between WTP 1 and WTP 3, the WTP for a greater improvement in the clarity of the night sky (WTP 2, \$33.97) is more than two times that of WTP 1 (\$14.99), suggesting that the marginal benefits curve regarding light pollution exhibits an uncharacteristic upward slope before turning downward. Typically, economists anticipate that marginal benefits curves for environmental goods will slope downward, just as the marginal benefits curves for other goods do ("Marginal Benefits", 2007). The upward slope at the beginning of the marginal benefits curve in the case of light pollution suggests that people may value light pollution differently than they do other goods, and even other environmental goods. As with the total benefits curve, more 
data points would help to strengthen or refute this conjecture, and potentially identify more clearly the "tipping point" at which the marginal benefits curve begins to slope downward if the point does exist.

The analyses from the previous paragraphs suggest some important and related policy implications. First, due to the fact that most respondents aren't willing to pay anything to improve the clarity of the night sky, but others are willing to pay various amounts, a simple suggestion might be that governments should consider enacting voluntary policies in which those who are interested in paying for light pollution reduction programs can do so, while others who are not interested in reducing light pollution do not have to contribute. However, enacting such policies can result in the problem of free ridership, that is, there is a disincentive to support implementation of a program in which not everyone contributes but everyone receives the benefits, particularly as the program population gets larger (Gupta, 2001). Without a requirement of contribution to a light pollution program, obtaining enough participation to successfully reduce the amount of sky glow in an area is unlikely.

Secondly, whether making a small improvement in the clarity of the night sky or preventing light pollution from getting worse, governments should expect both programs to have a similar amount of favorability (WTP). That is, no matter which particular issue a community or state is facing, light pollution reduction or prevention is a program that all communities can consider. Secondly, even though light pollution reduction and prevention programs of similar magnitude had similar WTP results, the total benefits 
curve suggests that governments who are able to make an even greater improvement in the clarity of the night sky, up to a certain point, may be able to gain more support for their program. If the benefits curve does indeed slope upward until it reaches a certain level, then a city or state that is looking to introduce a light pollution reduction program may want to consider at what maximum level they can implement the program, and determine where that level of light pollution reduction lies on the total benefits curve.

In addition to the WTP values themselves, policymakers may also look at the demographics of their population when making policy decisions. The results of this study are inconclusive regarding what variables most strongly affect a student's WTP. Though the correlation values overall were not high, the variables that were most strongly correlated with WTP were major, gender, hometown, and whether or not the student had heard of light pollution, with both major and whether or not the student had heard of light pollution having the strongest correlation values for all three WTP questions. Based on the regression results, however, the most significant variables affecting WTP were found to be whether or not the student thought that sky glow was a problem on RIT's campus, income, time spent outside on campus at night, and year in college. A majority of the variables in this study are (and were treated as) class variables in the regression analysis and the differing treatments of the data may be the cause of the varying results.

The results of the regression model show that there is no statistically significant difference between those who feel that there is not a problem with light pollution on RIT's campus and those who don't know if there is a problem. Both groups are willing to 
pay less than those who do think light pollution is a problem, which makes intuitive sense. For example, a computer user may not pay to have extra security features installed on their computer if they do not believe that they will have a problem with others compromising their personal information. Similarly, an investor is not going to buy stock of a company that they do not know anything about. Thus those who are most informed about light pollution conditions and feel that light pollution is a problem are willing to pay the most to alleviate or prevent it.

The regression model also shows that there is no statistically significant difference between respondents who are in their first or second years of college. Additionally, the values for years 3 and 4 are not statistically significant. Therefore two groups are represented by the data - those students in years 1 and 2, and the rest of the respondents. Those who are in their first or second year are willing to pay more than those in their fifth year, suggesting that students become less interested in supporting light pollution as they near graduation. The "year in college" variable also had the largest impact across the WTP questions; those students in their first and second years had the greatest percentage difference in WTP compared to the baseline value (year 5) for all the willingness to pay questions (with those in year 1 willing to pay $243 \%$ more and those in year 2 willing to pay $273 \%$ more than those in their $5^{\text {th }}$ year for WTP 1 , for example). These results suggest that a willingness to pay more to reduce light pollution may be affected by level of education obtained, but the increase in WTP is most discernable over larger education differences. One possibility is that those students who are further in their education may have had the opportunity to earn more money, and may have more income to spend. 
The "year in college" variable may seem unique to the college setting, but a similar variable may be utilized by policymakers performing this research in a community setting. Year in college represents, in part, the length of time that you have attended Rochester Institute of Technology. Similarly, a variable such as "years as resident" might represent the length of time that an individual has lived in a community (or state, or country). The results based on the "years as resident" would be expected to be opposite that of the "year in college" variable: while those in year 5 and the years approaching the end of their time at RIT may be willing to pay less because they are preparing to leave the RIT community, those in year 5 and the years approaching an extended period of living in a city or state may be willing to pay more because they are becoming more involved with and attached to their community. Additionally, a variable such as "level of education obtained" could pair with the "years as resident" variable and help determine if WTP is related to length of time spent in the community, level of education, or a combination of the two variables.

While opinions on whether or not sky glow is a problem on RIT's campus, as well as level of college education had a large impact on WTP, income had an extremely small effect. One reason for this may be that students' WTP decisions are not based on personal income. If people feel strongly one way or another about an issue, they may be willing to put a large amount (or no amount) of money towards that issue no matter how much their personal income is. For example, some people are willing to put a lot of money toward helping soldiers in Iraq, while other people are not willing to put any 
money toward that cause. In many cases, the decision to donate to the soldiers is not a decision based on income, but on political, religious, or moral preferences. If income is not a factor in WTP decisions, then communities should not determine that a light pollution policy is inappropriate for them based on the socioeconomic status of their citizens. Instead, cities and states can anticipate that the more light pollution information provided to the community, the greater the likelihood that the program will be supported. Information disseminated through many media outlets, such as television, newspaper, internet, and telephone, will ensure that persons of all socioeconomic status levels in the community have the greatest likelihood of obtaining and responding to the information.

Similar to income, timeout also had a small effect on WTP; timeout values had the smallest predicted percentage differences between the average value and the baseline value for all three WTP questions (the lowest value was $0 \%$, for WTP 1). Timeout may not have a large effect on WTP because if people are not actively stargazing or looking up, they may not notice or consider the quality of the night sky. Additionally, community members may feel that light pollution doesn't affect them in any particular way unless they are astronomers or enjoy looking at or observing the night sky.

Coupling the fact that timeout has a minimal effect on WTP with the fact that hometown and reside are not strongly significant variables (and were not included in the final regression models) suggests interesting policy implications. The size of a respondents' hometown may not affect WTP because they do not draw a connection between the experiences with light pollution they had or didn't have in their hometown and the 
experiences with light pollution they are having where they currently live. To determine this, policymakers could ask an additional question, such as "Do you currently live in the town you specified as your hometown?" and analyze how the WTP results are affected by yes and no responses to that question. Similarly, the size of respondents' hometowns may not have affected WTP because respondents may not be looking up at the night sky or respondents may not be making a connection between the light pollution conditions in their hometown and the light pollution conditions in their current community.

There are several additional recommendations to be made for policymakers based on the results discussed above. Policies and programs should consider that although respondents are willing to pay essentially the same amount to improve the light pollution situation in a community as they are to prevent light pollution from getting worse, mitigating a light pollution problem by replacing all current light-emitting fixtures, buildings, etc. with new technologies that meet shielding and other standards may be more costly than preventing the problem before light pollution becomes an issue. Rather than replacing current technologies, for example, communities and states could enact new building codes that require all newly installed fixtures, buildings, and other light-emitting construction to meet certain shielding standards that would prevent the amount of light pollution from worsening. Because such a project to prevent worsening of light pollution may seem less effective than a dramatic change in the clarity of the night sky caused by creating a light pollution improvement, focusing on providing information about potential problems and issues that worsening light pollution would cause may help to gain the support of more residents. 
Government policies should also consider the amount of information provided about a light pollution program for another reason - greater support for a light pollution program occurs when respondents are informed and able to form an opinion about the light pollution conditions in their area. Although this research focused on student "citizens" and tuition dollars, communities and states similarly utilize citizen tax dollars to implement many programs and policy initiatives. Depending on how a community or state is developing a program, citizens many times have an opportunity to vote in a referendum regarding a program that they are being asked to help fund through use of or increase of their tax dollars. Any increase in taxes that would occur due to adoption of a light pollution program may become an issue both with keeping residents in the community or state, and attracting new residents to the area. If citizens are in favor of the program, then resident inflow and outflow concerns may be alleviated, and those who understand the light pollution issue may be drawn to the city or state because of the program's efforts. Consequently, documentation and information about any potential light pollution program a government is considering should clearly inform citizens about the problem, the impacts, and the solution that the program being considered provides.

Informing citizens about potential light pollution programs and allowing them to respond to the idea of the programs using a WTP survey also supports the idea of participatory democracy. Weber et al. state that allowing the public to participate in environmental policy decision-making is important because "the competence of the final decision is higher when local knowledge is included and when expert knowledge is publicly 
examined" (Webler et al., 1995). Although Webler et al. specifically address Delphi panels and other methods of "cooperative discourse", allowing citizens to participate in contingent valuation surveys is another method of learning more about local opinions and values. Knowing more about citizens' preferences may help the government to create policies that will better reflect the values of their constituents (Irvin and Stansbury, 2004), and giving a contingent valuation survey to residents of the city or state is one way of directly obtaining the opinion of that group of stakeholders.

Finally, although most of the policy discussion in this chapter has centered on policy makers and residents of cities and states, light pollution legislation could also be introduced at a national level. The results of this contingent valuation study do not reflect the opinions of a population as large as the population that would be affected by federal light pollution legislation, but similar policy recommendations to those described above could be applied to an entire nation. For example, legislators might be interested in determining if a particular area or region of the United States, such as the southwest, is more supportive of light pollution legislation than another, such as the northeast. Knowing what areas of the United States are supportive of a national light pollution program and which are not, as well as how much each area is willing to pay would provide legislators with important information: which Congresspersons or Representatives are likely to support the bill based on the region they represent, which areas of the nation should be targeted with more information regarding light pollution and its consequences (e.g., television commercials, travelling presentations, etc.), and more 
generally, whether or not light pollution legislation has the potential to gain enough support to be enacted.

\section{Future Work}

Surveys such as the one given for this study are one way to involve students and those in other areas of the United States in the decision making process regarding light pollution programs. The survey scenario can be rewritten to discuss various programs, payment vehicles, and to gather many opinions about the program being offered. More generally, surveys such as the one implemented in this research can be useful tools to determine the economic value of environmental attributes based on government implemented programs if they are created, administered and assessed properly. Based on the findings of this research there are several important issues that should be addressed when using the contingent valuation method, more specifically contingent valuation surveys, to place an economic value on light pollution.

First, surveys should be extensively pre-tested and analyzed before being administered to the "survey population". As many researchers working with the CV method have stated, pre-testing and analyzing survey pre-tests allows the researcher to recognize any errors in the survey, as well as determine if the right questions are being asked. Survey pre-testing in the case of this research did reveal some errors in the wording of survey questions, but pre-testing did not reveal all of the errors in the final survey that was given out. Time and resources did not allow for more than one pre-test of the survey, but more extensive 
pre-testing and analysis might have uncovered these errors before they reached the final population, allowing for a more accurate survey.

The initial pre-test of the survey did not show any confusion regarding the order of the questions in the survey. However, grouping questions together and putting questions in a different order may have affected how students represented their WTP. For example, having respondents answer some demographic questions before stating their WTP, rather than asking all demographic questions at the end of the survey might cause respondents to more accurately consider their ability to pay before making a WTP choice. As previously stated, time and resources only allowed pre-testing one survey, but pre-testing different versions of the survey before giving the survey to the final groups might demonstrate that a different order of survey questions is more appropriate.

The survey population itself can also have an effect on the results of a study as well. Due to time and resources, the initial survey population of 163 students was smaller than a representative sample of the RIT student population. Comments can be made about the RIT population that was surveyed and the results found and techniques used can be discussed in the context of communities and states, however, not all of the results were obtained within the $95 \%$ confidence interval. A larger sample size would aid in reaching the greater confidence level and allow more accurate generalizations about the population to be made. 
The program described in the survey relates to the survey population by utilizing personal, out of pocket expenses as the vehicle for payment. However, the WTP responses of students were not correlated with personal income. The order of the income and WTP questions may have played a role in this result; because students were not asked to recall their personal income until after making their WTP decision, students may not have focused as strongly on their personal income when making their WTP decision. Additionally, other payment vehicles, such as tuition expenses or on-campus living expenses, might be more familiar to students who do not have their own personal income. More pre-testing of surveys with various scenarios and payment vehicles would determine which scenario is most appropriate for the survey population whether it is a campus, community, or state, and would also demonstrate whether or not the scenario is worded clearly and explained adequately, a key characteristic of CV surveys.

In addition to the characteristics of the $\mathrm{CV}$ scenario itself, when pictures or images are used in a CV scenario to represent the good in question or changes in that good, the pictures should be as representative of the specific situation as possible. The images created for this survey were made using accurate constellation depictions, with light pollution created under the guidance of an astronomy professor. Nonetheless, more accurate images of actual light pollution scenarios, especially of the actual sky above the location of the respondents (in this case RIT's campus), would elicit a more accurate WTP from the survey population. Future work should be done to more accurately measure the light pollution in the survey population area and to more accurately represent changes in the amount of light pollution at the location in question as well. 
Future work regarding analysis of the survey data collected from this survey would also be appropriate to more extensively capture and study the WTP of RIT students. As previously stated, a larger sample size would create WTP responses that are more representative of the RIT student population. Additionally, analysis techniques performed on the current data set or a larger data set would provide more information about the RIT population. Due to time constraints, a very simple but sophisticated analysis of the variables has been carried out in this research. Looking not just at how single variables affect WTP, but looking deeper into interaction effects between some of the variables might reveal that certain variables carry more statistical significance if they are considered together. For example, policymakers studying the WTP of a community could combine the responses to questions regarding hometown and current residence with the responses to the question "Have you ever experienced light pollution?" to determine if past experiences with light pollution in the respondents' hometown had an effect on WTP whether or not they currently live in their hometown. As the light pollution survey improves and the analysis of variables and their interactions is continued, the WTP of the population for a clear night sky will be more accurately revealed.

Finally, comparing the benefits study performed in this research with an analysis of the costs of implementing the light pollution reduction/prevention program would provide more information to policymakers about the potential of implementing the program. To accurately address the costs and benefits of the program, both measurements need to be as precise as possible. The survey used for this study has a disconnect between the levels 
of light pollution depicted in the picture and the amounts that students were asked to pay. Accurately depicting the possible light pollution changes in the area, as was previously suggested, will allow policy makers to not only more accurately estimate the benefits to the respondents, but also will allow policy makers to accurately estimate the cost of the resources needed to implement each change. Depending on how much those who would be financing the program are willing to pay for implementation, the costs may make the program feasible or impractical to carry out, and such information can provide policy makers with the information and tools that they need to develop a light pollution program that is easily approved and funded.

\section{Conclusion}

There is much more work that can be done relating the problem of light pollution in general, and more specifically the method of contingent valuation. This research adds to the knowledge base in both areas by using contingent valuation to place an economic value on light pollution for the RIT student community. Most students express a \$0 WTP for light pollution programs that would decrease the amount of light pollution on RIT's campus as well as programs that would prevent an increase in light pollution on RIT's campus. Using the OLS, IC and Tobit models, values for WTP were calculated and compared with demographic statistics for the population. The Tobit model showed that the most significant variables related to students' WTP for the light pollution programs were whether or not they thought that light pollution was a problem on RIT's campus, their year in college, the amount of time they spent outside on campus at night, and their personal income. 
Because of the size of the population used for the survey, the results of this work are generalizable at most to the entire RIT student community. Nonetheless, the results have provided many ideas regarding both how policymakers in communities and states can use the data obtained from a WTP survey, and how the data collection and analysis processes can be improved. With these changes, this type of policy analysis has the potential to be a valuable tool to policymakers at all levels who might be considering implementation of light pollution programs. 


\section{References}

Alberini, A., et al. (1997). Valuing health effects of air pollution in developing countries: The case of Taiwan. Journal of Environmental Economics and Management. 34, 2: $107-126$.

Alvarez del Castillo, Elizabeth M., et al. (2003). Preserving our nighttime environment: A global approach. In H.E. Schwarz (Ed.), Light Pollution: The Global View (4967). Dordrecht, The Netherlands: Kluwer Academic Publishers.

Arizona Revised Statutes (2007). http://www.azleg.gov/ArizonaRevisedStatutes.asp?Title=49. Last Accessed November 15, 2007.

Arrow, K.J., et al. (1993). Report of the NOAA panel on contingent valuation. Federal Register. 58: 4601-4614.

Bauer, (2007). Lake Hudson recreation area dark sky preserve. http://www.michigan.gov/dnr/0,1607,7-153-10365_41665-156957--,00.html. Last Accessed November 15, 2007.

Bird, Brittany L., et al. (2004). Research note: Effects of coastal lighting on foraging behavior of beach mice. Conservation Biology 18, 5: 1435-1439.

Bjørner, Thomas Bue, et al., (2004). Environmental labeling and consumers' choice - An empirical analysis of the effect of the Nordic Swan. Journal of Environmental Economics and Management, 47:3, 411-434.

Boyle, Kevin J. and Bishop, Richard C. (1998). Welfare measurements using contingent valuation: A comparison of techniques. American Agricultural Economics Association. 70, 1, 20-28.

Carson, Richard T., Flores, Nicholas E., and Meade, Norman F. (2001). Contingent valuation: Controversies and evidence. Environmental and Resource Economics. 19, 173-210.

Chen, Ingfei and Franklin, Deborah (1996). Light sleeper? It might be the lights. Health 10, 3: 23-24.

Cinzano, P., Falchi, F., Elvidge, C.D. (2001). The first World Atlas of the artificial night sky brightness. Mon. Not. R. Astron. Soc. 328, 689-707. 
Cooper, Philip, et al. (2004). The structure of motivation for contingent values: a case study of lake water quality improvement. Ecological Economics. 50, 69-82.

Diamond, Peter A., and Hausman, Jerry A. (1994). Contingent valuation: Is some number better than no number? Journal of Economic Perspectives. 8:4, 45-64.

Deck, Leland (1997). Visibility at the Grand Canyon and the Navajo Generating Station. In Richard D. Morgenstern, (Ed.). Economic Analysis at EPA (267). Washington, D.C.: Resources for the Future.

Feder, Toni (2005). Limiting light pollution is ongoing challenge. Physics Today. 58:6, 24-26.

Freeman III, A. Myrick (2003). The Measurement of Environmental and Natural Resource Values: Theory and Methods. Washington, D.C.: Resources for the Future.

Garstang, Roy H. (2000). Light pollution at Mt. Wilson: The effects of population growth and air pollution. Mem. S. A. It. 71:1, 71-81.

Golan, E.H. and Shechter, Mordechai (1993). Use of the contingent valuation method for calculating willingness to pay for health care services: Valuation of supplemental health care in Israel. Medical Decision Making. 13:4, 302-310.

Greeley, Tom (1985). Tucson turns down lights for observatory: Arizonans proud of role in preventing light pollution. Los Angeles Times, p.1. Retrieved November 8, 2007 from Los Angeles Times database.

Gupta, Dipak K. (2001). Analyzing Public Policy: Concepts, Tools, and Techniques. Washington, D.C.: CQ Press.

Hackl, Franz, and Pruckner, Gerald J. (1999). On the gap between payment card and closed ended CVM-answers. Applied Economics. 31, 733-742.

Hanemann, W. Michael (1994). Valuing the environment through contingent valuation. The Journal of Economic Perspectives. 8: 4, 19-43.

Harder, Ben (2006). Bright Lights, Big Cancer: Melatonin-depleted blood spurs tumor growth. http://www.sciencenews.org/articles/20060107/bob9.asp. Last Accessed April 29, 2006.

Heberlein, Thomas A., et al. (2005). Rethinking the scope test as a criterion for validity in contingent valuation. Journal of Environmental Economics and Management. 50, 1-22. 
Hoversten, Paul (1999). Glare from Earth blocking view of stars, planets: Scientists push methods to cut 'light pollution'. USA Today, p. 13A. Retrieved November 8, 2007 from National Newspapers (27) database.

Hunter, Tim B., M.D., and Crawford, David L. (1991). Economics of light pollution. In David Crawford (Ed.). Light Pollution, Radio Interference, and Space Debris (89). Astronomical Society of the Pacific.

Irvin, Renee A. and Stansbury, John (2004). Citizen participation in decision making: Is it worth the effort?. Public Administration Review. 64, 1: 55-65.

Johnston, Robert J. (2006). Is hypothetical bias universal? Validating contingent valuation responses using a binding public referendum. Journal of Environmental Economics and Management. 52, 469-481.

Kirkwood, Scott (2006). Star Struck. National Parks, Summer 2006. 8, 10.

Lazo, Jeffrey K., et al. (1997). Economic theory and psychology of non-use values. Land Economics. 73: 3, 358-371.

Lexin, Li, Simonoff, Jeffrey S., and Chih-Ling Tsai (2007). Tobit model estimation and sliced inverse regression. Statistical Modelling. 7:2, 107-123.

Luginbuhl, C.B. (2001). Why astronomy needs low-pressure sodium lighting. In R.J. Cohen and W.T. Sullivan (Eds). Preserving the Astronomical Sky: Proceedings IAU Symposium 196. San Francisco: The Astronomical Society of the Pacific.

"Luminance" (1997). The American Heritage College Dictionary. Third Edition. Boston: Houghton Mifflin Company.

Marginal Benefits and Marginal Costs (2007). http://courses.agecon.1su.edu/3000/AGEC3503/WebUnit4/Web\%20Unit\%2042.htm. Last Accessed November 29, 2007.

Miller, Mark W. (2006). Apparent effects of light pollution on singing behavior of American Robins. The Condor 108, 1:130.

Mitchell, Robert Cameron and Carson, Richard T. (1989). Using Surveys to Value Public Goods: The Contingent Valuation Method. Washington, D.C.: Hopkins University Press.

Mitchell, Robert Cameron and Carson, Richard T. (1995). Current issues in the design, administration, and analysis of contingent valuation surveys. In Per-Olov Johansson, Bengt Kriström and Karl-Göran Mäler (Eds). Current Issues in Environmental Economics. New York: Manchester University Press. 
Narisada, Kohei and Schreuder, Duco (2004). Light Pollution Handbook. Dordrecht, The Netherlands: Springer.

Natural lightscape management: A cultural resource (2006). http://www2.nature.nps.gov/air/lightscapes/culturalResource.cfm. Last Accessed November 21, 2007.

Natural lightscapes monitoring and data: Night sky Assessments (2006). http://www2.nature.nps.gov/air/lightscapes/monitorData/index.cfm. Last Accessed August 21, 2006.

Portney, Paul R. (1994). The contingent valuation debate: Why economists should care. Journal of Economic Perspectives. 8, 4: 3-17.

Reiss, Valerie (2003). New York City sees stars. http://www.science spirit.org/article_detail.php?article_id=379. Last Accessed December 7, 2007.

Resources Library (2006). International Dark-Sky Association. http://www.darksky.org/resources/index.html. Last Accessed August 21, 2006.

Rimmer, David R., et. al (2000). Dynamic resetting of the human circadian pacemaker by intermittent bright light. American Journal of Physiology - Regulatory, Integrative and Comparative Physiology 279, 5: R1574-R1579.

Salmon, Michael (2003). Artificial night lighting and sea turtles. Biologist 50, 4: 163 168.

Stevens, Thomas, et al. (1991). Measuring the existance value of wildlife: What do CVM estimates really show? Land Economics. 67, 4: 390-400.

Summers, Frank (2006). StarSplatter visualization. http://terpsichore.stsci.edu/ summers/viz/starsplatter/starsplatter.html. Last Accessed January 29, 2007.

"The Costs of Light Pollution" (2006). Newsletter of the International Dark-Sky Association. http://www.darksky.org/news/newsletter-67-1.html. Last Accessed November 15, 2007.

Thomsen, Scott (2002). Astronomers see the light - and really hate it. Los Angeles Times, p. B.7. Retrieved November 8, 2007 from Los Angeles Times database.

Venkatachalam, L. (2004). The contingent valuation method, a review. Environmental Impact Assessment Review. 24: 89-124. 
Vossler, Christian A., and Kerkvliet, Joe (2003). A criterion validity test of the contingent valuation method: comparing hypothetical and actual voting behavior for a public referendum. Journal of Environmental Economics and Management. 45, 631649.

Webler, Thomas, et al. (1995). Public participation in impact assessment: A social learning perspective. Environmental Impact Assessment Review. 15: 443-463.

What is light pollution? (2004). http://www.lrc.rpi.edu/programs/nlpip/lightinganswers/lightpollution/lightPollutio n.asp. Last Accessed May 14, 2006.

What is sky glow? (2004).

http://www.lrc.rpi.edu/programs/nlpip/lightinganswers/lightpollution/skyGlow.as p. Last Accessed August 16, 2006.

Wooldridge, Jeffrey M. (2006). Introductory Econometrics: A Modern Approach (3 $3^{\text {rd }}$ ed.). Southwestern: Thompson. 


\section{Appendix A. Light Pollution Survey}

The next pages contain the final light pollution survey in its entirety. 
[The Value of a Clear Night Sky on RIT's Campus]

\author{
A Survey \\ Conducted by Stephanie Simpson \\ Masters Degree Candidate \\ Science, Technology and Public Policy \\ RIT
}




\title{
Please Read ALL Instructions Before Turning the Page!
}

\section{Informed Consent:}

This research is being done as part of a master's thesis research project to determine the value of a clear night sky. You are being asked to fill out this survey, which will take approximately 20 minutes to complete. Participation in this survey is completely voluntary. Participation or non-participation in this survey will not affect your grade in this class in any way, positively or negatively. You may change your mind about participating at any time while taking the survey, and doing so will also not affect your grade in this class in any way, positively or negatively. The information you provide in the survey will be put together with information from other participants in your class and in other classes and will be anonymous. If you have any questions about the study or your participation after I have left your class, you may contact me at the email address I have provided on the white board in the front of the room.

\section{Instructions:}

1. Please check to make sure that your packet contains 10 pages. If it does not, please bring it up to me and ask for a new one.

\author{
2. When asked to reference pictures, please refer to the slideshow \\ being played at the front of the room.
}

3. Please read each question carefully and answer the question to the best of your ability.

4. Please answer the questions in the order that they are given.

5. If you do not know the answer to a question, please give your best guess. 


\section{A. Thinking About Light Pollution on RIT's Campus}

Q.1. Have you heard the term "light pollution" used before? (Please circle the appropriate answer.)

$$
\text { Yes No }
$$

Q.2. What do you think light pollution is? Please answer regardless of answer above. 
Light that is directed into a place where it is not wanted is considered light pollution and is an unwanted consequence of outdoor lighting. Many times the light pollution can be described as "sky glow", which occurs when light is directed upward into the night sky, decreasing the ability to view a clear night sky. A night sky that contains sky glow has fewer stars visible, and may seem to have an orange glow.

Q.3. Have you ever experienced sky glow? (Please circle appropriate answer.)

$$
\text { Yes No }
$$

Q.4. If you have experienced sky glow, please describe this experience. If you have not experienced sky glow, please skip to question 5 .

Q.5. In your personal opinion, is sky glow is a problem on Rochester Institute of Technology's (RIT's) campus at night? (Please circle the appropriate answer.)
Yes
No
I Don't Know

Q.6. If you answered "yes" or "no" to Q.5., please explain why or why not. 
Q.7. Do you reside on - campus or off - campus? (Please circle the appropriate answer.)
On - Campus $\quad$ (RIT Residence Halls or Apartments)
Off - Campus (Residence other than RIT Residence Halls or Apartments, including RIT Inn.)

Q.8. On average during your academic year, how many hours per week would you say that you spend on campus? (Include all quarters that you are enrolled in classes in this estimation.)

Q.9. On average during your academic year, how many hours per week would you say that you spend outside on campus at night (after sunset and before sunrise)? (Include all quarters that you are enrolled in classes in this estimation.) 


\section{B. What is the Value of a Clear Night Sky on the RIT Campus?}

The amount of light pollution in a given area can be decreased if the appropriate lighting technologies are utilized. These technologies reduce the amount of sky glow in an area by directing light only where it is needed and sometimes altering the type of lighting that is used. Introducing these technologies into an area has a cost, whether these technologies are introduced on their own or as replacements for existing technologies.

New light pollution controls for colleges and universities in the United States, if adopted, may require that colleges and universities fund light pollution reduction projects on their own campuses. Implementation of these programs could mean increased costs and fees for colleges and universities, as these colleges and universities replace their current lighting technologies with technologies that reduce sky glow. Colleges and universities built in the future would also be required to comply with any adopted lighting regulations. The next questions concern how much obtaining improvements and preventing increased sky glow on RIT's campus would be worth to you as a student at RIT.

The following questions only concern night sky visibility on RIT's campus as it is affected by the light fixtures and lighting practices of RIT. Assume that there will be no change in the lighting practices of neighboring businesses, residences, cities and towns, or any other sources of light near to or surrounding RIT's campus. Assume that any change in RIT's lighting practices would occur immediately and would be a permanent change. Also assume that the associated costs would be covered by payments made by all current and future RIT students. These payments would be made per quarter, and would occur each quarter the individual is a student at RIT. 
Q.1. With additional light pollution controls aimed at reducing sky glow, average visibility conditions of the night sky on RIT's campus could improve. What is the most you would be willing to pay in out of pocket expenses per quarter for a change in visibility from Picture A to Picture B? (In the table below, circle the value that best represents your willingness to pay for the change described above.)

$\begin{array}{llccccc}\$ 0.00 & \$ 2 & \$ 8 & \$ 25 & \$ 60 & \$ 150 & \$ 400 \\ \$ 0.50 & \$ 3 & \$ 10 & \$ 30 & \$ 75 & \$ 200 & \$ 500 \\ \$ 1.00 & \$ 4 & \$ 15 & \$ 40 & \$ 100 & \$ 250 & \$ 750 \\ \$ 1.50 & \$ 5 & \$ 20 & \$ 50 & \$ 125 & \$ 300 & \text { More than } \$ 750\end{array}$

Q.2. With additional light pollution controls aimed at reducing sky glow, average visibility conditions of the night sky on RIT's campus could improve. What is the most you would be willing to pay in out of pocket expenses per quarter for a change in visibility from Picture A to Picture C? (In the table below, circle the value that best represents your willingness to pay for the change described above.)

$\begin{array}{lcccccc}\$ 0.00 & \$ 2 & \$ 8 & \$ 25 & \$ 60 & \$ 150 & \$ 400 \\ \$ 0.50 & \$ 3 & \$ 10 & \$ 30 & \$ 75 & \$ 200 & \$ 500 \\ \$ 1.00 & \$ 4 & \$ 15 & \$ 40 & \$ 100 & \$ 250 & \$ 750 \\ \$ 1.50 & \$ 5 & \$ 20 & \$ 50 & \$ 125 & \$ 300 & \text { More than } \$ 750\end{array}$

Q.3. It is possible that some additional light pollution controls may be needed just to keep visibility conditions of the night sky on RIT's campus from getting worse. What is the most you would be willing to pay in out of pocket expenses to prevent average visibility on RIT's campus from becoming like Picture $\mathrm{D}$ rather than remaining at the level of Picture A? (In the table below, circle the value that best represents your willingness to pay for the change described above.)

$\begin{array}{lcccccc}\$ 0.00 & \$ 2 & \$ 8 & \$ 25 & \$ 60 & \$ 150 & \$ 400 \\ \$ 0.50 & \$ 3 & \$ 10 & \$ 30 & \$ 75 & \$ 200 & \$ 500 \\ \$ 1.00 & \$ 4 & \$ 15 & \$ 40 & \$ 100 & \$ 250 & \$ 750 \\ \$ 1.50 & \$ 5 & \$ 20 & \$ 50 & \$ 125 & \$ 300 & \text { More than } \$ 750\end{array}$




\section{Demographic Questions}

Finally, we would like to learn more about you. Please answer the following questions by circling or writing your response where appropriate:

1. Age: Under $16 \quad 16-20 \quad 20-24 \quad$ Above 24

2. Gender: $\quad M \quad F$

3. Major:

4. Year in College (Please circle the appropriate degree level/year):

$\begin{array}{lllllll}\text { Undergraduate Year: } & 1 & 2 & 3 & 4 & 5 & 6 \text { or greater }\end{array}$

Graduate Year: $1 \quad 2 \quad 3$ or greater

5. Which of the following represents your hometown? (Circle appropriate answer.)

A Large Metropolitan Area (Over 1 million people)

A Large City (100,000 to 1 million people)

A Small City or Town (10,000 to 100,000 people)

A Very Small Town or Rural Area (under 10,000 people) 
6. Please estimate your personal income per quarter:

7. How accurate is this estimate:

Very accurate Somewhat accurate Not at all accurate

Please provide any additional comments on light pollution or visibility of the night sky on RIT's campus if you desire. 
This is the end of the survey.

Please return the completed survey to the person who handed it out to you.

\section{Thank you for completing the survey!}

Credit for Original Night Sky Images:

Dr. Frank Summers, http://terpsichore.stsci.edu/ summers/viz/starsplatter/starsplatter.html 


\section{Appendix B. Informed Consent Statement}

The following statement is the statement that was spoken to the students in each of the four classes that participated in the survey.

\section{Survey Introduction Script}

$\mathrm{Hi}$, as your professor said, my name is Stephanie Simpson, and I am a graduate student in the Science, Technology, and Public Policy department here at RIT. I am here in your class today because I'd like to have you fill out a survey that is a part of my master's thesis. Using the surveys that I give out, I am hoping to determine the value of a clear night sky. This type of study can aid policymakers in making policy decisions regarding light pollution.

The survey should take about 20 minutes to complete, but you may have as much time as you need. You will also read this in the survey instructions, but I want to point out that participation in this survey is completely voluntary. Neither participation nor nonparticipation in this survey will affect your grade in this class in any way, positively or negatively.

I will pass out the surveys now. Please don't look at the survey until I have given the ok and everyone has one. If you do not wish to participate in the survey, please just do not take a survey. Does everyone have one? Ok. Please read the instructions carefully and answer each question to the best of your ability. If you have any questions or problems, please come up and ask me. You may start! 


\section{Appendix C. Correlation Table and Histograms}

Correlation values and histograms for the variables used in the analysis. All variables that were included in the initial analysis are included in the correlation table.

\begin{tabular}{|c|c|c|c|}
\hline Variables & WTP 1 & WTP 2 & WTP 3 \\
\hline HEARDOF & 0.16 & 0.16 & 0.12 \\
\hline EXPERIENCESG & 0.03 & 0.01 & 0.08 \\
\hline SGRIT & 0.11 & 0.10 & 0.09 \\
\hline RESIDE & 0.01 & 0.01 & 0.03 \\
\hline TIMEOUT & 0.12 & 0.04 & 0.09 \\
\hline GENDER & 0.18 & 0.11 & 0.23 \\
\hline MAJORBC & 0.22 & 0.16 & 0.19 \\
\hline YRCOLLEGE & -0.11 & -0.11 & -0.10 \\
\hline HMTWN & 0.07 & 0.16 & 0.08 \\
\hline INCOME & -0.06 & -0.04 & -0.04 \\
\hline
\end{tabular}

Table 8. Correlation statistics for variables.

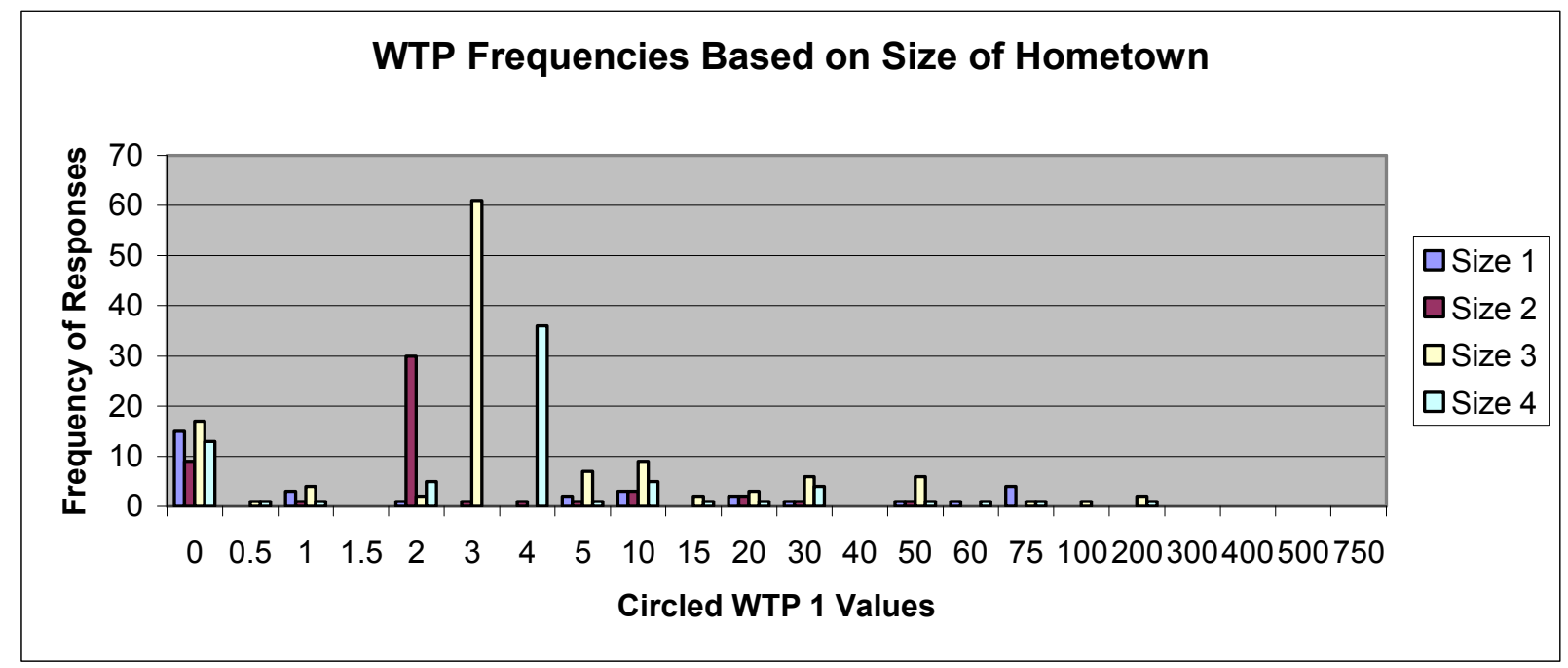

Figure 10. WTP 1 Responses vs. Size of Hometown. 


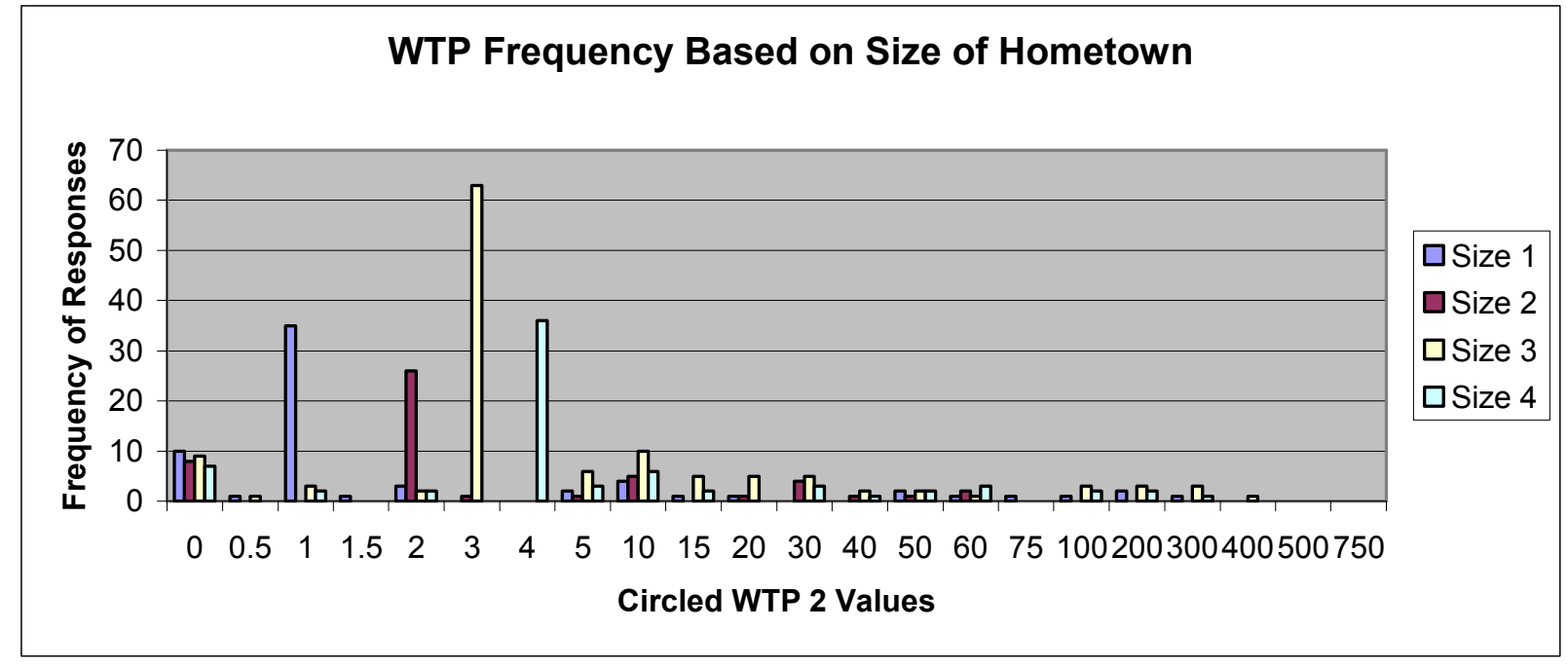

Figure 11. WTP 2 Responses vs. Size of Hometown.

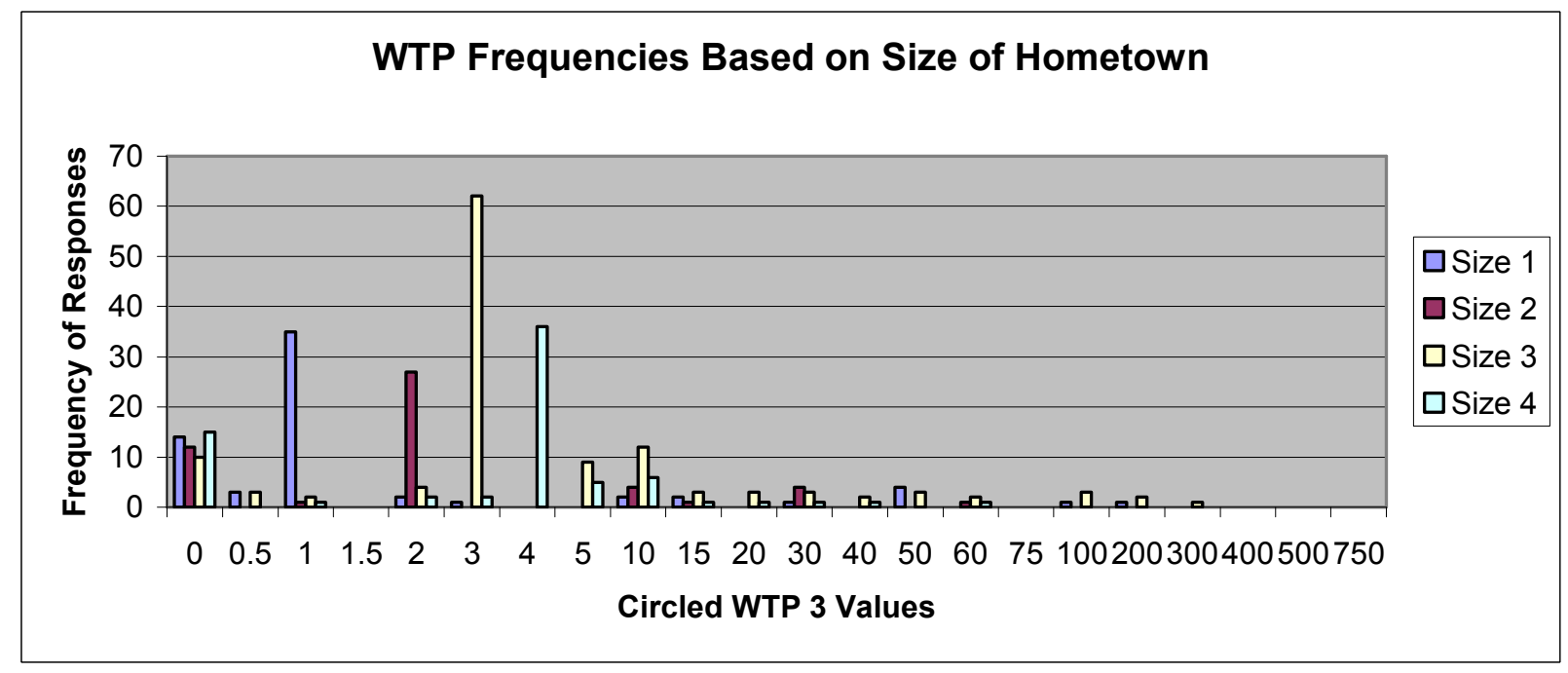

Figure 12. WTP 3 Responses vs. Size of Hometown. 


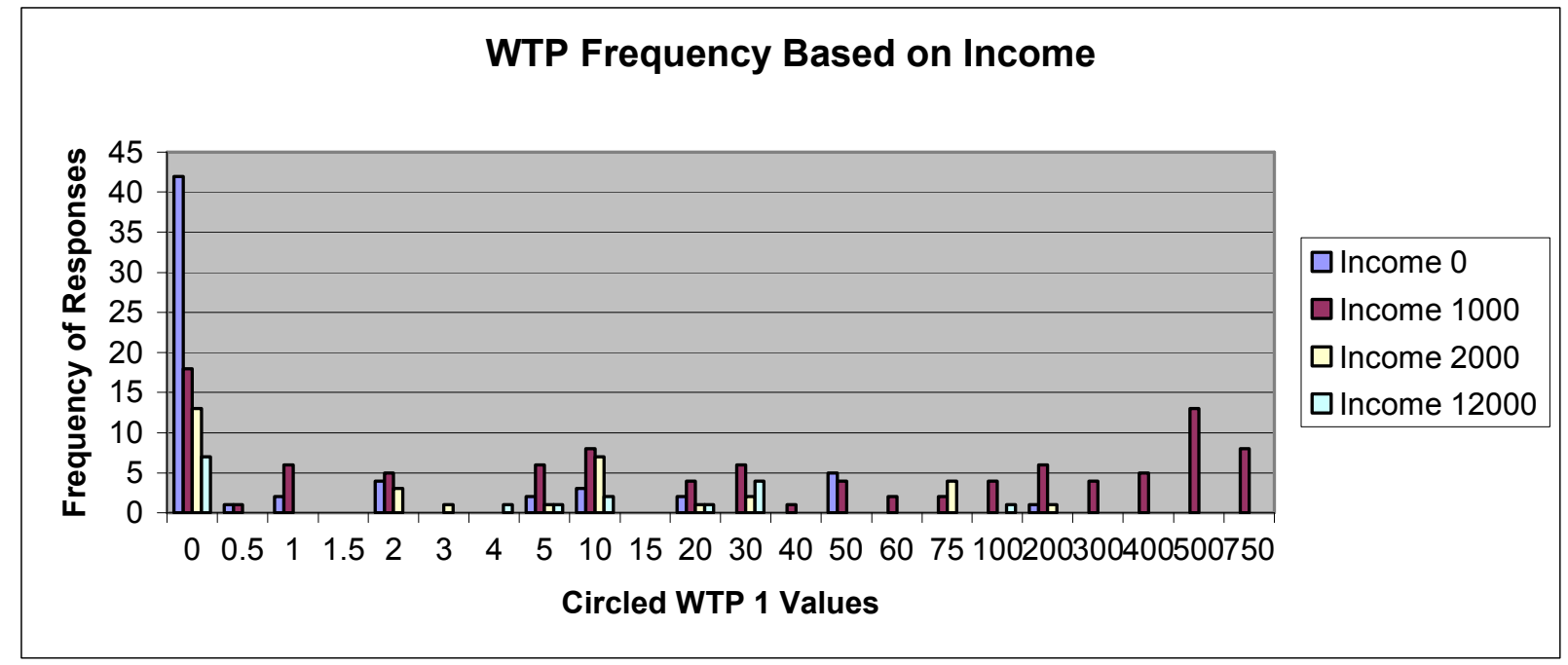

Figure 13. WTP 1 Responses vs. Income.

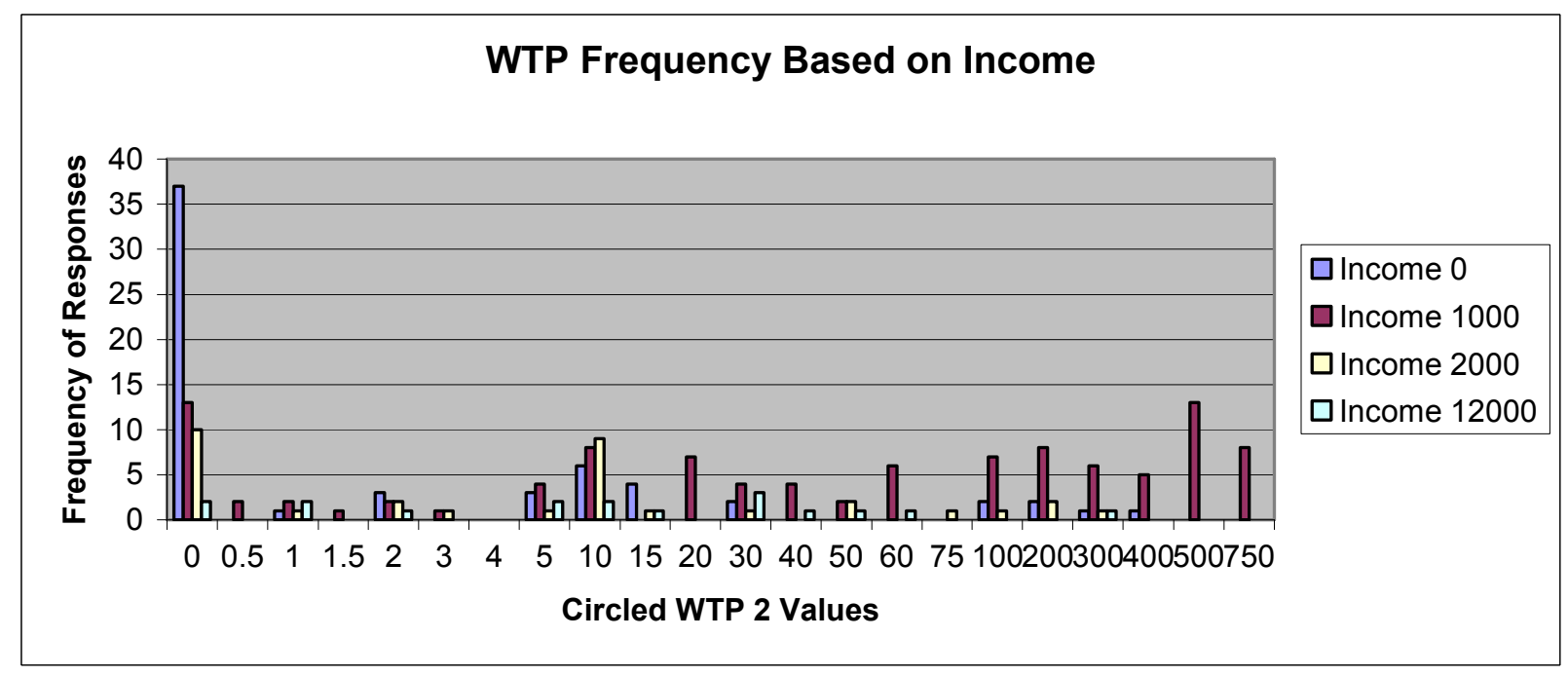

Figure 14. WTP 2 Responses vs. Income. 


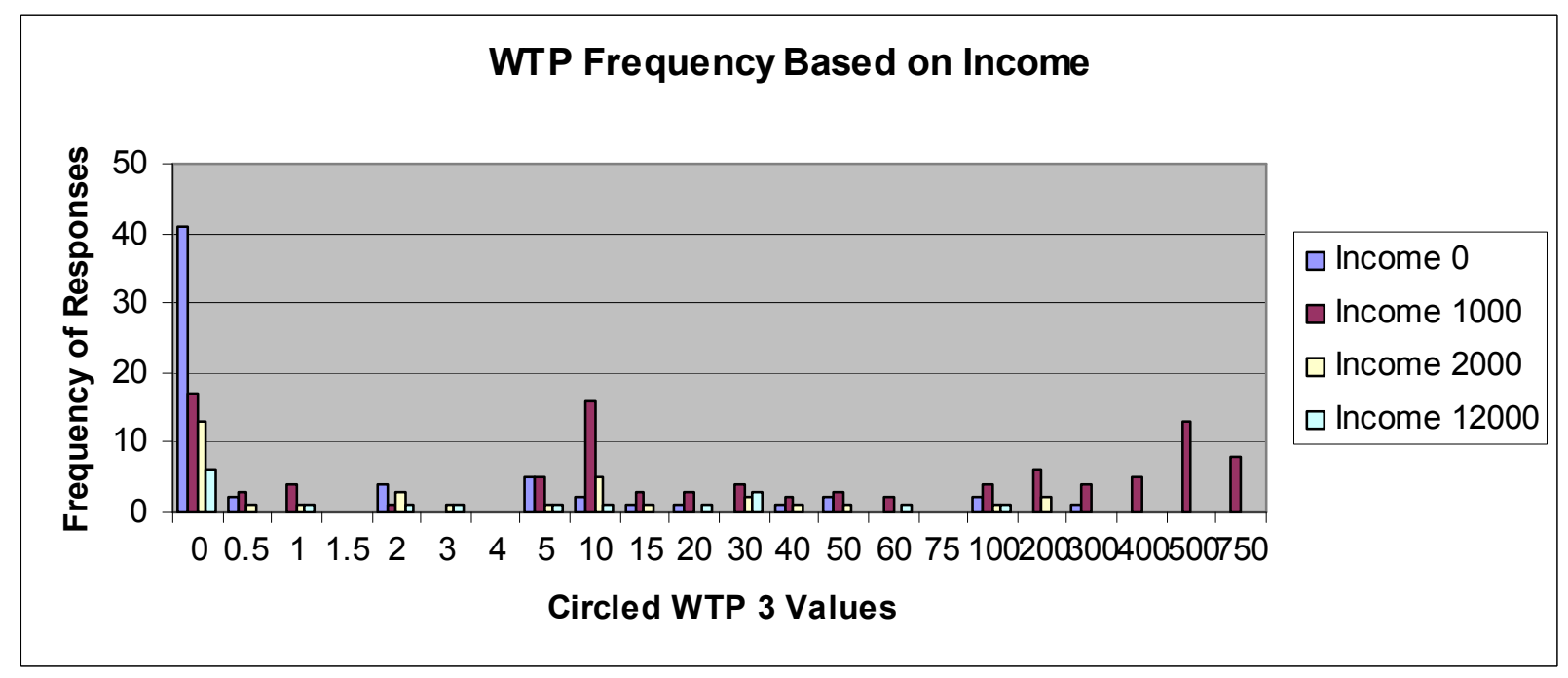

Figure 15. WTP 3 Responses vs. Income.

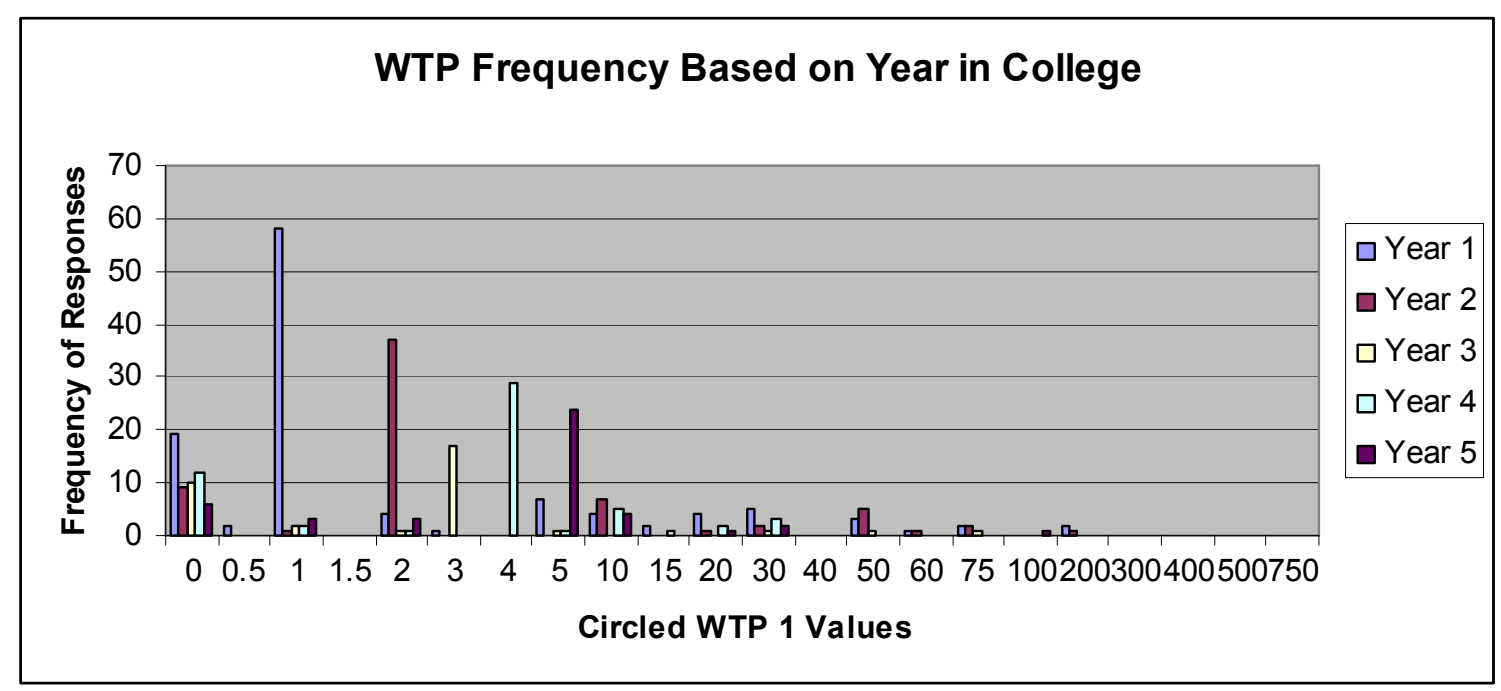

Figure 16. WTP 1 Responses vs. Year in College. 


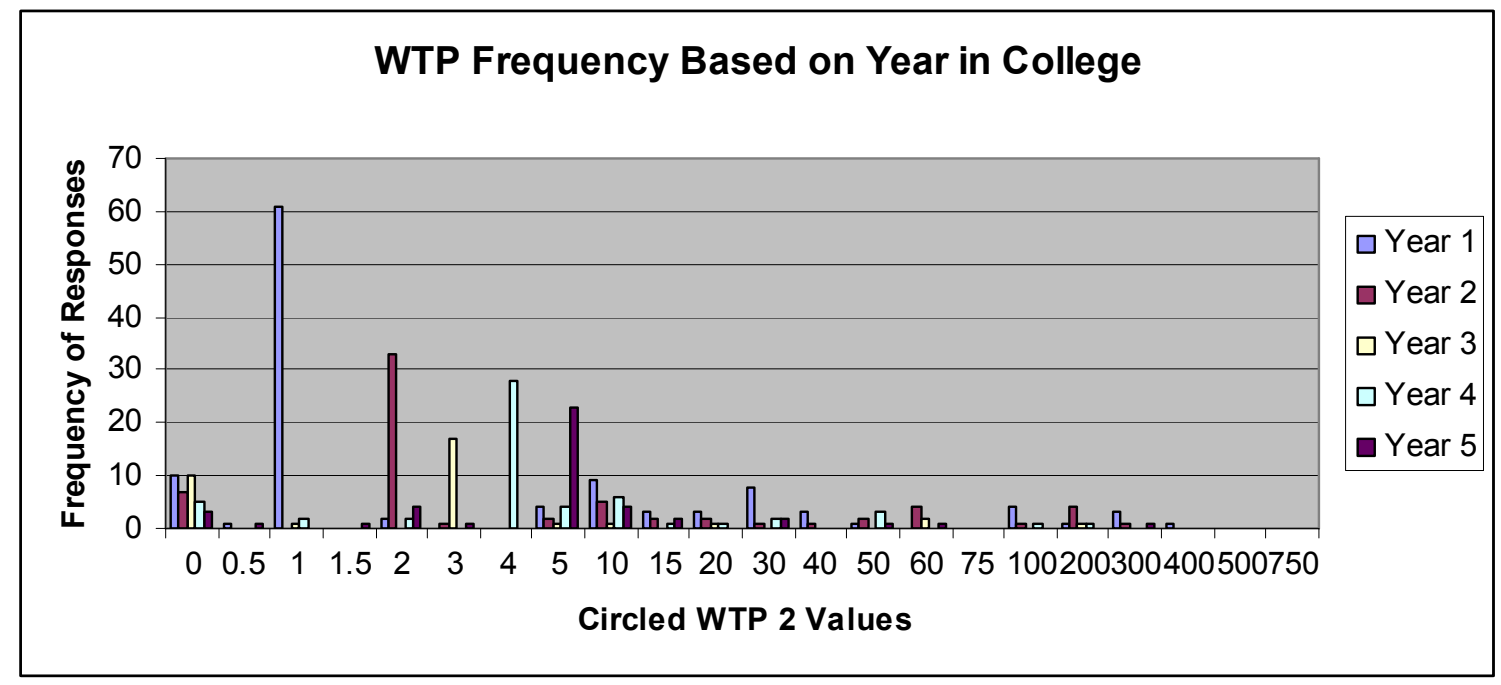

Figure 17. WTP 2 Responses vs. Year in College.

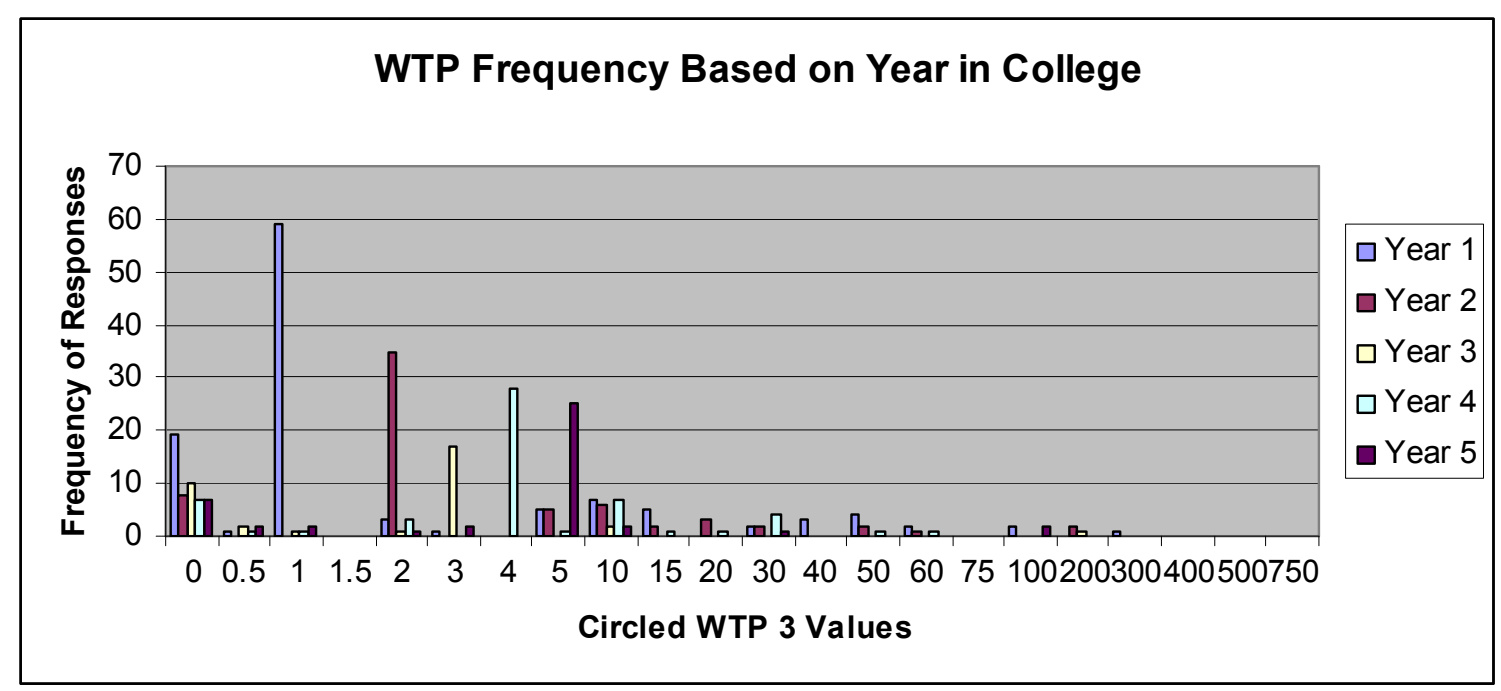

Figure 18. WTP 3 Responses vs. Year in College. 


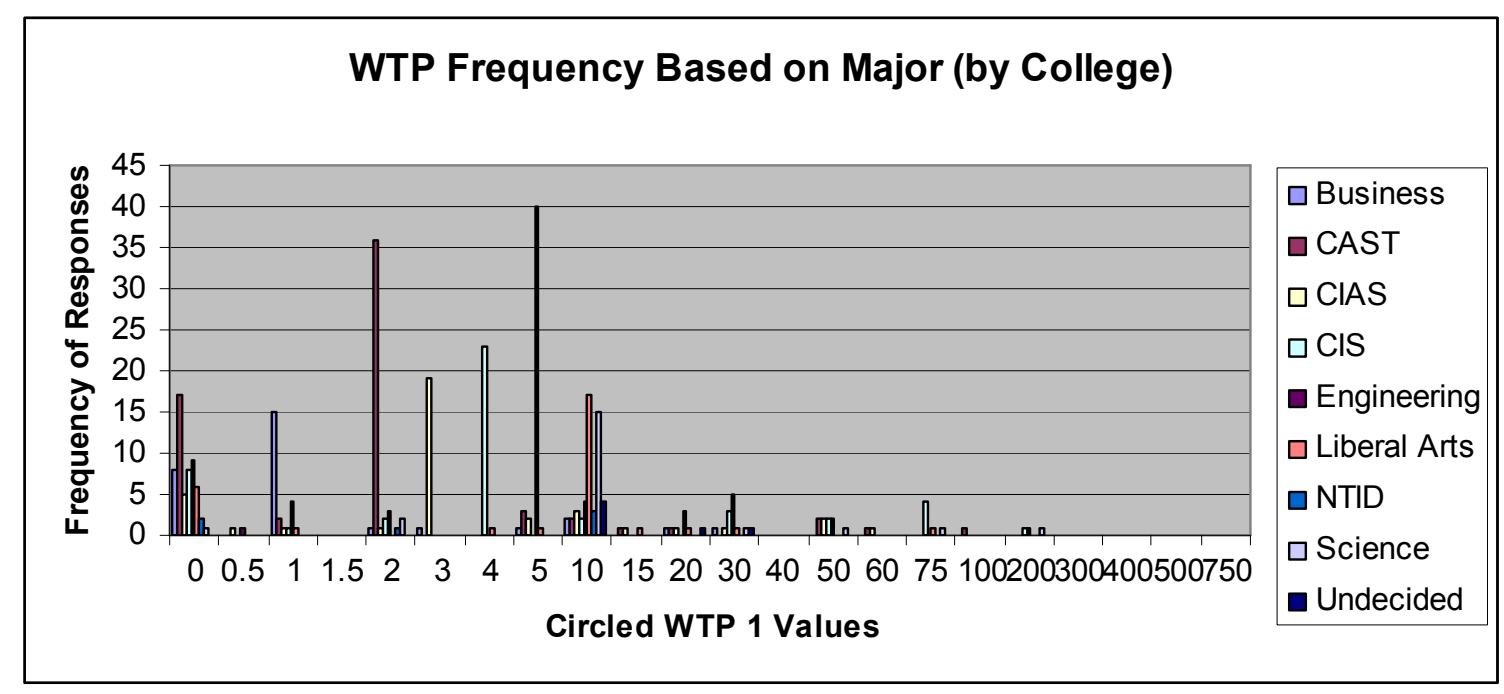

Figure 19. WTP 1 Responses vs. Major (by College).

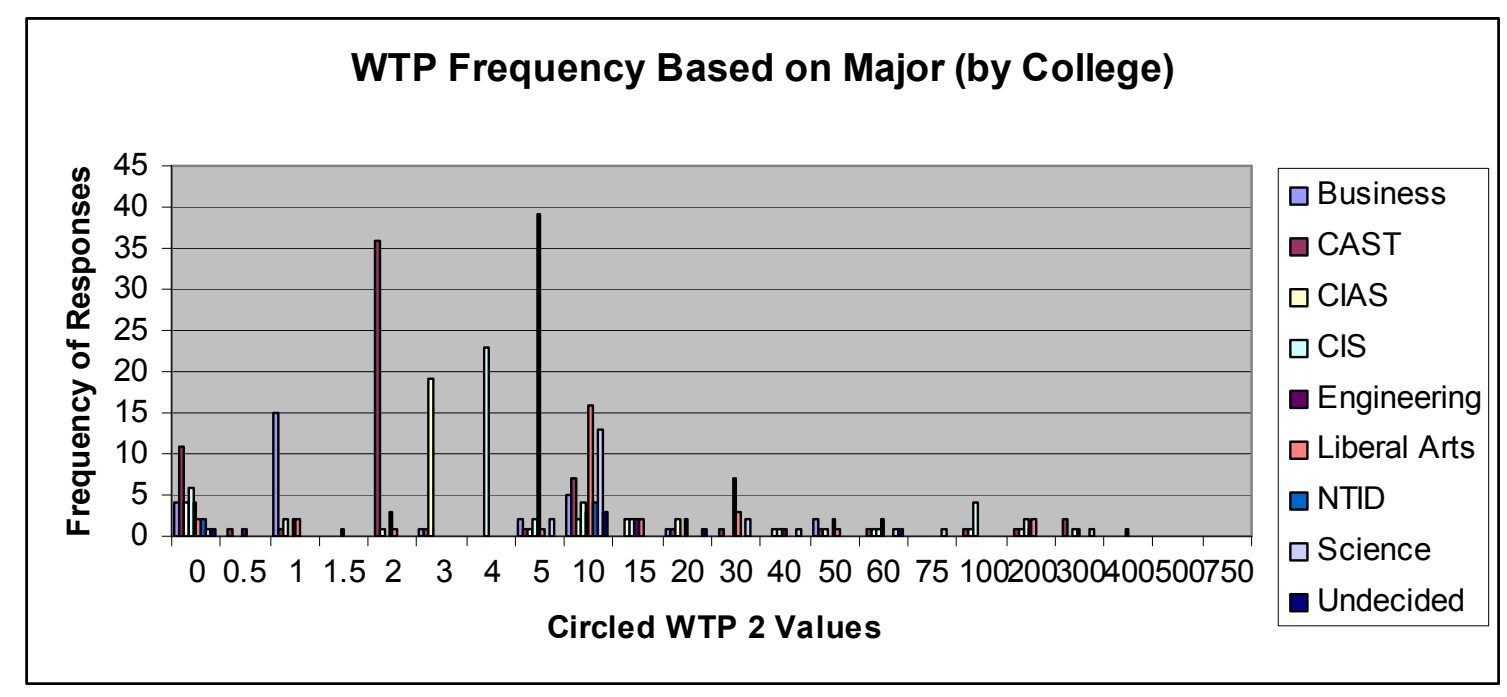

Figure 20. WTP 2 Responses vs. Major (by College). 


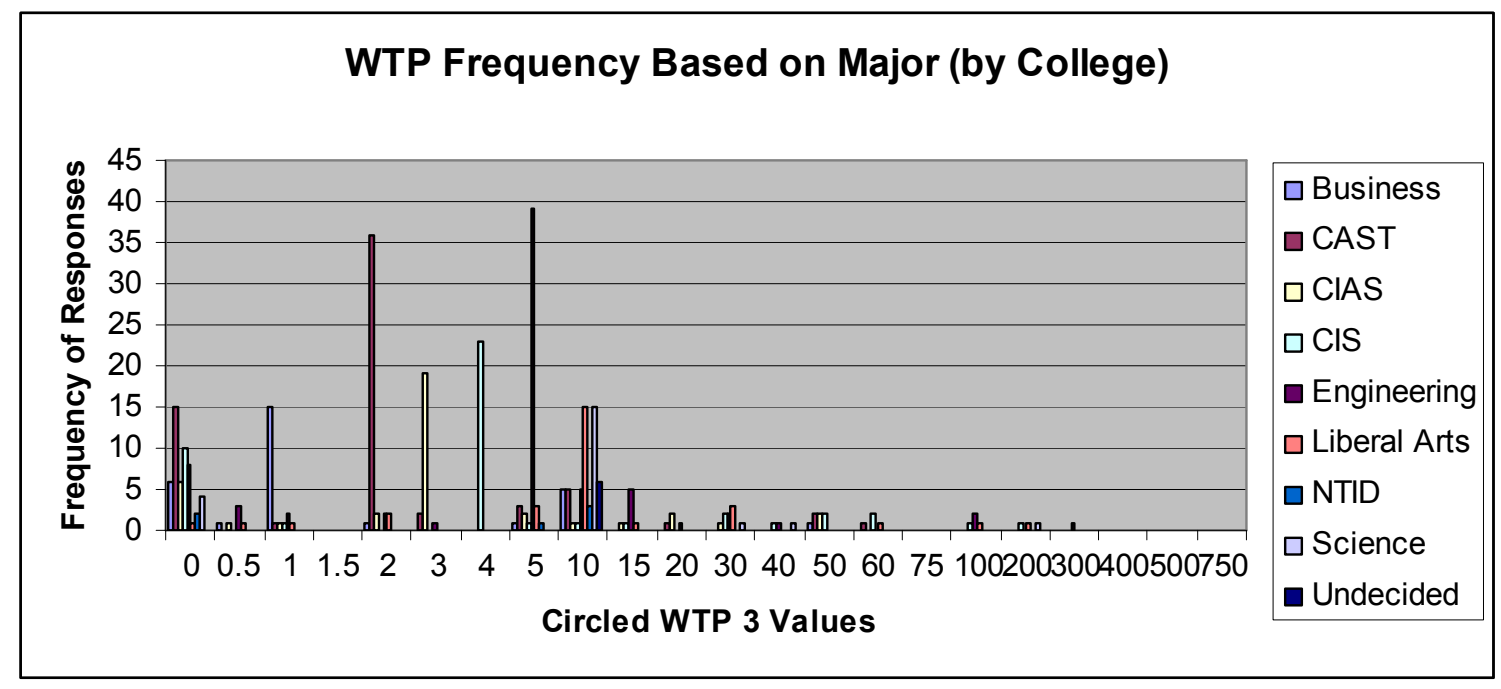

Figure 21. WTP 3 Responses vs. Major (by College).

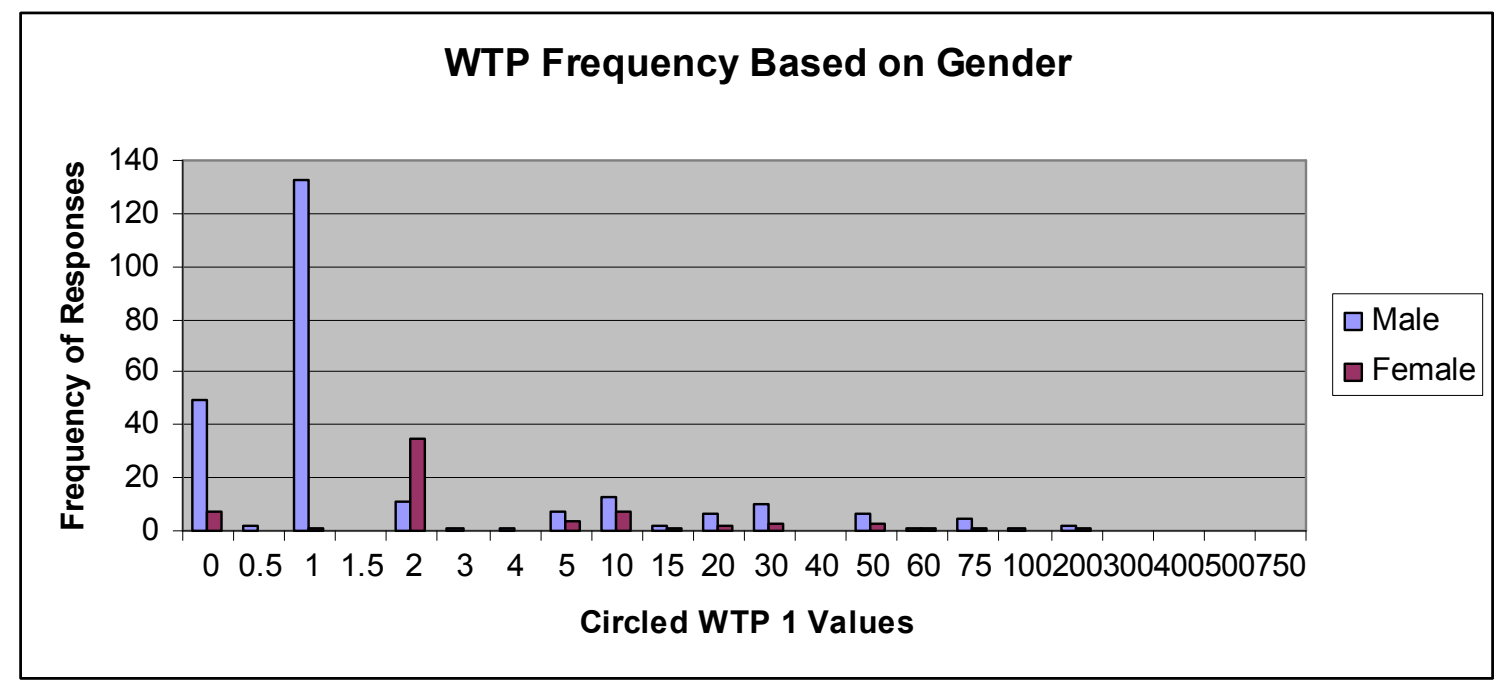

Figure 22. WTP 1 Responses vs. Gender. 


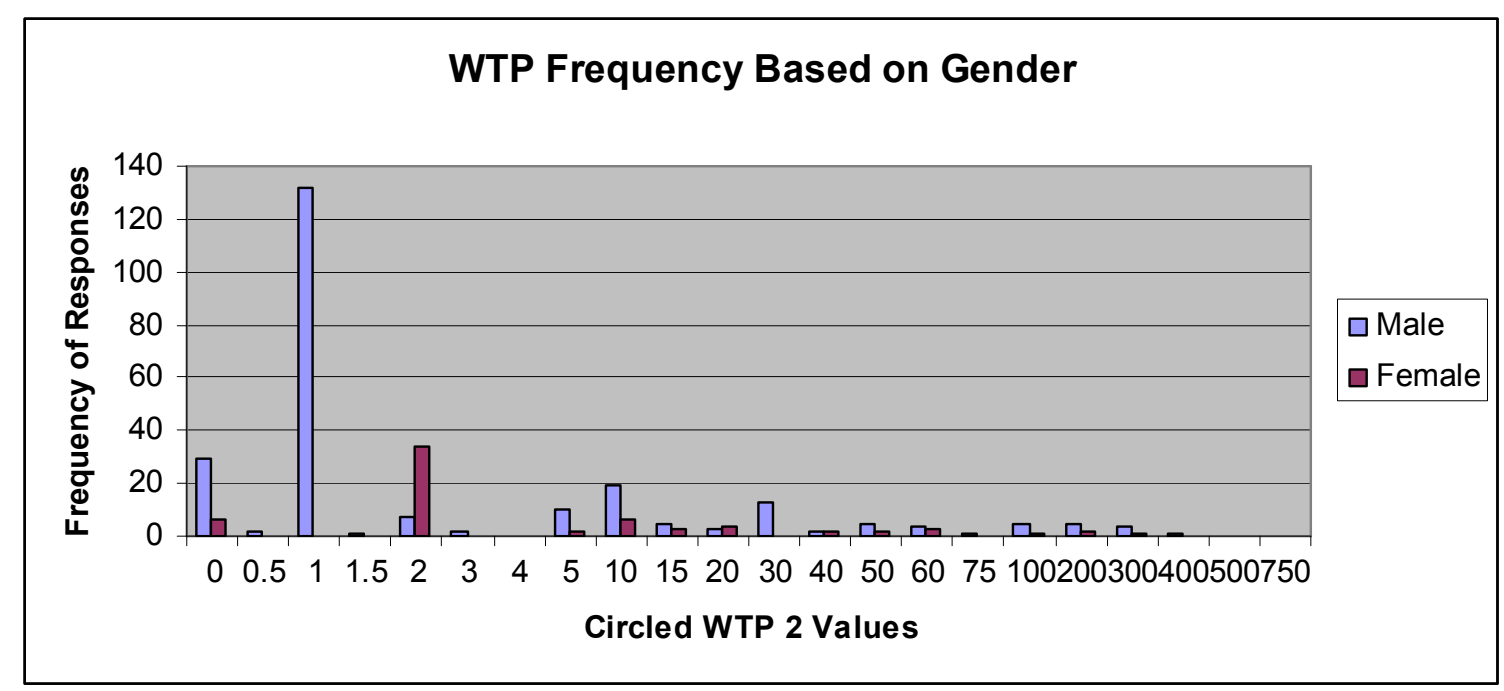

Figure 23. WTP 2 Responses vs. Gender.

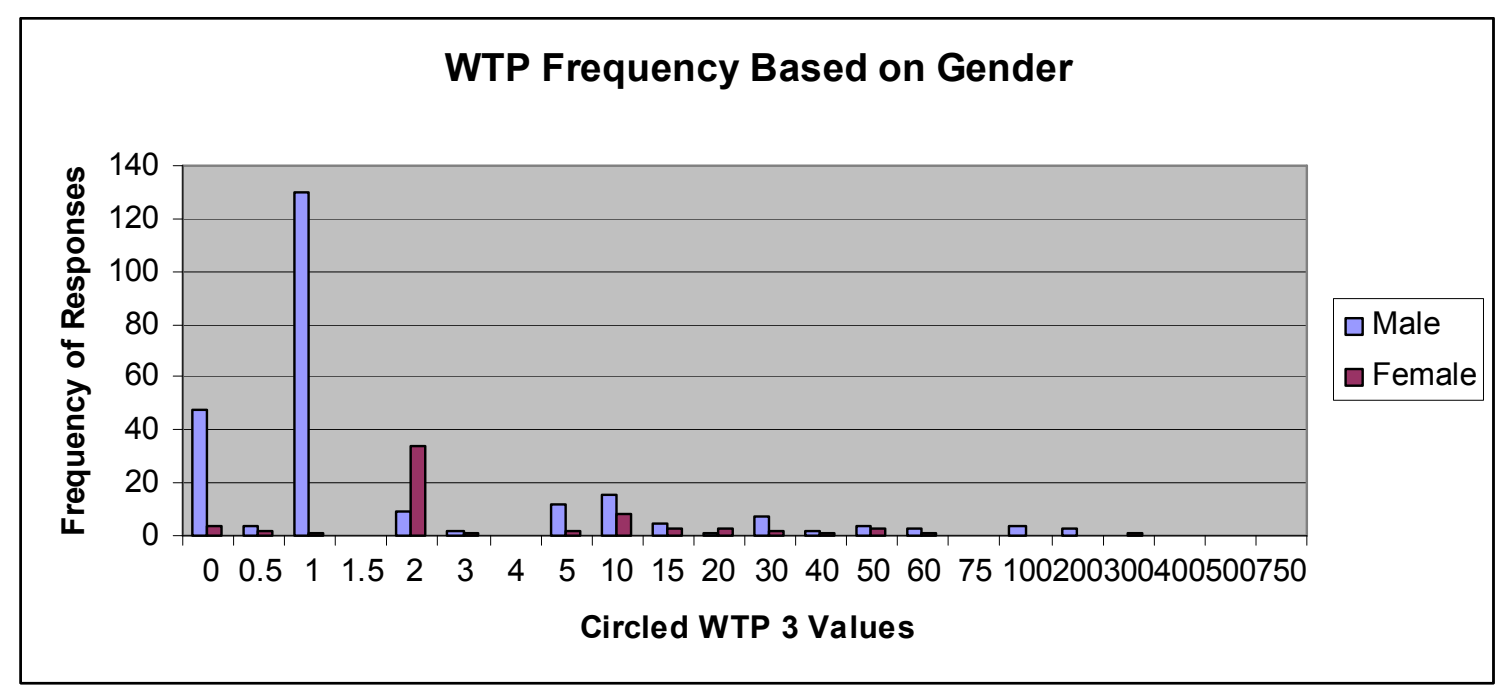

Figure 24. WTP 3 Responses vs. Gender. 


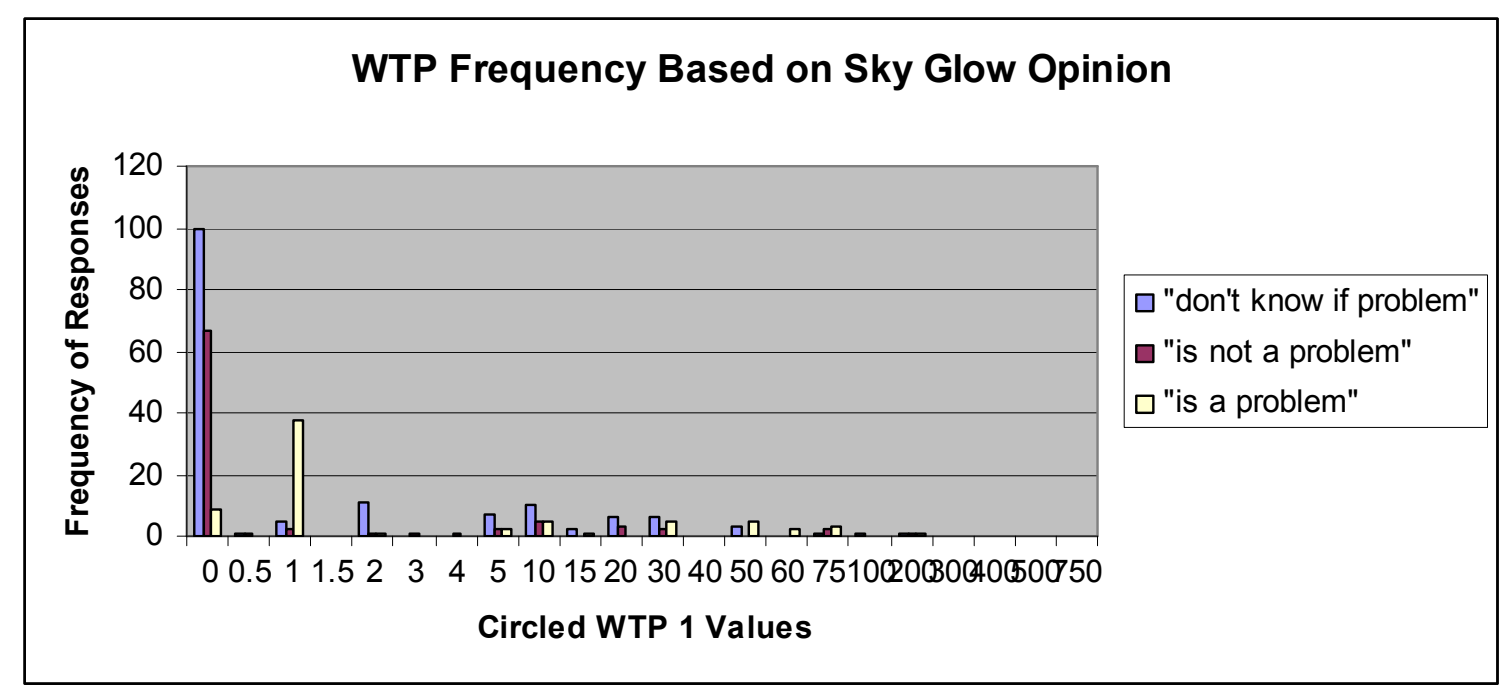

Figure 25. WTP 1 Responses vs. Sky Glow Opinion.

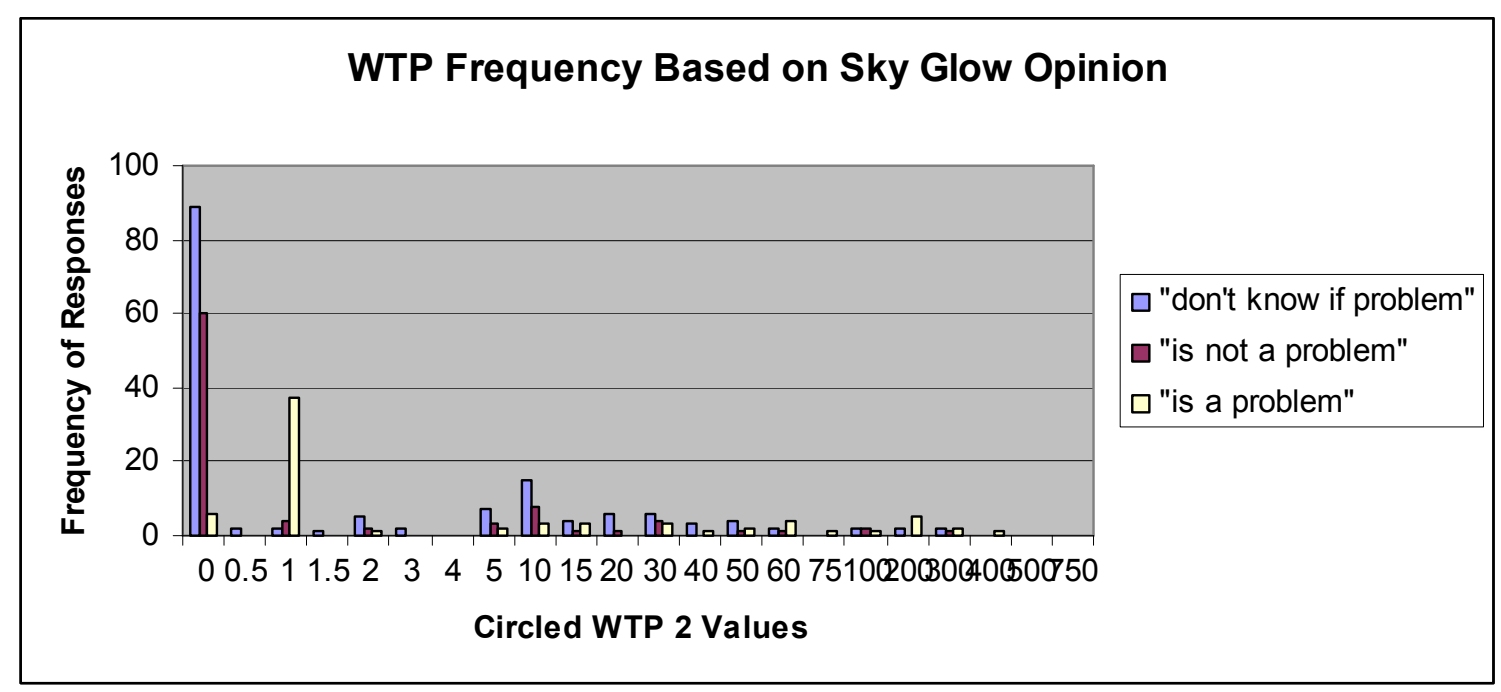

Figure 26. WTP 2 Responses vs. Sky Glow Opinion. 


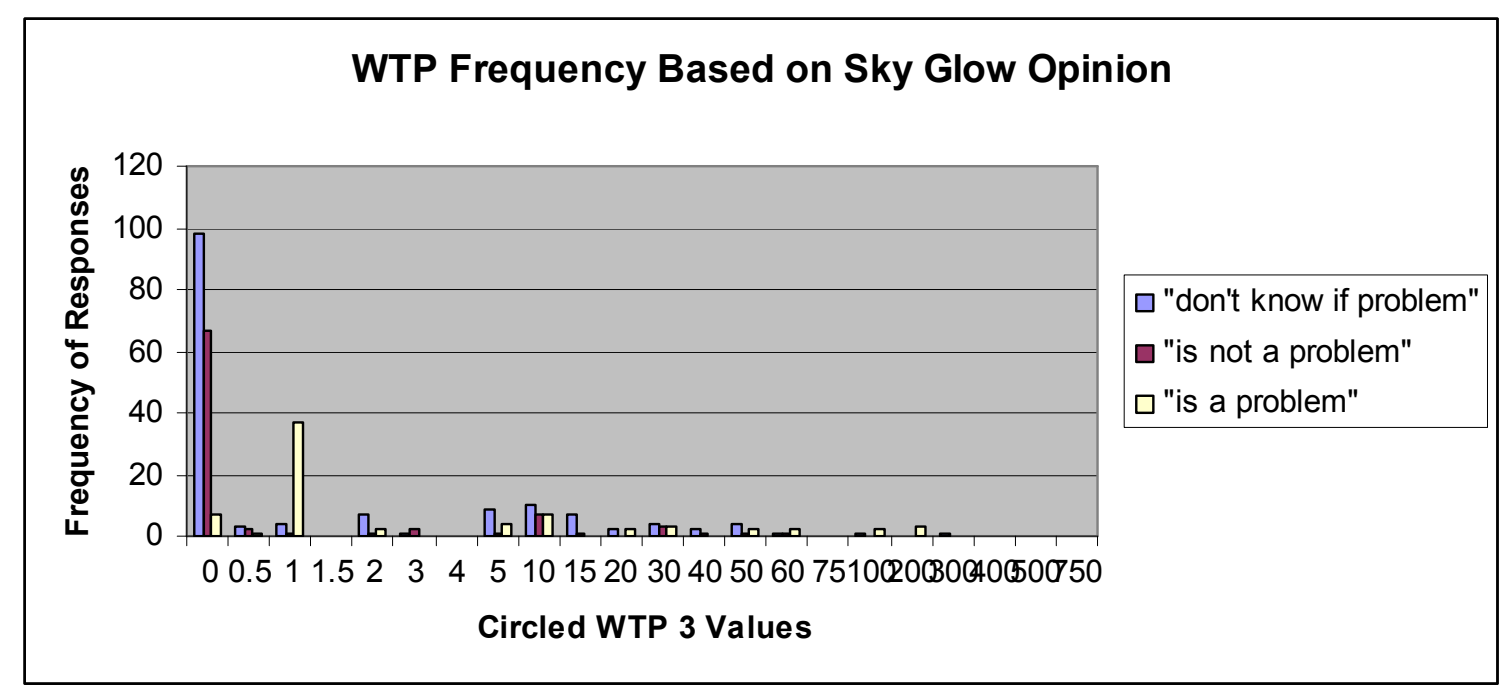

Figure 27. WTP 3 Responses vs. Sky Glow Opinion.

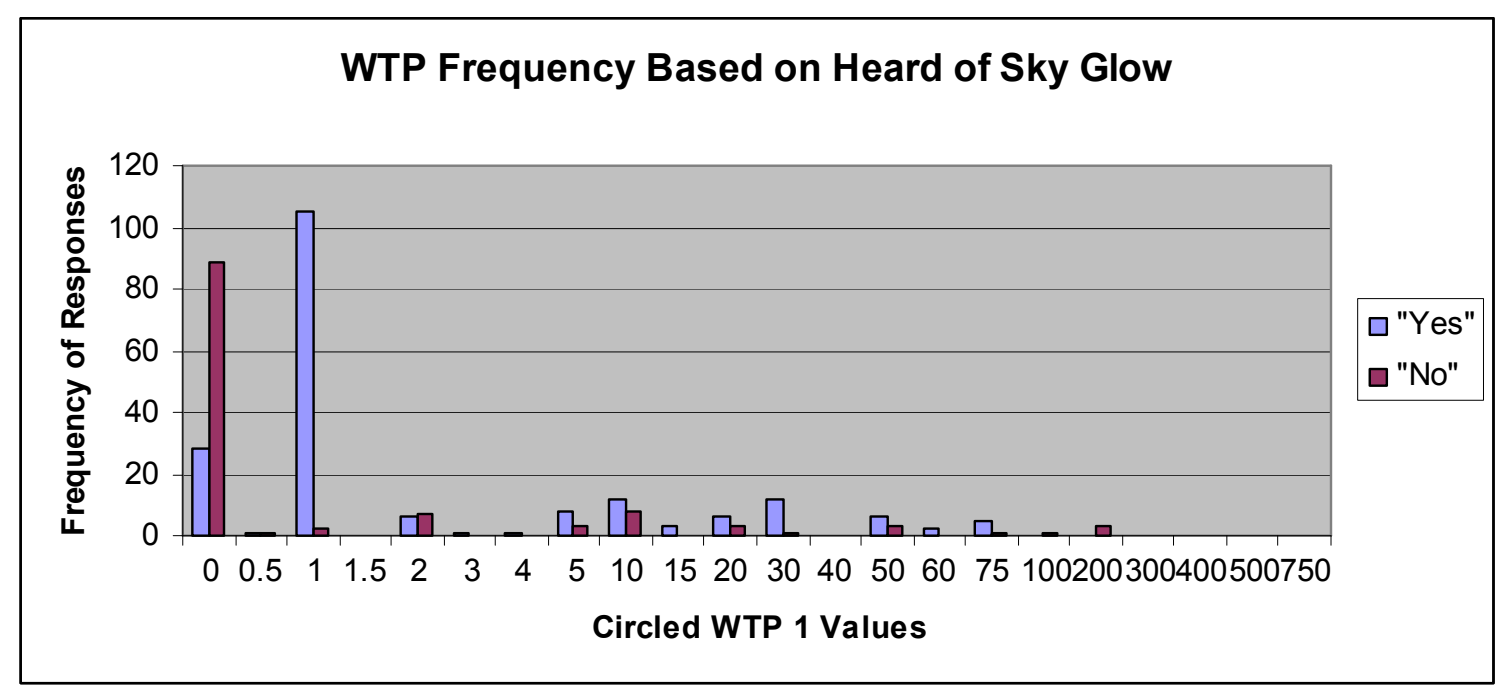

Figure 28. WTP 1 Responses vs. Heard of Sky Glow 


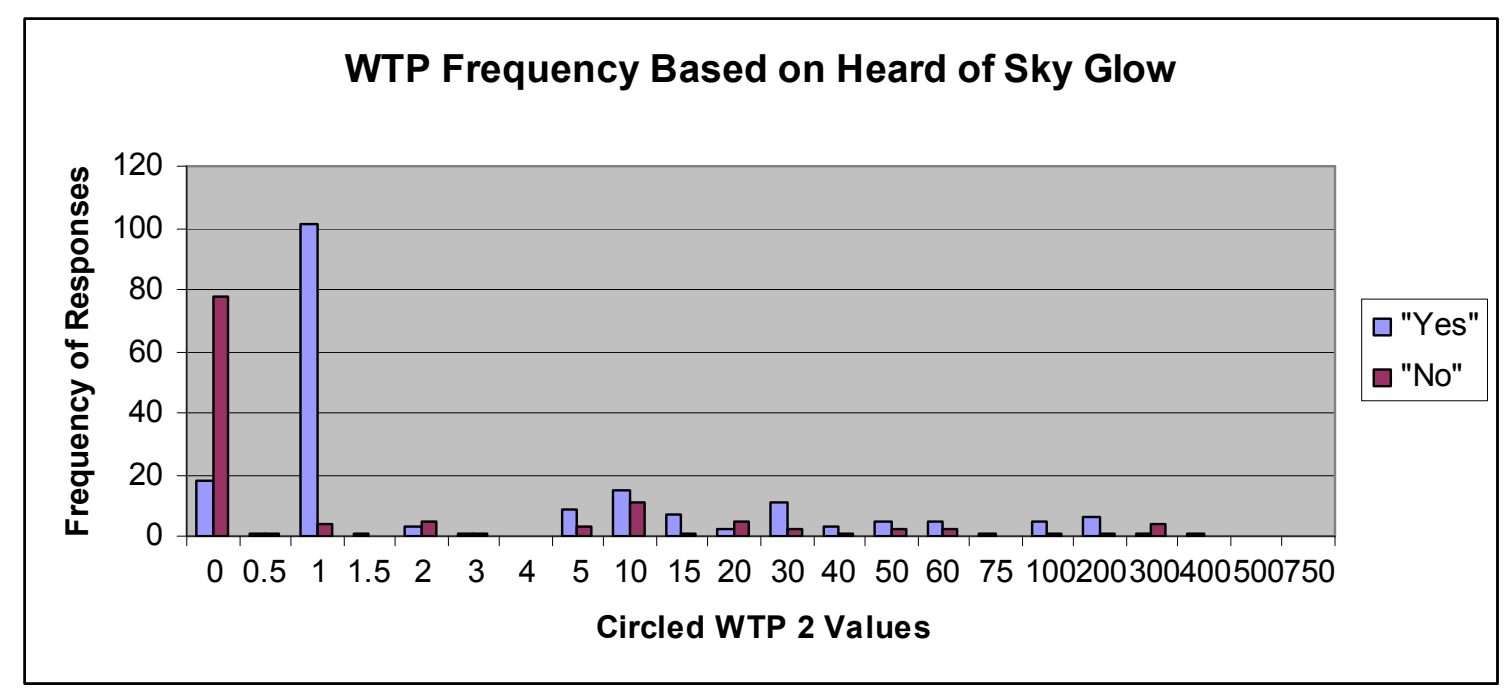

Figure 29. WTP 2 Responses vs. Heard of Sky Glow.

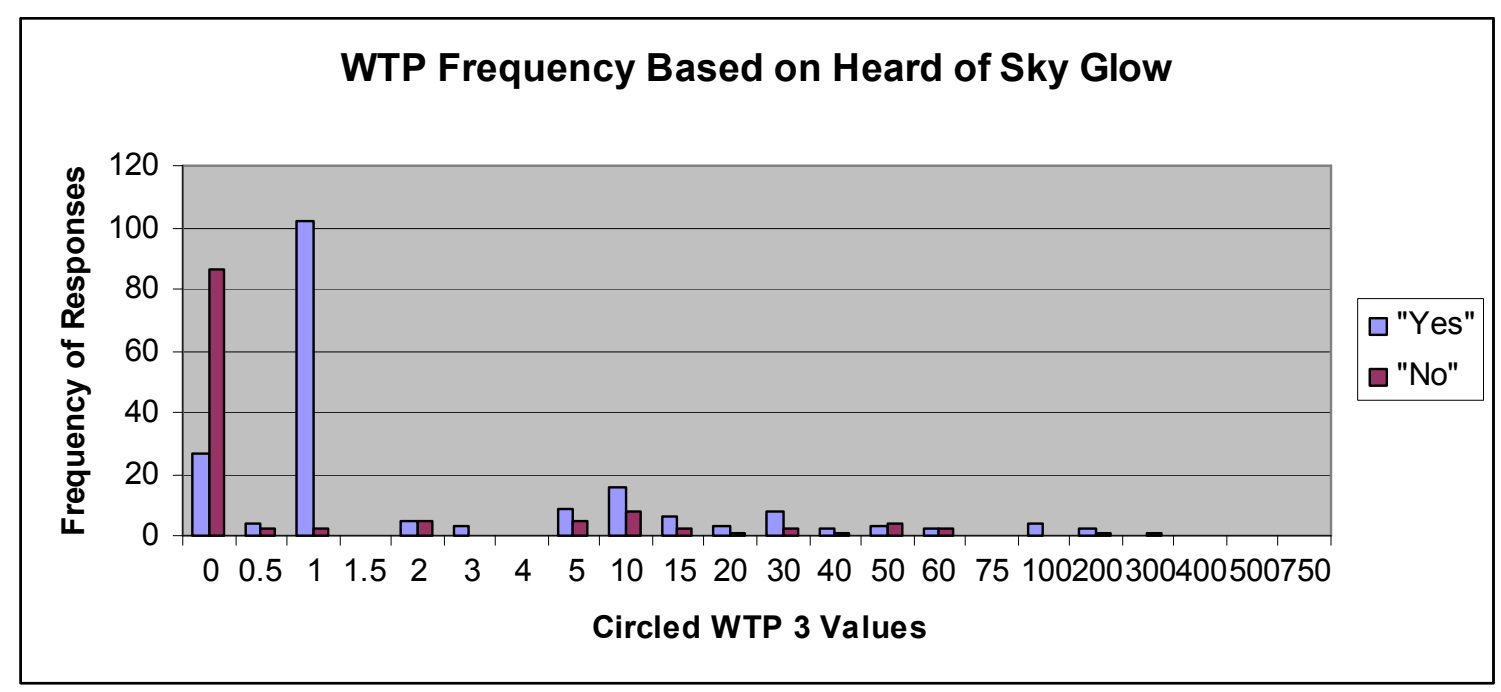

Figure 30. WTP 3 Responses vs. Heard of Sky Glow. 


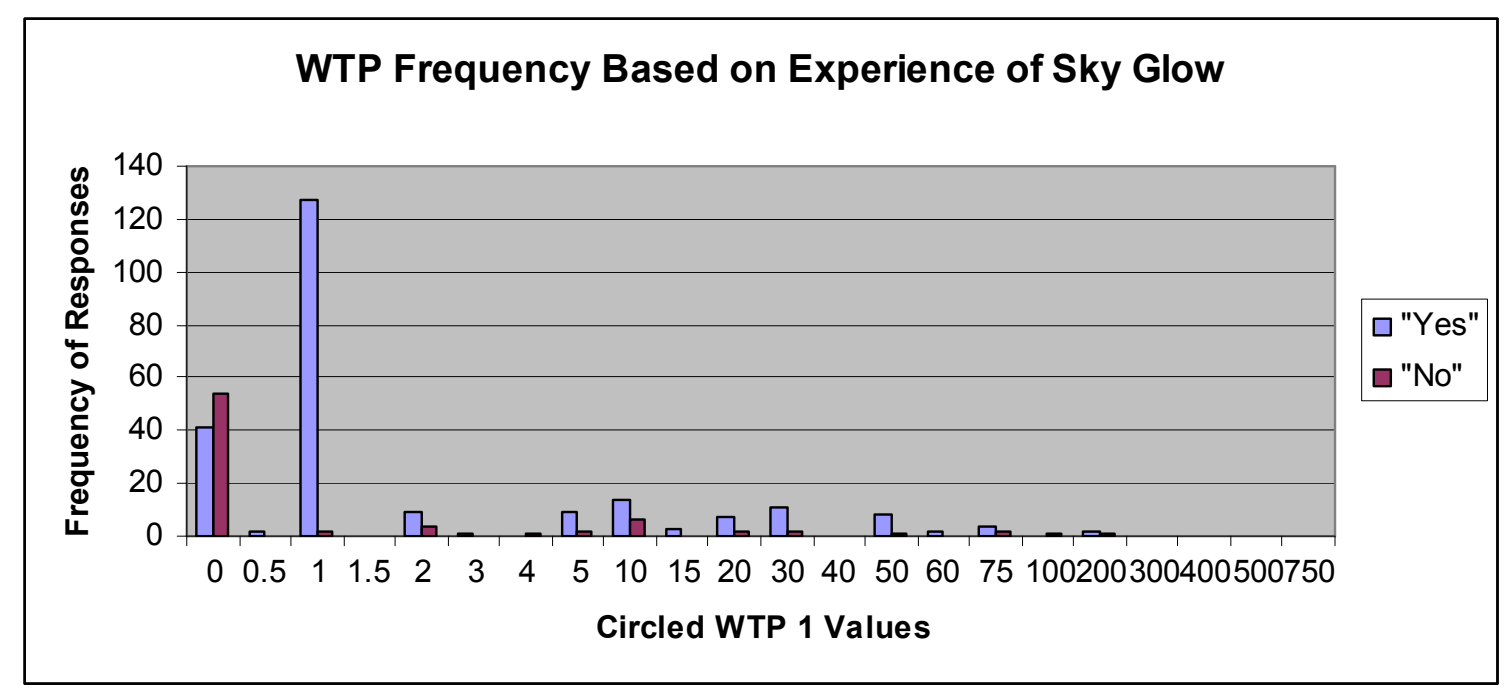

Figure 31. WTP Responses vs. Experience of Sky Glow.

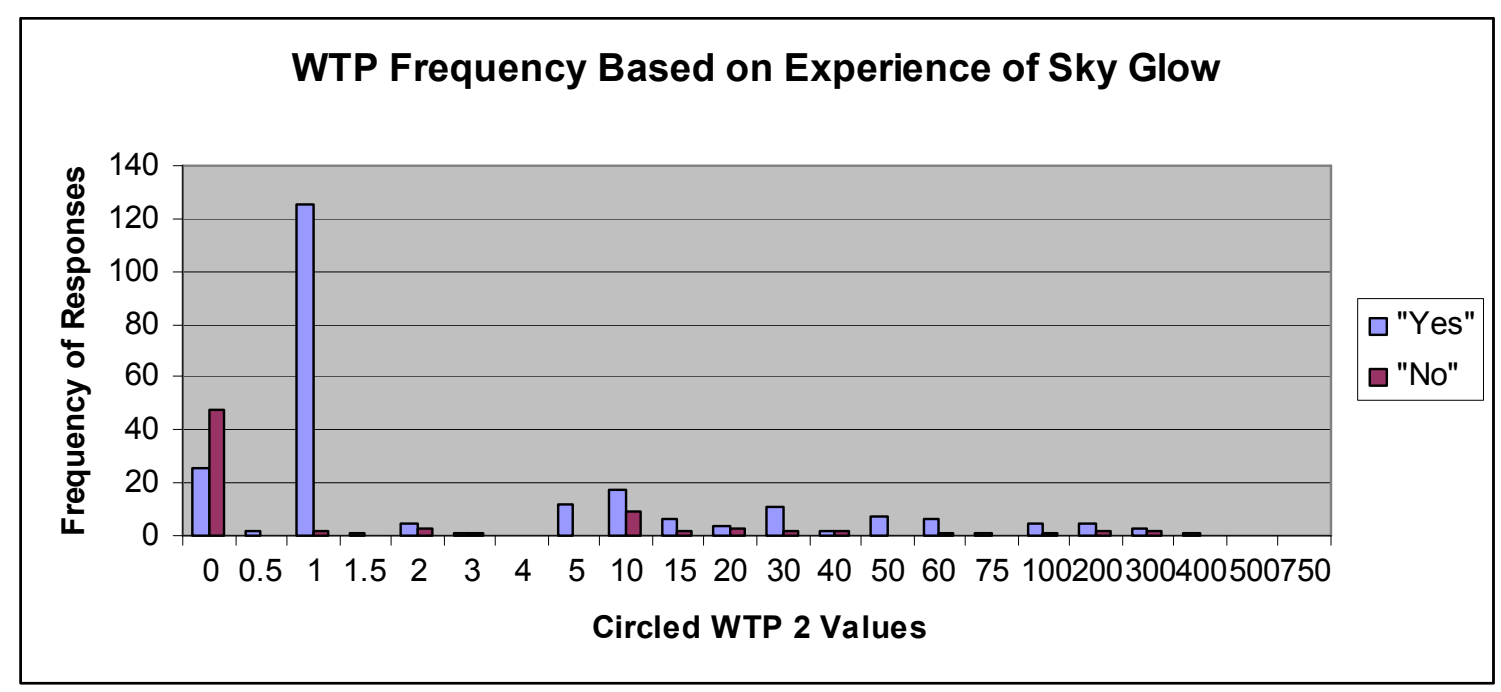

Figure 32. WTP Responses vs. Experience of Sky Glow. 


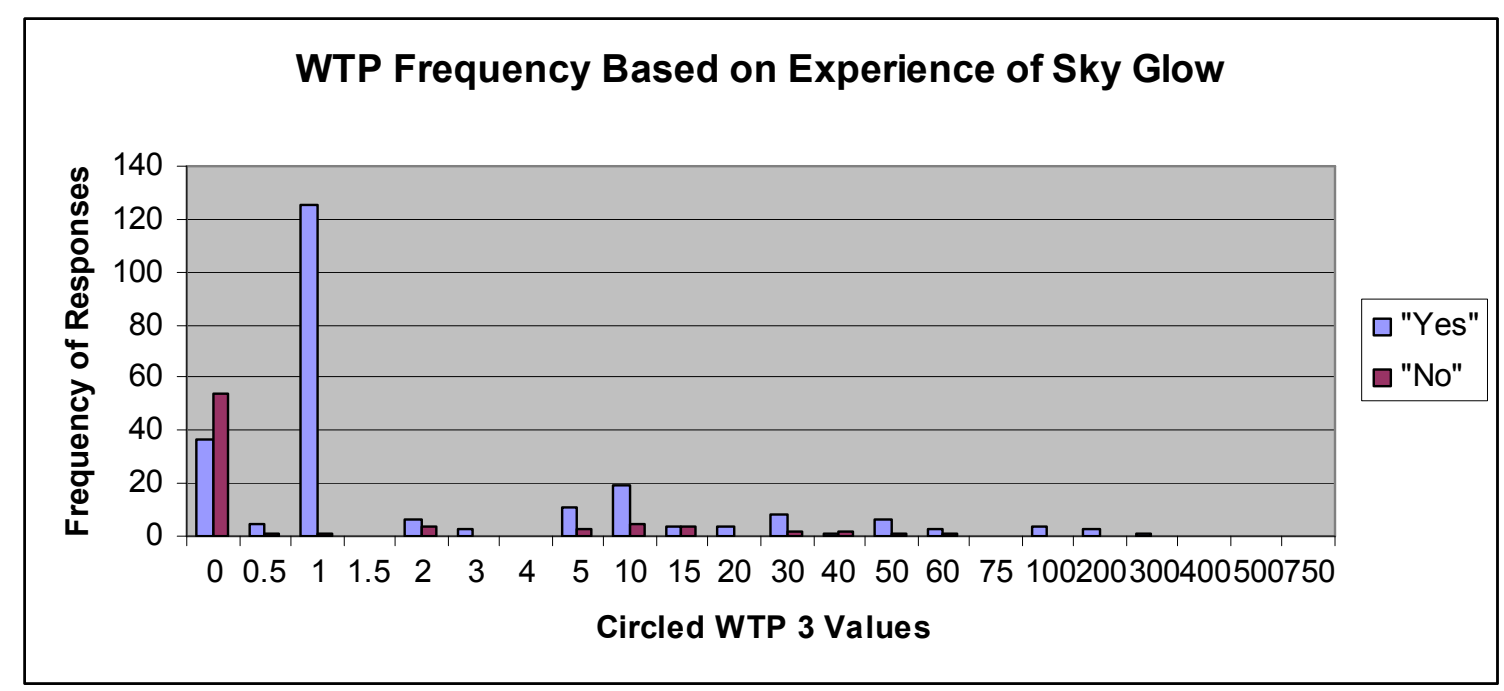

Figure 33. WTP Responses vs. Experience of Sky Glow.

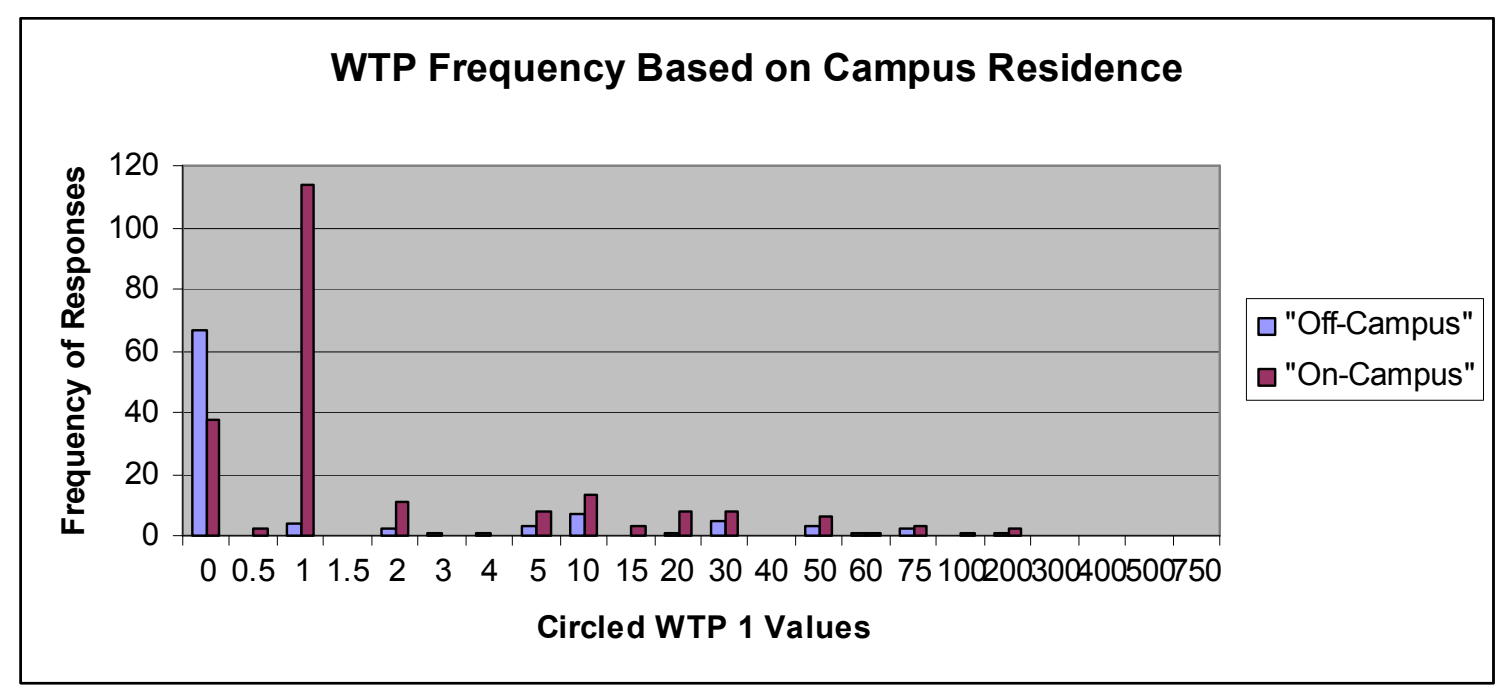

Figure 34. WTP 1 Responses vs. Campus Residence. 


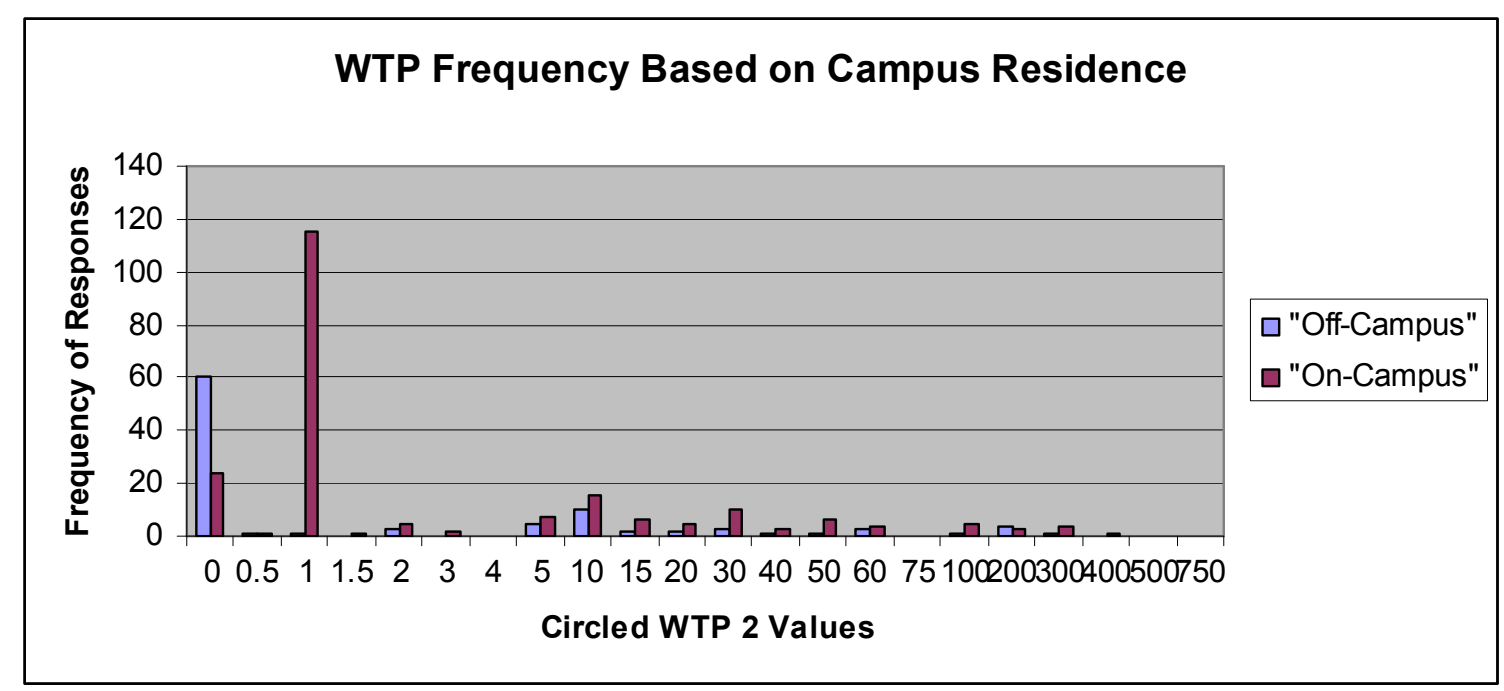

Figure 35. WTP 2 Responses vs. Campus Residence.

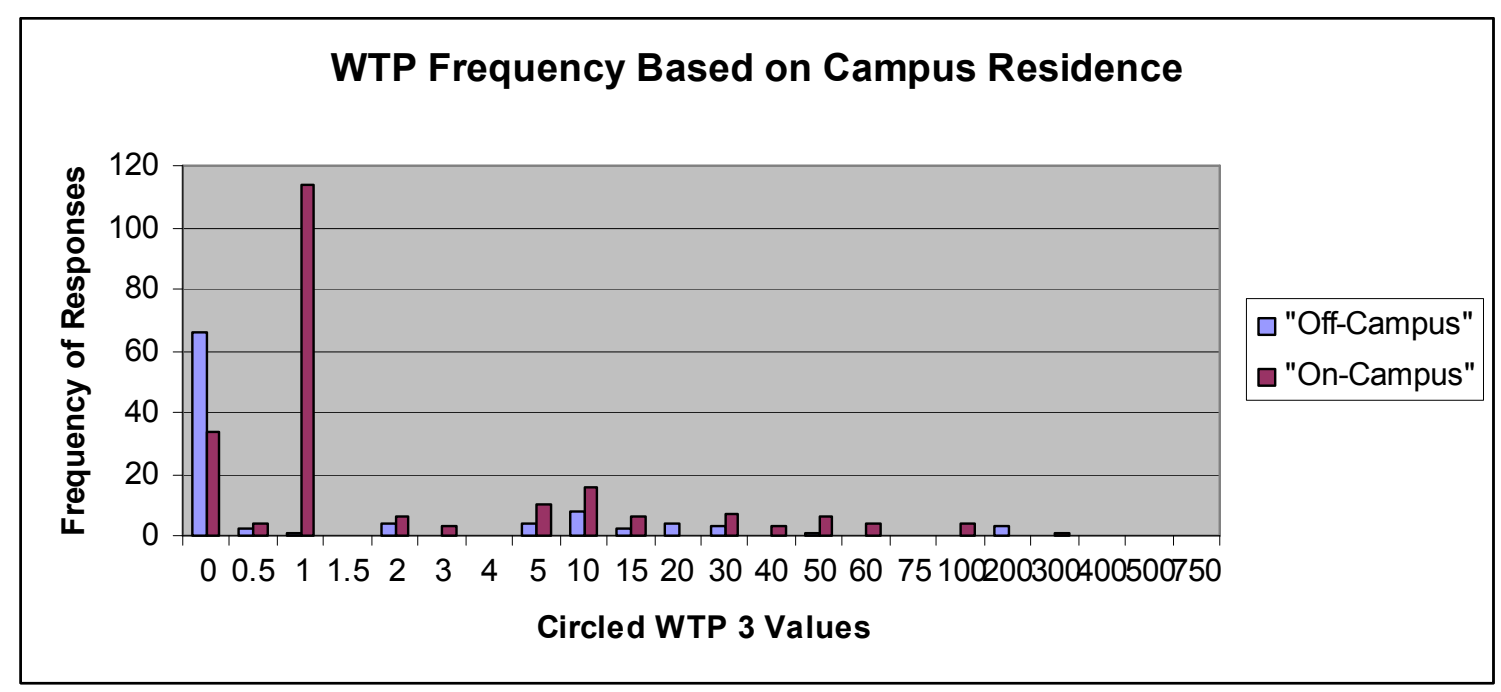

Figure 36. WTP 3 Responses vs. Campus Residence. 


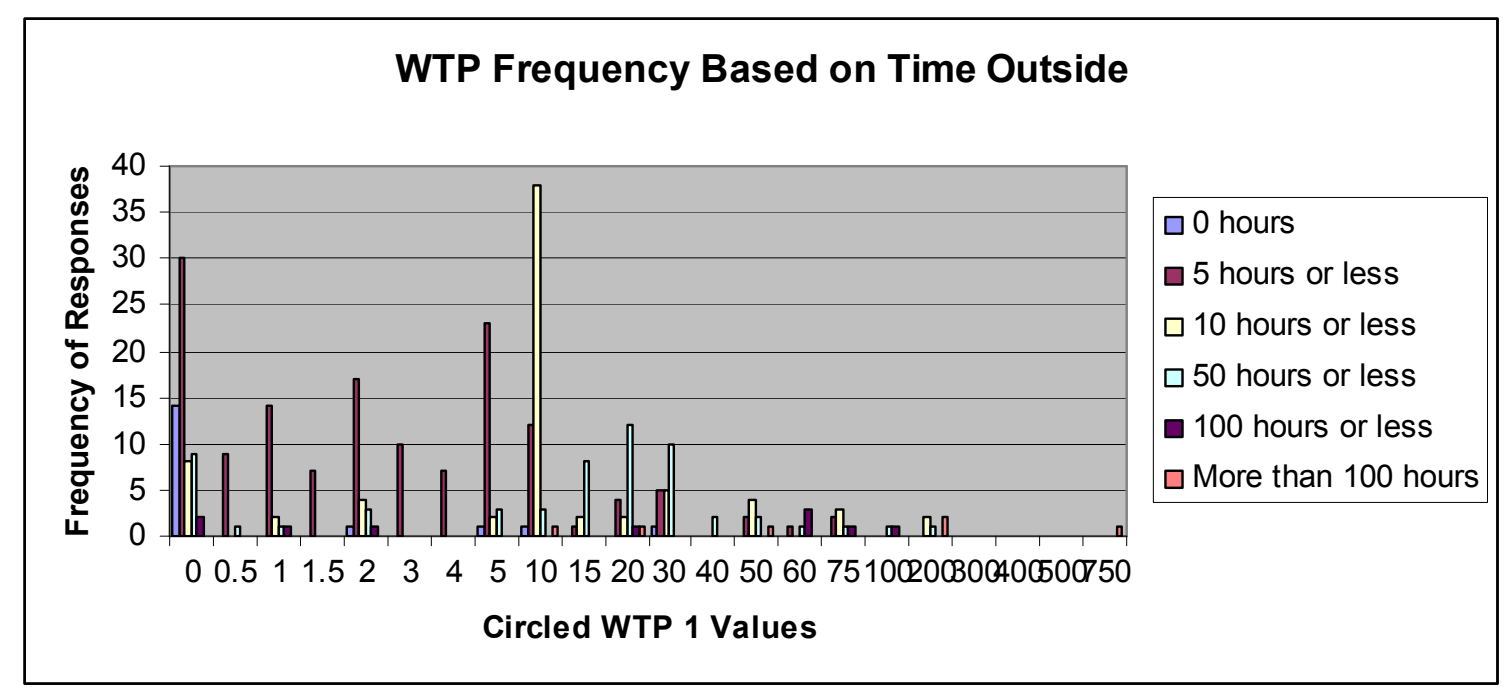

Figure 37. WTP 1 Responses vs. Time Spent Outside.

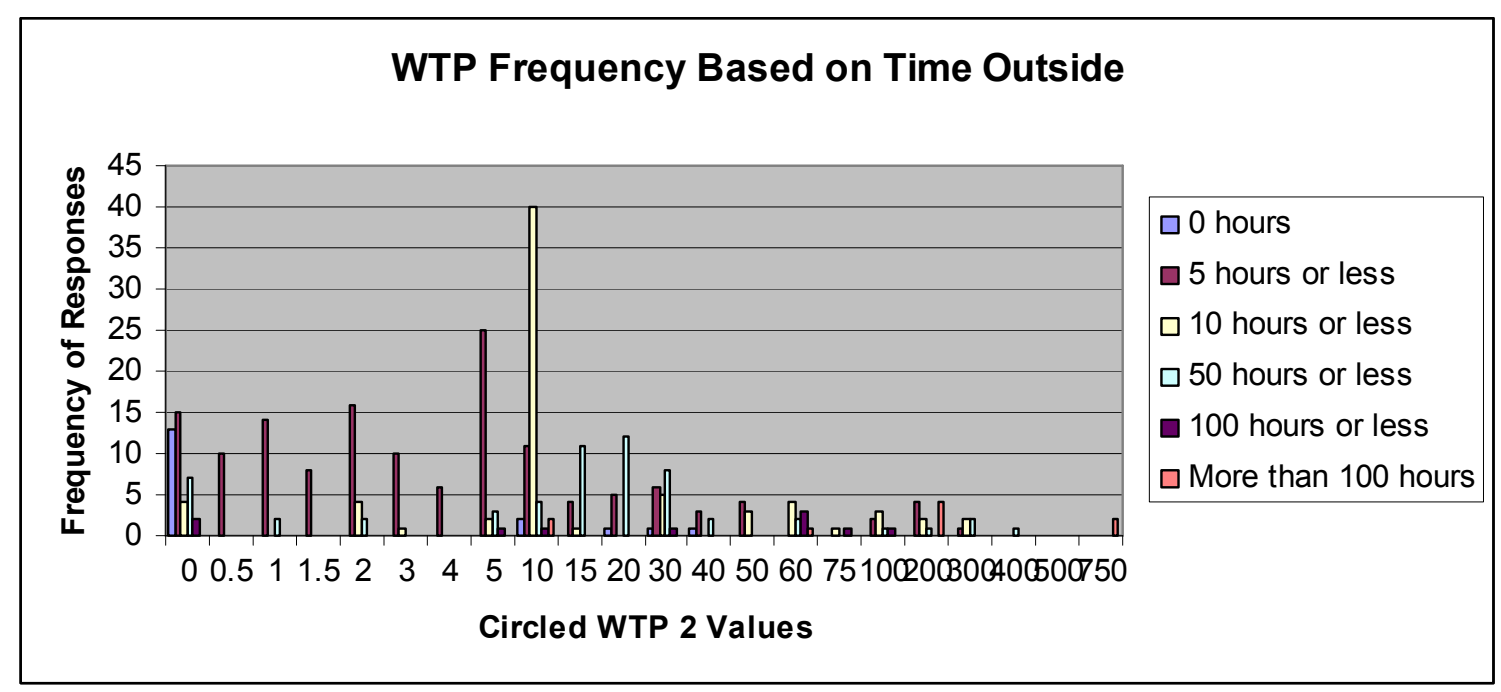

Figure 38. WTP 2 Responses vs. Time Spent Outside. 


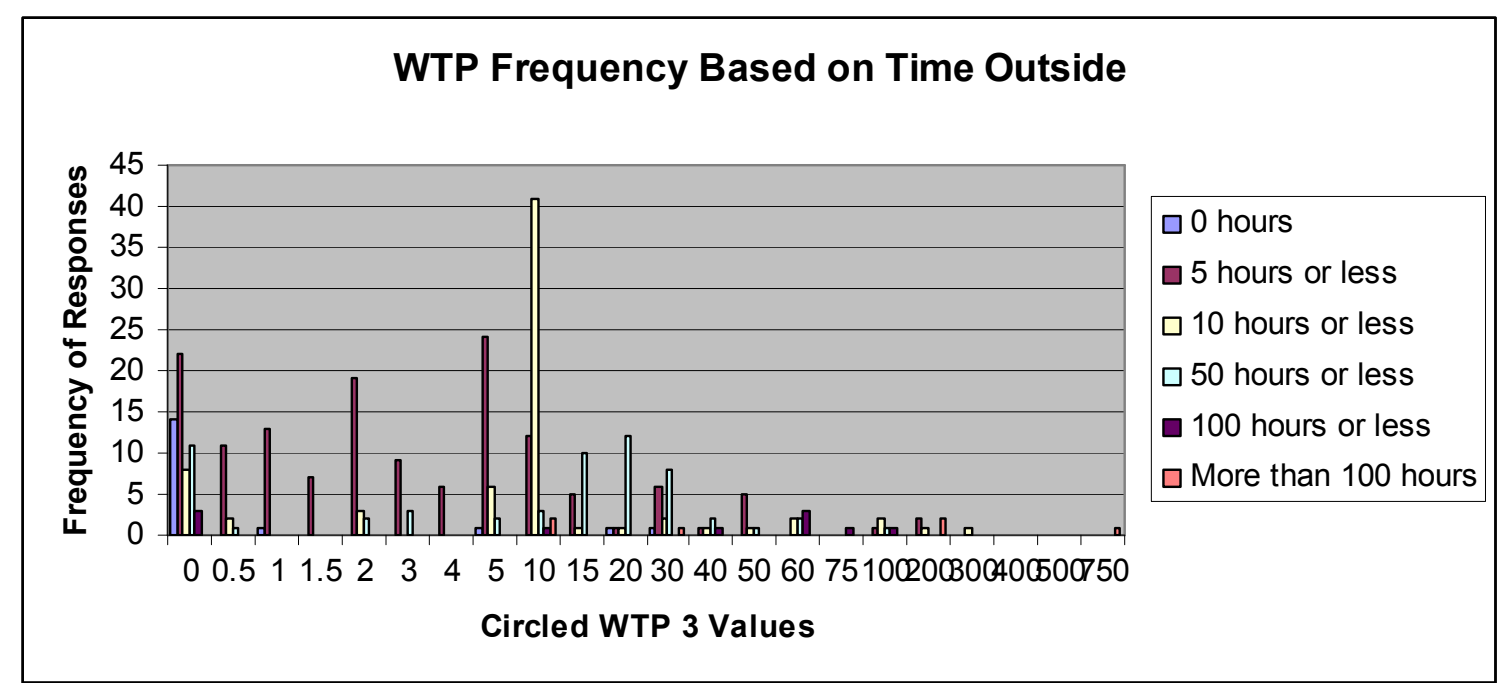

Figure 39. WTP 3 Responses vs. Time Spent Outside. 


\section{Appendix D. Regression Equation Results}

\begin{tabular}{|c|c|c|c|c|}
\hline IC Model & & WTP 1 & WTP 2 & WTP 3 \\
\hline Description & Variable & $\begin{array}{c}\text { Estimate } \\
\text { (Standard Error) }\end{array}$ & $\begin{array}{c}\text { Estimate } \\
\text { (Standard Error) }\end{array}$ & $\begin{array}{c}\text { Estimate } \\
\text { (Standard Error) }\end{array}$ \\
\hline Intercept & INTERCEPT & $\begin{array}{l}6.5825^{*} \\
(0.4538)\end{array}$ & $\begin{array}{l}7.4339 * \\
(0.4572)\end{array}$ & $\begin{array}{l}6.8070 * \\
(0.4648)\end{array}$ \\
\hline $\begin{array}{c}\text { "Don't know if } \\
\text { sky glow is a } \\
\text { problem at } \\
\text { RIT" }\end{array}$ & SGRIT (-1) & $\begin{array}{c}-0.8883 * \\
(0.3213)\end{array}$ & $\begin{array}{c}-0.8869 * \\
(0.3399)\end{array}$ & $\begin{array}{c}-0.6993 * \\
(0.3332)\end{array}$ \\
\hline $\begin{array}{c}\text { "Sky glow is } \\
\text { not a problem at } \\
\text { RIT" }\end{array}$ & SGRIT (0) & $\begin{array}{l}-0.6741 \\
(0.3893)\end{array}$ & $\begin{array}{c}-0.8685^{*} \\
(0.4048)\end{array}$ & $\begin{array}{l}-0.6238 \\
(0.4130)\end{array}$ \\
\hline "First year" & $\begin{array}{l}\text { YRCOLLEGE } \\
\text { (1) }\end{array}$ & $\begin{array}{c}0.9466 * \\
(0.4038)\end{array}$ & $\begin{array}{l}0.7813 \\
(0.4122)\end{array}$ & $\begin{array}{c}0.9714 * \\
(0.4401)\end{array}$ \\
\hline "Second year" & $\begin{array}{l}\text { YRCOLLEGE } \\
\text { (2) }\end{array}$ & $\begin{array}{l}1.1959 * \\
(0.4433)\end{array}$ & $\begin{array}{l}1.1459 * \\
(0.4596)\end{array}$ & $\begin{array}{l}0.9956 * \\
(0.4692)\end{array}$ \\
\hline "Third year" & $\begin{array}{l}\text { YRCOLLEGE } \\
\text { (3) }\end{array}$ & $\begin{array}{l}0.9260 \\
(0.6611)\end{array}$ & $\begin{array}{l}0.6844 \\
(0.6779)\end{array}$ & $\begin{array}{c}-0.0550 \\
(0.6569)\end{array}$ \\
\hline "Fourth year" & $\begin{array}{c}\text { YRCOLLEGE } \\
\text { (4) }\end{array}$ & $\begin{array}{l}0.3143 \\
(0.4674)\end{array}$ & $\begin{array}{l}0.0693 \\
(0.4499)\end{array}$ & $\begin{array}{l}0.3271 \\
(0.4668)\end{array}$ \\
\hline $\begin{array}{l}\text { "Time spent } \\
\text { outside on } \\
\text { campus at } \\
\text { night" }\end{array}$ & TIMEOUT & $\begin{array}{l}0.0031 \\
(0.0050)\end{array}$ & $\begin{array}{l}0.0009 \\
(0.0056)\end{array}$ & $\begin{array}{l}-0.0021 \\
(0.0054)\end{array}$ \\
\hline $\begin{array}{l}\text { "Personal } \\
\text { income" }\end{array}$ & INCOME & $\begin{array}{l}0.0003 * \\
(0.0001)\end{array}$ & $\begin{array}{l}0.0001 \\
(0.0001)\end{array}$ & $\begin{array}{l}0.0001 \\
(0.0001)\end{array}$ \\
\hline
\end{tabular}

Table 9. IC model estimate results. ${ }^{6}$

\footnotetext{
${ }^{6}$ Starred values are significant at the $5 \%$ level; related variables shaded in grey are not statistically different from one another. SGRIT (1) ("sky glow is a problem at RIT"), YRCOLLEGE (5) ("Fifth year") are dummy variables.
} 


\begin{tabular}{|c|c|c|c|c|}
\hline OLS Model & & WTP 1 & WTP 2 & WTP 3 \\
\hline Description & Variable & $\begin{array}{c}\text { Estimate } \\
\text { (Standard Error) }\end{array}$ & $\begin{array}{c}\text { Estimate } \\
\text { (Standard Error) }\end{array}$ & $\begin{array}{c}\text { Estimate } \\
\text { (Standard Error) }\end{array}$ \\
\hline Intercept & INTERCEPT & $\begin{array}{c}6.6436^{*} \\
(0.6169)\end{array}$ & $\begin{array}{r}7.6061 * \\
(0.6267)\end{array}$ & $\begin{array}{r}6.1559^{*} \\
(0.6044)\end{array}$ \\
\hline $\begin{array}{l}\text { "Don't know if } \\
\text { sky glow is a } \\
\text { problem at } \\
\text { RIT" }\end{array}$ & SGRIT (-1) & $\begin{array}{r}-0.8204 \\
(0.4529)\end{array}$ & $\begin{array}{c}-0.9588 * \\
(0.4602)\end{array}$ & $\begin{array}{r}-0.7215 \\
(0.4438)\end{array}$ \\
\hline $\begin{array}{c}\text { "Sky glow is } \\
\text { not a problem at } \\
\text { RIT" }\end{array}$ & SGRIT (0) & $\begin{array}{c}-1.4035^{*} \\
(0.4983)\end{array}$ & $\begin{array}{c}-1.6511 * \\
(0.5062)\end{array}$ & $\begin{array}{c}-1.6457^{*} \\
(0.4882)\end{array}$ \\
\hline "First year" & $\begin{array}{l}\text { YRCOLLEGE } \\
\text { (1) }\end{array}$ & $\begin{array}{r}-0.0085 \\
(0.5720) \\
\end{array}$ & $\begin{array}{l}0.0987 \\
(0.5811)\end{array}$ & $\begin{array}{l}0.5489 \\
(0.5604)\end{array}$ \\
\hline "Second year" & $\begin{array}{l}\text { YRCOLLEGE } \\
(2)\end{array}$ & $\begin{array}{l}0.2553 \\
(0.6173) \\
\end{array}$ & $\begin{array}{l}0.3414 \\
(0.6272) \\
\end{array}$ & $\begin{array}{l}0.9256 \\
(0.6049) \\
\end{array}$ \\
\hline "Third year" & $\begin{array}{l}\text { YRCOLLEGE } \\
\text { (3) }\end{array}$ & $\begin{array}{r}-1.2021 \\
(0.7399) \\
\end{array}$ & $\begin{array}{r}-1.4082 \\
(0.7517) \\
\end{array}$ & $\begin{array}{r}-0.7566 \\
(0.7249) \\
\end{array}$ \\
\hline "Fourth year" & $\begin{array}{l}\text { YRCOLLEGE } \\
\text { (4) }\end{array}$ & $\begin{array}{r}-0.7504 \\
(0.6184) \\
\end{array}$ & $\begin{array}{l}-0.3170 \\
(0.6283) \\
\end{array}$ & $\begin{array}{l}0.5578 \\
(0.6059) \\
\end{array}$ \\
\hline $\begin{array}{l}\text { "Time spent } \\
\text { outside on } \\
\text { campus at } \\
\text { night" }\end{array}$ & TIMEOUT & $\begin{array}{l}0.0085 \\
(0.0079)\end{array}$ & $\begin{array}{l}0.0012 \\
(0.0081)\end{array}$ & $\begin{array}{l}0.0028 \\
(0.0078)\end{array}$ \\
\hline $\begin{array}{l}\text { "Personal } \\
\text { income" }\end{array}$ & INCOME & $\begin{array}{l}0.00002 \\
(0.00009)\end{array}$ & $\begin{array}{l}0.00003 \\
(0.00009) \\
\end{array}$ & $\begin{array}{l}0.00004 \\
(0.00009)\end{array}$ \\
\hline
\end{tabular}

Table 10. OLS model estimate results. ${ }^{7}$

\footnotetext{
${ }^{7}$ Starred values are significant at the $5 \%$ level; related variables shaded in grey are not statistically different from one another. SGRIT (1) ("sky glow is a problem at RIT"), YRCOLLEGE (5) ("Fifth year") are dummy variables.
} 


\begin{tabular}{|c|c|c|c|c|}
\hline IC Model & & WTP 1 & WTP 2 & WTP 3 \\
\hline Description & Variable & \multicolumn{3}{|c|}{ Predicted Value (cents) } \\
\hline $\begin{array}{c}\text { "Don't know if sky } \\
\text { glow is a problem } \\
\text { at RIT" }\end{array}$ & SGRIT (-1) & 252.45 & 808.38 & 478.92 \\
\hline $\begin{array}{l}\text { "Sky glow is not a } \\
\text { problem at RIT" }\end{array}$ & SGRIT (0) & 100.19 & 823.40 & 516.50 \\
\hline $\begin{array}{l}\text { "Sky glow is a } \\
\text { problem at RIT" }\end{array}$ & SGRIT (1) & 519.43 & 1962.33 & 963.77 \\
\hline "First year" & $\begin{array}{l}\text { YRCOLLEGE } \\
\text { (1) }\end{array}$ & 899.29 & 4286.35 & 2545.95 \\
\hline "Second year" & $\begin{array}{l}\text { YRCOLLEGE } \\
\text { (2) }\end{array}$ & 1310.74 & 6171.89 & 2608.34 \\
\hline "Third year" & $\begin{array}{l}\text { YRCOLLEGE } \\
\text { (3) }\end{array}$ & 243.75 & 3890.53 & 912.16 \\
\hline "Fourth year" & $\begin{array}{l}\text { YRCOLLEGE } \\
\text { (4) }\end{array}$ & 907.32 & 2103.13 & 1336.74 \\
\hline "Fifth year" & $\begin{array}{l}\text { YRCOLLEGE } \\
\text { (5) }\end{array}$ & 519.43 & 1962.33 & 963.77 \\
\hline $\begin{array}{l}\text { "Average time } \\
\text { spent outside on } \\
\text { campus at night" }\end{array}$ & $\begin{array}{l}\text { TIMEOUT } \\
\text { (AVERAGE) }\end{array}$ & 519.43 & 1962.33 & 963.77 \\
\hline $\begin{array}{l}\text { "No time spent } \\
\text { outside on campus } \\
\text { at night" }\end{array}$ & TIMEOUT $(0)$ & 497.86 & 1936.10 & 994.06 \\
\hline $\begin{array}{l}\text { "Average personal } \\
\text { income" }\end{array}$ & $\begin{array}{c}\text { INCOME } \\
\text { (AVERAGE) }\end{array}$ & 519.43 & 1936.10 & 994.06 \\
\hline $\begin{array}{l}\text { "No personal } \\
\text { income" }\end{array}$ & $\operatorname{INCOME}(0)$ & 491.91 & 1715.36 & 876.62 \\
\hline
\end{tabular}

Table 11. IC Model Predicted WTP Values. ${ }^{8}$

\footnotetext{
${ }^{8}$ Predicted values are based on those who think that sky glow is a problem at RIT, are in their fifth year, who spend average time outside on campus at night (15.01 hrs), and/or who have average personal income (\$1375.07).
} 


\begin{tabular}{|c|c|c|c|c|}
\hline OLS Model & & WTP 1 & WTP 2 & WTP 3 \\
\hline Description & Variable & \multicolumn{3}{|c|}{ Predicted Value (cents) } \\
\hline $\begin{array}{c}\text { "Don't know if sky } \\
\text { glow is a problem } \\
\text { at RIT" }\end{array}$ & SGRIT (-1) & 394.47 & 820.54 & 252.45 \\
\hline $\begin{array}{l}\text { "Sky glow is not a } \\
\text { problem at RIT" }\end{array}$ & SGRIT (0) & 220.17 & 410.64 & 100.19 \\
\hline $\begin{array}{l}\text { "Sky glow is a } \\
\text { problem at RIT" }\end{array}$ & SGRIT (1) & 895.99 & 2140.47 & 519.43 \\
\hline "First year" & $\begin{array}{l}\text { YRCOLLEGE } \\
\text { (1) }\end{array}$ & 888.41 & 2362.56 & 899.29 \\
\hline "Second year" & $\begin{array}{l}\text { YRCOLLEGE } \\
\text { (2) }\end{array}$ & 1156.60 & 3011.49 & 1310.74 \\
\hline "Third year" & $\begin{array}{l}\text { YRCOLLEGE } \\
\text { (3) }\end{array}$ & 269.30 & 523.52 & 243.75 \\
\hline "Fourth year" & $\begin{array}{l}\text { YRCOLLEGE } \\
\text { (4) }\end{array}$ & 423.08 & 1558.98 & 907.32 \\
\hline "Fifth year" & $\begin{array}{l}\text { YRCOLLEGE } \\
(5)\end{array}$ & 895.99 & 2140.47 & 519.43 \\
\hline $\begin{array}{l}\text { "Average time } \\
\text { spent outside on } \\
\text { campus at night" }\end{array}$ & $\begin{array}{l}\text { TIMEOUT } \\
\text { (AVERAGE) }\end{array}$ & 895.99 & 2140.47 & 519.43 \\
\hline $\begin{array}{l}\text { "No time spent } \\
\text { outside on campus } \\
\text { at night" }\end{array}$ & TIMEOUT (0) & 789.18 & 2103.67 & 497.86 \\
\hline $\begin{array}{l}\text { "Average personal } \\
\text { income" }\end{array}$ & $\begin{array}{c}\text { INCOME } \\
\text { (AVERAGE) }\end{array}$ & 895.99 & 2140.47 & 519.43 \\
\hline $\begin{array}{l}\text { "No personal } \\
\text { income" }\end{array}$ & INCOME (0) & 871.75 & 2045.59 & 491.91 \\
\hline
\end{tabular}

Table 12. OLS Model Predicted WTP Values. ${ }^{9}$

\footnotetext{
${ }^{9}$ Predicted values are based on those who think that sky glow is a problem at RIT, are in their fifth year, who spend average time outside on campus at night (15.01 hrs), and/or who have average personal income (\$1375.07).
} 


\begin{tabular}{|c|c|c|c|c|c|}
\hline IC Model & & & WTP 1 & WTP 2 & WTP 3 \\
\hline Description & Compared To & Difference & \multicolumn{3}{|c|}{$\begin{array}{c}\text { Predicted Percentage Difference in } \\
\text { WTP }\end{array}$} \\
\hline $\begin{array}{l}\text { "Don't know if sky glow is } \\
\text { a problem at RIT" }\end{array}$ & \multirow{2}{*}{$\begin{array}{l}\text { "Sky glow is a } \\
\text { problem at RIT" }\end{array}$} & SGRIT (-1) - SGRIT (1) & 0.41 & -0.59 & -0.50 \\
\hline $\begin{array}{c}\text { "Sky glow is not a problem } \\
\text { at RIT" }\end{array}$ & & SGRIT (0) - SGRIT (1) & 0.51 & -0.58 & -0.46 \\
\hline "First year" & \multirow{4}{*}{ "Fifth year" } & YRCOLLEGE (1) - YRCOLLEGE (5) & 2.58 & 1.18 & 1.64 \\
\hline "Second year" & & YRCOLLEGE (2) - YRCOLLEGE (5) & 3.31 & 2.15 & 1.71 \\
\hline "Third year" & & YRCOLLEGE (3) - YRCOLLEGE (5) & 2.52 & 0.98 & -0.05 \\
\hline "Fourth year" & & YRCOLLEGE (4) - YRCOLLEGE (5) & 1.37 & 0.07 & 0.39 \\
\hline $\begin{array}{l}\text { "No time spent outside on } \\
\text { campus at night" }\end{array}$ & $\begin{array}{l}\text { "Average time } \\
\text { spent outside on } \\
\text { campus at night" }\end{array}$ & TIMEOUT (0) - TIMEOUT (average) & -1.05 & -0.01 & 0.03 \\
\hline "Zero personal income" & $\begin{array}{c}\text { "Average } \\
\text { Personal Income" }\end{array}$ & INCOME (0) - INCOME (average) & -1.43 & -0.13 & -0.13 \\
\hline
\end{tabular}

Table 13. IC Model Predicted Percentage Differences. 


\begin{tabular}{|c|c|c|c|c|c|}
\hline OLS Model & & & WTP 1 & WTP 2 & WTP 3 \\
\hline Description & Compared To & Difference & \multicolumn{3}{|c|}{$\begin{array}{c}\text { Predicted Percentage Difference in } \\
\text { WTP }\end{array}$} \\
\hline $\begin{array}{l}\text { "Don't know if sky glow is } \\
\text { a problem at RIT" }\end{array}$ & \multirow{2}{*}{$\begin{array}{l}\text { "Sky glow is a } \\
\text { problem at RIT" }\end{array}$} & SGRIT (-1) - SGRIT (1) & -0.56 & -0.62 & -0.51 \\
\hline $\begin{array}{c}\text { "Sky glow is not a problem } \\
\text { at RIT" }\end{array}$ & & SGRIT (0) - SGRIT (1) & -0.75 & -0.81 & -0.81 \\
\hline "First year" & \multirow{4}{*}{ "Fifth year" } & YRCOLLEGE (1) - YRCOLLEGE (5) & -0.01 & 0.10 & 0.73 \\
\hline "Second year" & & YRCOLLEGE (2) - YRCOLLEGE (5) & 0.29 & 0.41 & 1.52 \\
\hline "Third year" & & YRCOLLEGE (3) - YRCOLLEGE (5) & -0.70 & -0.76 & -0.53 \\
\hline "Fourth year" & & YRCOLLEGE (4) - YRCOLLEGE (5) & -0.53 & -0.27 & 0.75 \\
\hline $\begin{array}{l}\text { "No time spent outside on } \\
\text { campus at night" }\end{array}$ & $\begin{array}{l}\text { "Average time } \\
\text { spent outside on } \\
\text { campus at night" }\end{array}$ & TIMEOUT (0) - TIMEOUT (average) & -0.14 & -0.02 & -0.04 \\
\hline "Zero personal income" & $\begin{array}{c}\text { "Average } \\
\text { Personal Income" }\end{array}$ & INCOME (0) - INCOME (average) & -0.03 & -0.05 & -0.06 \\
\hline
\end{tabular}

Table 14. OLS Model Predicted Percentage Differences. 